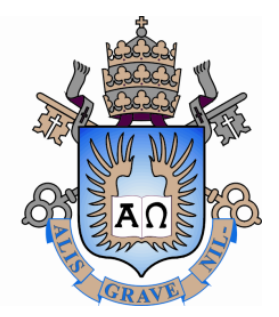

Mario Alberto Ramirez Castaño

\title{
Modelagens 2D e 3D para avaliação de reativação de falhas geológicas em reservatórios de petróleo
}

\section{Dissertação de Mestrado}

Dissertação apresentada ao programa de Pós-Graduação em Engenharia Civil do Departamento de Engenharia Civil da PUC-Rio como requisito parcial para obtenção do grau de Mestre em Engenharia Civil.

Orientadora: Profa. Deane Mesquita Roehl Coorientador: Dr. Roberto Quevedo Quispe

Rio de Janeiro 


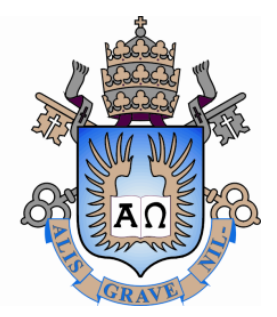

Mario Alberto Ramirez Castaño

\section{Modelagens 2D e 3D para avaliação de reativação de falhas geológicas em reservatórios de petróleo}

Dissertação apresentada como requisito parcial para obtenção do grau de Mestre pelo Programa de Pós-Graduação em Engenharia Civil do Departamento de Engenharia Civil do Centro Técnico Científico da PUC-Rio. Aprovada pela Comissão Examinadora abaixo assinada.

Profa. Deane de Mesquita Roehl.

Orientadora

Departamento de Engenharia Civil - PUC-Rio

Dr. Roberto Quevedo Quispe

Coorientador

Tecgraf - PUC-Rio

Prof. Celso Romanel

Departamento de Engenharia Civil - PUC-Rio

Dr. Leonardo Cabral Pereira CENPES-PETROBRAS

Prof. Márcio da Silveira Carvalho

Coordenador Setorial do Centro

Técnico Científico - PUC-Rio

Rio de Janeiro, 09 de Dezembro de 2016 
Todos os direitos reservados. É proibida a reprodução total ou parcial do trabalho sem autorização da universidade, da autora e do orientador.

\section{Mario Alberto Ramirez Castaño}

Graduou-se em Engenharia Civil pela Universidad Nacional de Colômbia em 2010. Terminou a pós-graduação em Estruturas na Universidad Nacional de Colômbia (Sede Manizales). Em 2014 ingressou no curso de Mestrado em Engenharia Civil da Pontifícia Universidade Católica do Rio de Janeiro, na área de Estruturas, onde vem desenvolvendo investigações na linha de pesquisa de geomecânica computacional

Ficha Catalográfica

Castaño, Mario Alberto Ramirez.

Modelagens 2D e 3D para avaliação de reativação de falhas geológicas em reservatórios de petróleo/ Mario Alberto Ramirez Castaño; orientador: Deane de Mesquita Roehl; Roberto Juan Quevedo Quispe. - Rio de Janeiro: PUC, Departamento de Engenharia Civil, 2016,

105 f. : il;(color); 29,7 cm.

Dissertação (Mestrado em Engenharia Civil) - Pontifícia Universidade Católica de Rio de Janeiro, Departamento de Engenharia Civil, 2016.

Inclui bibliografia

1. Engenharia Civil - Teses. 2. Método dos elementos finitos. 3. Reativaçao de falhas. 4. Elemento de Interface. 5. Geomecânica de reservatórios I. Roehl, Deane de Mesquita. II. Roberto Quevedo Quispe III. Pontifícia Universidade Católica do rio de Janeiro. Departamento de Engenharia Civil. IV. Título.

CDD: 624 
A mi adorada madre Maria Judith y a mis abuelitas Nohemy y Maria, a mis tias Beti y Paty por el amor y apoyo incondicional. Las amo 


\section{Agradecimentos}

A Deus, pela força que sempre me dá nos momentos de fraqueza e por ser o motor para seguir conquistando cada dia mais novos sonhos.

À minha mãe Maria Judith, por ser a melhor do mundo, por sempre ser o meu apoio e sempre acreditar em mim. Mãe, obrigado por dar tudo à mim e ao meu irmão a quem também amo muito.

Às minhas tias Betico e Paty, por sempre estarem ao meu lado nos momentos difíceis dando o seu amor. À minha avó Nohemy, por ser sempre o motor e motivação da nossa família.

À minha orientadora, professora Deane Roehl, pela orientação e dedicação no desenvolvimento deste trabalho, por ter me dado confiança e oportunidade de trabalhar no grupo de geomecânica do Tecgraf.

Ao meu coorientador, senhor Roberto Quevedo, pelo apoio e supervisão deste trabalho que, além de coorientador, tornou-se meu guia e amigo.

Aos colegas e amigos do Tecgraf, senhor Francisco, Nilthson, Cristian, Maria Fernanda, por me ajudarem nas dúvidas que tive no começo desta dissertação. A Pedro, Marcelo, Fernandita, Joana, Helvio, Nuno, Marko, Marlene, Leo e Luis por compartilhar comigo o tempo que estive no Tecgraf.

Aos meus amigos e família no Rio, Juancho el chatico, Jhonsito el Harrys, Rodri, Chechito, Renatico, Eliot, Willi, Danielito, Juaco, Jesse, Lorenita, Dalmita, Diliecita, Luisita, Margarita, Moni, Leidicita, Jenny Jenny, com vocês aprendi 
muitas coisas e compartilhei os melhores momentos no Rio. Obrigado pela força nos momentos difíceis e os sorrisos compartilhados.

À PUC-Rio, pela oportunidade de me permitir assumir este desafio.

Ao programa CAPES, pelo apoio financeiro durante o mestrado.

Ao Instituto Tecgraf, pela oportunidade de trabalhar com um tema de grande relevância e desafios. 


\section{Resumo}

Castaño, Mario Alberto Ramirez; Roehl, Deane de Mesquita; Quispe, Roberto Quevedo. Modelagens 2D e 3D para avaliação de reativação de falhas geológicas em reservatórios de petróleo. Rio de Janeiro, 2016. 105p. Dissertação de Mestrado - Departamento de Engenharia Civil, Pontifícia Universidade Católica do Rio de Janeiro.

Reservatórios de petróleo e gás estruturalmente compartimentados por falhas geológicas selantes são encontrados em diversas regiões do mundo. Durante a fase de explotação, a integridade do selo destas falhas pode ser comprometida pelas deformações decorrentes dos processos de depleção e/ou injeção de fluidos. Estas deformações, em conjunto com as propriedades físicas e geométricas das rochas e falhas presentes, podem alterar significativamente o estado de tensões do maciço rochoso fazendo com que uma falha reative e se torne hidraulicamente condutora. A esse fenômeno estão associados riscos de exsudação, perda de integridade de poços e outros potencias problemas geomecânicos. Na literatura, diversas modelagens numéricas têm sido utilizadas a fim de caracterizar e prever os fenômenos de reativação e/ou abertura de falhas geológicas. A maior parte de estas abordagens faz uso de modelos bidimensionais considerando seções críticas na hipótese de estado plano de deformação. Essas simplificações são adotadas a fim de evitar a complexidade geométrica e o alto custo computacional de uma modelagem tridimensional. No entanto, a configuração tridimensional dos planos de falha pode induzir a reativação em direção a zonas mais críticas do que aquelas contidas numa única seção. Neste trabalho apresenta-se uma metodologia para análise de reativação de falhas geológicas e discute-se a importância do uso dos modelos 3D na previsão do comportamento geomecânico de reservatórios compartimentados por falhas geológicas. São apresentados 3 modelos diferentes. O primeiro exemplo traz um modelo bidimensional apresentado na literatura, faz-se uma comparação dos resultados com representação por meio do elemento de interface, por meio do continuo equivalente e por meio de um elemento solido com fraturas embutidas. O segundo exemplo faz-se um comparativo entre a utilização de elementos quadrilaterais e triangulais para a representação da falha em modelos 
3D. Para o terceiro modelo foram realizadas simulações numéricas considerando modelos 2D e 3D em um simulador in-house baseado no método dos elementos finitos. Para a representação do meio continuo foram utilizados elementos quadrilaterais para o caso $2 \mathrm{D}$, e elementos hexaédricos e tetraédricos para o caso 3D. Para a representação das falhas geológicas foram utilizados elementos de interface de espessura nula segundo o critério de ruptura de Mohr-Coulomb. Da comparação dos resultados, constata-se que as análises 2D e 3D forneceram previsões de reativação similares. No entanto, as previsões de pressões de abertura foram distintas em ambos os modelos devido às diferentes trajetórias de migração de fluido. Particularmente em modelos com geometria irregular confirma-se a importância do emprego de modelo 3D.

\section{Palavras-chave}

Método dos elementos finitos; reativação de falhas; elemento de interface; geomecânica de reservatórios. 


\section{Abstract}

Castaño, Mario Alberto Ramirez; Roehl, Deane de Mesquita (Advisor); Quispe, Roberto Quevedo (Co-advisor). 2D and 3D modeling to evaluate reactivation of geological faults in oil reservoirs. Rio de Janeiro, 2016. 105p. MSc. Dissertation - Departamento de Engenharia Civil, Pontifícia Universidade Católica do Rio de Janeiro.

Oil and gas reservoirs that are structurally compartmented by sealing geological faults are common in several areas around the world. During production, the deformations from the processes of fluid depletion and/or injection can compromise the integrity of the seal of the faults. This deformation, together with the physical and geometrical properties from the rocks and faults can significantly change the stress state. Therefore, it might cause fault reactivation, turning it in a hydraulic conduit. Related to this phenomenon, are the exudation, loss of wellbore integrity and other potential geomechanical problems. There are several numerical modelling techniques available in literature to characterize and predict the reactivation and/or opening of geological faults. In most of these modelling approaches, bi-dimensional models are used for critical sections through the assumption of plane strain conditions. The reason for using $2 \mathrm{D}$ models is to avoid the geometrical complexity and the high computational costs associated to threedimensional modeling. On the other hand, the fault planes in the three-dimensional approach can show fault reactivation in a more critical direction e than the one represented by the bi-dimensional model. In this work, a methodology is presented in order to assess geological fault reactivation. In addition, the importance of using 3D models in the prediction of the geomechanical behavior of reservoirs compartmented by geological faults is discussed. Three different models are presented. The first example is based on a two dimensional model from the literature. A comparison between approaches using interface elements, equivalent continuum elements and solid element with fractures is carried out in the first example. The second example brings a comparison between the quadrilateral and triangular elements to represent faults in a 3D model. In addition, an analysis was carried out considering 2D and 3D models using an in house software based on the finite element method. To simulate the continuum medium, quadrilateral elements 
are used in the 2D case and in the 3D case hexahedral and tetrahedral elements are employed. In addition, to represent the geological faults, interface elements with zero thickness are used in association with the Mohr-Coulomb failure criterion. In the case study, predictions of fault reactivation were similar in the $2 \mathrm{D}$ and $3 \mathrm{D}$ models. However, fault opening pressures were different in both models, due to the 3D fluid migration path. It also confirmed the importance of using 3D models when simulating irregular geometries.

\section{Keywords}

Finite element method; fault reactivation; interface element; reservoir geomechanics. 


\section{Sumário}

1 Introdução 20

1.1. Relevância e motivação 20

1.2. Objetivos e Metodologia 22

1.3. Estrutura da dissertação 23

2 Revisão Bibliográfica 25

2.1. Falhas geológicas e propriedades da zona da falha 25

2.2. Análise de tendência de reativação de falhas 28

2.2.1. Solução analítica e semianalítica 28

$\begin{array}{ll}\text { 2.2.2. Soluções numéricas } & 31\end{array}$

3 Análise 3D de reativação de falhas pelo método dos elementos finitos

3.1. Relações constitutivas 38

3.1.1. Lei de Hooke generalizada 38

3.1.2. Definição da matriz constitutiva 39

3.1.3. Modelo Constitutivo de Mohr-Coulomb com Cut-off 43

3.1.4. Integração numérica das tensões 47

3.2. Formulação pelo método dos elementos finitos 53

3.2.1. Equação de equilíbrio 53

3.2.2. Discretização espacial 54

3.2.3. Avaliação dos deslocamentos 57

3.2.4. Avaliação das deformações 57

3.2.5. Avaliação da matriz de rotação 58

3.2.6. Avaliação da matriz de rigidez 61

3.3. Validação em modelos 3D 63

3.3.1. Elemento de interface sob tração 63

3.3.2. Elemento de interface sob cisalhamento 64

3.3.3. Elemento de interface sob tração e cisalhamento 65 
4 Exemplos de aplicação $\quad 67$

$\begin{array}{ll}\text { 4.1. Simulações 2D } & 67\end{array}$

4.1.1. Descrição dos modelos $\quad 67$

4.1.2. Análise e discussão de resultados 71

4.2. Simulações 3D 78

4.2.1. Descrição dos modelos 78

4.2.2. Análise e discussão de resultados 81

4.3. Comparação entre simulações 2D e 3D 84

5 Conclusões e Sugestões $\quad 88$

5.1. Conclusões 88

5.2. Sugestões 90

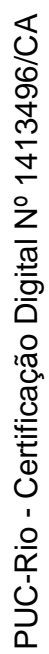

$\begin{array}{ll}\text { Referências bibliográficas } & 91\end{array}$

$\begin{array}{ll}\text { Apêndice A } & 102\end{array}$ 


\section{Lista de figuras}

Figura 2-1 Orientação das tensões principais e seus tipos de falhas associadas (adaptado de Burg, 2013)

Figura 2-2 Núcleo e zona de dano em uma falha, adaptado de (Gudmundsson et al., 2010).

Figura 2-3 (a) Diagrama esquemático da estrutura transversal da zona da falha (b) permeabilidade (c) modulo de elasticidade. Cappa \& Rutqvist (2010)

Figura 2-4 (a) Tensões atuantes na falha; (b) efeito pelo o incremento de poropressão na estabilidade da falha (Streit et al., 2004)

Figura 2-5 Esboço para explicar as posições dos pontos A, B, C. (Altmann et al., 2013)

Figura 2-6 Elemento 2D do continuo equivalente (a) rocha intata cruzada por uma falha (b).

Figura 2-7 Representação do fluxo através de meios fraturados

Figura 2-8 (a) Horizontes das superfícies que cortam a falha (SMB Fault) e

(b) malha de elementos finitos (Vidal-Gilbert et al., 2009)

Figura 2-9 Evolução da poropressão nos poços injetores no reservatório $D$

Figura 3-1 Representação da superfície de escoamento no sistema de eixos principais de tensões

Figura 3-2 Comportamento perfeitamente plástico

Figura 3-3 Superfície de potencial plástico

Figura 3-4 Envoltória de Mohr-Coulomb no espaço $\sigma n^{\prime}-\tau$ (adaptado de Sørensen 2012)

Figura 3-5 Representação das componentes de tensão

Figura 3-6 Definição ângulo $\beta$

Figura 3-7 Envoltória de Mohr-Coulomb com cut-off no espaço $\sigma n^{\prime}-\tau$

Figura 3-8 Regiões para o retorno perpendicular fonte: Manual de reativação de falhas Instituto TecGraf 2014.

Figura 3-9 Elementos de interface 2D

Figura 3-10 Elementos de Interface triangulares

Figura 3-11 Elementos de Interface quadrilaterais.

Figura 3-12 Ângulos de Euler para definir a matriz de rotação no espaço 3D. Fonte: S. Widnall 16.07 Dynamics Fall 2009 
Figura 3-13 Definição geométrica de strike, dip e dip direction.

Figura 3-14 Vetores no plano de falha

Figura 3-15 Modelo sintético submetido à tração

Figura 3-16 Trajetória de tensões para elemento de interface sometido a tensão normal

Figura 3-17 Elemento de interface sometido a tensão cisalhante

Figura 3-18 Trajetória de tensões para elemento de interface sometido a esforços cisalhantes.

Figura 3-19 Modelo sintético com falha inclinada

Figura 3-20 Trajetória de tensões

Figura 4-1 Geometria do modelo 2D com falha inclinada.

Figura 4-2 Malha para o modelo com representação da falha por meio de elementos de interface

Figura 4-3 Representação das falhas com os diferentes tipos de elementos (adaptado de Cappa and Rutqvist, 2010).

Figura 4-4 Variação das tensões ao longo do comprimento da falha no início do processo da reativação.

Figura 4-5 Trajetória de tensões para os pontos inferior (base do reservatório) e superior (topo do reservatório).

Figura 4-6 Resultados ao longo do comprimento da falha no final das simulações

Figura 4-7 Variação da poropressão ao longo do comprimento da falha.

Figura 4-8 Variação das tensões ao longo do comprimento da falha sem consideração de rotação das tensões principais.

Figura 4-9 Descrição das camadas e das falhas geológicas para as simulações 3D.

Figura 4-10 Malha de elementos finitos empregada no modelo 1.

Figura 4-11 Malha de elementos finitos empregada no modelo 2.

Figura 4-12. Primeiros pontos de reativação nas simulações 3D após um incremento de poropressão de 2,5MPa.

Figura 4-13 Evolução do índice de reativação com o incremento de poropressão no ponto A para os modelos 1 e 3.

Figura 4-14 Evolução das tensões, normal efetiva e cisalhante, com o incremento de poropressão no ponto A para os modelos 1 e 3.

Figura 4-15 Regiões que indicam os primeiros pontos de reativação nos modelos 1 e 2 . 
Figura 4-16 Evolução da migração da poropressão em todo o modelo 1 (esquerda) e em todo o modelo 2 (direita)

Figura 4-17 Geometria e malha de elementos finitos para a modelo 2D.

Figura 4-18 Regiões que indicam os primeiros pontos de reativação no modelo 2D

Figura 4-19 Evolução do índice de reativação com o incremento de poropressão no ponto $A$.

Figura 4-20 Evolução das tensões, cisalhante e normal efetiva, com o incremento de poropressão no ponto $A$

Figura 4-21 Evolução da migração da poropressão em todo o modelo 2D. Malha deformada em 60 vezes.

Figura 4-22 Migração de fluido através da falha F2 no final da simulação do modelo 3D.

Figura 4-23 a) Evolução do índice de reativação com a pressão de injeção e b) Evolução da tensão normal efetiva com a pressão de injeção, ambos na 


\section{Lista de tabelas}

Tabela 3.1. Condição de instabilidade 46

Tabela 3.2. Propriedades do modelo sintético para avaliação das tensões 63

Tabela 4.1 Propriedades utilizadas nos modelos 2D (Cappa \& Rutqvist, 2010) 68

Tabela 4.2 Resultados comparativos de pressão de reativação na falha. 71

$\begin{array}{ll}\text { Tabela 4.3. Propriedades da rocha para os elementos sólidos } & 79\end{array}$

Tabela 4.4. Propriedades da falha para os elementos de interface 79 


\section{Lista de símbolos}

$B \quad$ Matriz que relaciona os deslocamentos com as deformações

$C^{R} \quad$ Tensor elastico do continuo equivalente

CI Condição de instabilidade

$C_{x} \quad$ Componenente do vetor $Z$ "

$C_{y} \quad$ Componenente do vetor $Z$ "

$C_{Z} \quad$ Componenente do vetor $Z$ "

D Matriz constitutiva da falha

$D^{e} \quad$ Matriz constitutiva elastica

$D^{e p} \quad$ Matriz constitutiva elasto plastica

E Módulo de Elasticidade

F $\quad$ Superfície de escoamento

$F_{1} \quad$ Função de plastificação de Mohr-Coulomb

$F_{2} \quad$ Função de corte ("Cut-off")

$F_{\text {ext }} \quad$ Vetor de forças externas

G Modulo de cisalhamento

IR Índice de reativação

K Matriz de rigidez

L Matriz de acoplamento

$N_{\text {noel }} \quad$ Numero de nós do elemento de interface

$\mathrm{N}_{p} \quad$ Funções de forma para descrição da variação da porpressão

$N_{i} \quad$ Funções de forma para os graus

P Poropressão

$\mathrm{R} \quad$ Matriz de rotação do sistema de coordenadas global para o local

$\mathrm{T}$ Resistência à tração da falha

$\mathrm{u}_{G}^{\text {topo }} \quad$ Deslocamentos a nivel global no topo do elemento de interface

$\mathrm{u}_{G}^{\text {base }} \quad$ Deslocamentos a nivel global na base do elemento de interface

$\mathrm{u}_{L}^{\text {topo }}$ Deslocamentos a nivel local no topo do elemento de interface

$\mathrm{u}_{L}^{b a s e} \quad$ Deslocamentos a nivel local na base do elemento de interface

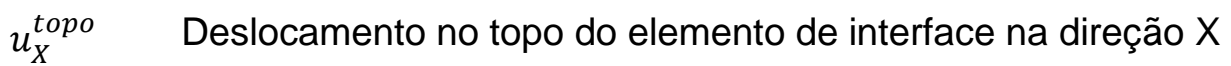

$u_{Y}^{\text {topo }} \quad$ Deslocamento no topo do elemento de interface na direção $Y$

$u_{z}^{\text {topo }} \quad$ Deslocamento no topo do elemento de interface na direção Z 
$u_{X}^{b a s e} \quad$ Deslocamento na base do elemento de interface na direção $X$

$u_{Y}^{b a s e} \quad$ Deslocamento na base do elemento de interface na direção $Y$

$u_{Z}^{\text {base }} \quad$ Deslocamento na base do elemento de interface na direção $Z$

Z' Vetor perpendicular ao plano de falha

b Abertura da fratura

$\mathrm{b}_{0} \quad$ Abertura inicial da fratura

c Coesão

e Espessura equivalente da falha geologica

k Permeabilidade intrínseca

$k_{N} \quad$ Coeficiente de rigidez normal da falha

$k_{S} \quad$ Coeficiente de cisalhante da falha

$\mathrm{m}$

vetor que introduz a influência da poropressão na direção normal do tensor de tensões

$s \quad$ Espaçamento entre fraturas

$s_{0} \quad$ Espaçamento inicial entre fraturas

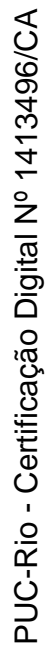

$\Lambda \quad$ Multiplicador plastico

$u \quad$ Deslocamentos nodais

$\alpha \quad$ Coeficiente de Biot

$\beta \quad$ Ângulo entre a resulante das tensoes cisalhantes e $\tau_{1}$

$\delta_{i}^{F} \quad$ Deslocamento relativo no plano de falha

$\delta_{i}^{R} \quad$ Deslocamento na rocha intata

$\Delta \quad$ Incremento / Variação

$\varepsilon^{p} \quad$ Deformação plastica

$\varepsilon^{R} \quad$ Vetor de deformaçoes para o continuo equivalente

$\theta \quad$ Ângulo entre o vetor normal ao plano de falha

$v \quad$ Coeficiente de Poisson

$\mu \quad$ Coeficiente de atrito

$\sigma \quad$ Vetor de Tensão

$\sigma_{1} \quad$ Tensão principal máxima

$\sigma_{2} \quad$ Tensão principal intermediária

$\sigma_{3} \quad$ Tensão principal mínima

$\sigma_{n} \quad$ Tensão normal

$\sigma_{n}^{\prime} \quad$ Tensão normal efetiva

$\sigma_{n+1}^{\text {trial }} \quad$ Tensão preditora

$\tau \quad$ Tensão cisalhante 
$\tau_{1} \quad$ Tensão cisalhante ao plano da falha

$\tau_{2} \quad$ Tensão cisalhante ao plano de falha

$\tau_{\text {res }} \quad$ Resistência ao cisalhamento no plano de falha

$\phi \quad$ Ângulo de atrito

$\Omega_{e} \quad$ Dominio do elemento de interface

$\{k\} \quad$ Parametro de amolecimento/encruamento

|J| Determinante Jacobiano 


\section{Introdução}

\section{1.}

\section{Relevância e motivação}

Na etapa de produção de hidrocarbonetos em um campo petrolífero, alterações no estado de tensões são induzidas no reservatório e nas rochas adjacentes devido à injeção e à extração de fluidos. Essas mudanças no estado de tensões também acontecem no plano das falhas geológicas, podendo causar a desestabilização de falhas previamente estáveis. Essa desestabilização pode se apresentar como a reativação ou a abertura na falha, aumentando assim as deformações do maciço rochoso. Em casos críticos essas deformações podem alterar as tensões in-situ com consequências indesejáveis tais como colapso de revestimentos, instabilidade de poços e subsidência excessiva. Além disso, podem ocorrer sismos induzidos pelos processos de injeção e recuperação de petróleo (Healy et al., 1968; Raleigh et al., 1976; Segall et al., 1998).

O movimento das falhas também pode quebrar o selo de estanqueidade, permitindo que fluidos migrem ao longo da superfície da falha, causando em casos mais críticos a exsudação destes fluidos para a superfície (Sibson, 1990). As falhas que são consideradas selantes podem constituir um controle primário sobre o trapeamento nos reservatórios, mas também podem dividir um reservatório relativamente grande de modo a que se comporte como um grupo de reservatórios, onde cada um pode ter suas próprias características de pressão e fluido. Na literatura encontram-se alguns estudos realizados sobre processos de migração de fluidos através de falhas. No trabalho de Gartrell et al., 2003 sobre o campo de Timor Sea, Northewest Shelf, Australia é apresentado um modelo 3D com uma série de falhas interceptadas, semelhante ao problema real, onde o principal controle de vazamento dos hidrocarbonetos é a dilatação apresentada nas falhas produto das pequenas deformações. A intersecção de falhas também mostrou ser uma área de tensão de cisalhamento relativamente baixa, o que pode aumentar o potencial de fluxo de fluido nesses locais. South Eugene Island 330 field, northern Gulf of Mexico 
(Finkbeiner et al., 2001) apresenta um modelo dinâmico para descrever o estado das tensões que pode controlar a migração de fluidos do reservatório. Outro exemplo na literatura sobre processos de migração de fluidos através de falhas é o campo de East Coast of Trinidad descrito em Heppard et al., 1998.

Com a finalidade de prever a reativação de falhas geológicas e suas posteriores consequências, diversos autores têm realizado simulações numéricas considerando os processos de produção do reservatório (Segall et al., 1994; Finkbeiner et al., 1997; Fouladvand et al., 2009). Diferentes métodos numéricos têm sido utilizados para esta finalidade, tais como o método das diferenças finitas (Zhang et al., 2009; Fouladvand et al., 2009), o método dos elementos discretos (Zhang \& Sanderson, 1996), o método dos elementos finitos (Vidal-Gilbert, 2009; Zhang et al., 2009; Mendes et al., 2010) ou uma combinação destes (Rutqvist et al., 2007). A modelagem numérica do processo de reativação de falhas basicamente consiste de duas parcelas que ocorrem simultaneamente: uma hidráulica, responsável pela variação espacial e temporal das poropressões dentro do reservatório e, uma geomecânica, responsável pelo campo de deformações e pela alteração do estado de tensões dentro e fora do reservatório. Essas metodologias numéricas têm por finalidade limitar as mudanças de pressão dentro do reservatório para garantir a estabilidade das falhas geológicas. Numa abordagem simplificada, as variações de poropressão obtidas por um simulador de fluxo de reservatórios são transferidas como carregamentos para um simulador geomecânico a fim de determinar variações nos campos de tensão e deformação. Esta estratégia tem sido utilizada por Costa (1984), Bostrøm \& Skomedal (2004) e Mendes et al., (2010), fornecendo resultados satisfatórios na determinação dos limites de pressões de injeção em reservatórios. Nestas análises foram utilizados modelos geomecânicos bidimensionais com elementos contínuos para a representação da matriz rochosa e elementos de interface de espessura nula na representação das falhas geológicas.

Desde o ano de 2007, o grupo de geomecânica computacional do instituto Tecgraf também tem realizado simulações numéricas na previsão de processos de reativação de falhas geológicas em diversos campos de petróleo. Nacht et al., (2010) apresentaram um estudo da reativação de falhas geológicas através de um método analítico simplificado utilizando uma solução fechada implementada em uma ferramenta computacional denominada Fault Line. Rueda (2013) estudou o problema de reativação de falhas através da sua representação explícita por meio de 
elementos finitos de interface. Estes elementos de interface foram implementados através de sub-rotinas de usuário no software comercial ABAQUS®. Pereira et al., (2014) apresentaram um estudo sobre a perda da integridade da rocha capeadora devido a reativação de falhas em um aquífero real, utilizando uma abordagem probabilística que considera a variação das propriedades do material e o estado de tensão inicial. Rueda et al., (2014) compararam os resultados de quatro formulações numéricas empregando o método de elementos finitos na reativação de falhas. Estes autores concluíram que a representação explicita da falha através dos elementos de interface permite uma melhor avaliação deste fenômeno. Mejia et al. (2015) realizaram um estudo da reativação de falhas geológicas por meio de um elemento continuo equivalente, obtendo resultados similares quando a representação é feita por meio de elementos de interface.

Todos esses estudos foram realizados considerando modelos em estado plano de deformação. Estes modelos bidimensionais são comumente adotados a fim de evitar a complexidade geométrica e o alto custo computacional que uma modelagem tridimensional demanda. No entanto, a configuração tridimensional dos planos de falha pode induzir a reativação em direção a zonas mais críticas do que aquelas contidas em uma única seção. Recentemente, vários trabalhos têm chamado a atenção à importância uso de modelos 3D, principalmente na análise de migração de fluidos pela reativação de falhas geológicas que se interceptam (Fang, 2014; Serajian et al., 2016, Vidal-Gilbert et al., 2009).

\section{2.}

\section{Objetivos e Metodologia}

O objetivo principal deste trabalho é estudar o comportamento das falhas geológicas em reservatórios de petróleo submetidos a mudanças de poropressão utilizando elementos de interface 2D e 3D para representação das falhas geológicas. É também objetivo do trabalho comparar diferentes metodologias numéricas para avaliação de reativação de falhas. Para isto apresenta-se uma revisão bibliográfica das diferentes metodologias que têm sido propostas na literatura. Em seguida, pretende-se comparar estes métodos através de diversas modelagens da reativação de falhas geológicas e uma possível migração de fluidos através destas. Com este 
fim, foram realizadas algumas implementações como são os elementos de interface em um simulador in-house de elementos finitos 2D/3D, desenvolvido no instituto Tecgraf com base no trabalho apresentado por Quevedo (2012). O simulador denominado "AMARILIS" é capaz de simular processos transientes termo-hidrogeomecânicos através de meios porosos. Para representação explícita das falhas geológicas, rotinas que definem elementos de interface de espessura nula com comportamento geomecânico descrito pelo modelo critério de Mohr-Coulomb foram adicionadas às bibliotecas do programa principal. Estas rotinas foram criadas com base naquelas desenvolvidas por Rueda (2013) para representação de falhas, e foram estendidas para seu uso, não apenas na condição de estado plano de deformação, mas também em domínios 3D. Desta forma, as capacidades do programa foram estendidas para modelagem da reativação de falhas geológicas através de análises 2D e 3D, possibilitando uma comparação de resultados entre ambos domínios. Para este objetivo, foi criado um modelo de um campo hipotético 3D com diversas falhas incluídas.

\section{3. \\ Estrutura da dissertação}

Além desse capitulo inicial que apresenta a motivação, objetivo e metodologia, este trabalho é composto por 5 capítulos, conforme descrito a seguir.

No Capítulo 2, apresenta uma revisão bibliográfica sobre a consideração de falhas geológicas em problemas geomecânicos. Apresentam-se também os critérios para a avaliação da poropressão máxima a injetar em reservatórios e as diferentes abordagens para o seu cálculo. Além disso, o capítulo traz uma breve descrição das propriedades hidromecânicas de zonas de falha.

No Capítulo 3 apresentam-se as relações constitutivas para a representação do comportamento mecânico da falha geológica e a formulação pelo método de elementos finitos para o elemento de interface. Apresentam-se também os diferentes tipos de elementos de interface implementados para a discretização espacial da falha são descritos. Testes de validação da formulação do elemento de interface para utilização em modelos tridimensionais encerram o capítulo. 
No Capítulo 4 três exemplos de aplicação são empregados para avaliar as formulações numéricas para modelagem de falhas geológicas. O primeiro exemplo traz um modelo bidimensional apresentado na literatura, faz-se uma comparação dos resultados com representação por meio do elemento de interface, por meio do continuo equivalente e por meio de um elemento solido com fraturas embutidas. $\mathrm{O}$ segundo exemplo apresenta um campo hipotético com sete camadas e três falhas geológicas na região de injeção. Com base neste campo são investigadas as modelagens com elementos de interface triangulares e quadrilaterais. $\mathrm{O}$ terceiro exemplo apresenta um comparativo entre os resultados obtidos de uma seção 2D com os de um modelo 3D.

Finalmente, o Capitulo 5 traz as considerações finais do trabalho e, posteriormente são apresentadas algumas sugestões para trabalhos futuros. 


\section{2 \\ Revisão Bibliográfica}

Neste capitulo o principal objetivo é apresentar algumas metodologias de análise e as principais características físicas, mecânicas e hidromecânicas que são levadas em conta para uma melhor idealização de uma falha geológica em um modelo numérico de reservatórios.

\subsection{Falhas geológicas e propriedades da zona da falha}

Falhas geológicas são planos de descontinuidade em maciços rochosos através da qual ocorreram deslocamentos relativos entre as camadas de rocha adjacentes (Pollard and Segall, 1987) causadas pela resposta de um material frágil para um campo de tensões quando é excedido seu o limite de resistência. Diferentes tipos de falhas podem se formar dependendo do campo de tensões em que se encontrem.

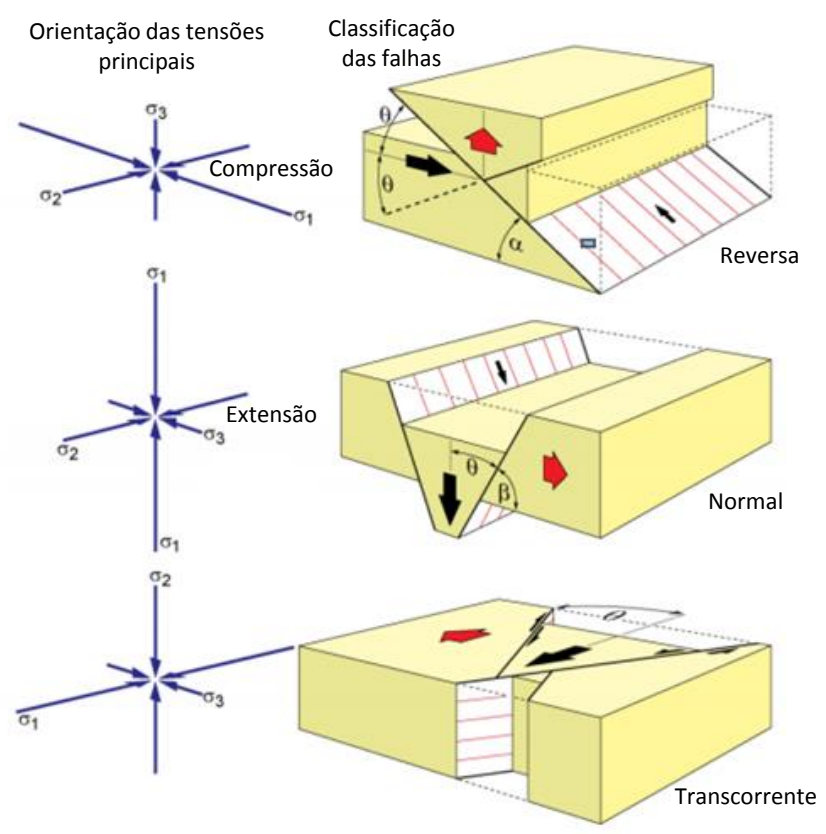

Figura 2-1 Orientação das tensões principais e seus tipos de falhas associadas (adaptado de Burg, 2013)

onde, 
Regime normal: $\mathrm{S}_{\mathrm{v}}=\sigma_{1}>\mathrm{S}_{\mathrm{H}}=\sigma_{2}>\mathrm{S}_{\mathrm{h}}=\sigma_{3}$

Regime reverso: $\mathrm{S}_{\mathrm{H}}=\sigma_{1}>\mathrm{S}_{\mathrm{h}}=\sigma_{2}>\mathrm{S}_{\mathrm{v}}=\sigma_{3}$

Regime transcorrente: $\mathrm{S}_{\mathrm{H}}=\sigma_{1}>\mathrm{S}_{\mathrm{v}}=\sigma_{2}>\mathrm{S}_{\mathrm{h}}=\sigma_{3}$

onde, $S_{\mathrm{v}}$ é a tensão vertical e $S_{\mathrm{H}}$ e $S_{\mathrm{h}}$ são as tensões horizontais.

Os autores (Price,1966; Hobss et al, 1976) definem a falha como um plano, conhecido como plano de deslizamento ou fratura de cortante. Esse plano de deslizamento está associado a uma zona delgada de rocha triturada em comparação com as outras dimensões. Essa zona é chamada de núcleo da falha (Caine et al, 1996). O material de preenchimento da zona de falha é função do tipo de reservatório estudado se o campo estudado não é um reservatório carbonático. $\mathrm{O}$ núcleo da falha é geralmente considerado como a zona onde é absorvida a maior parte dos deslocamentos que ocorrem na falha. Geralmente este núcleo é composto de gouge e cataclástico (Chambon et al., 2006). Além do núcleo da falha existe a zona de dano que se encontra no contorno da falha (Figura 2-2), comumente formada por fraturas em diferentes escalas, de micro a macro fraturas que podem absorver pequenos deslocamentos de cisalhamento (Faulkner et al., 2010).

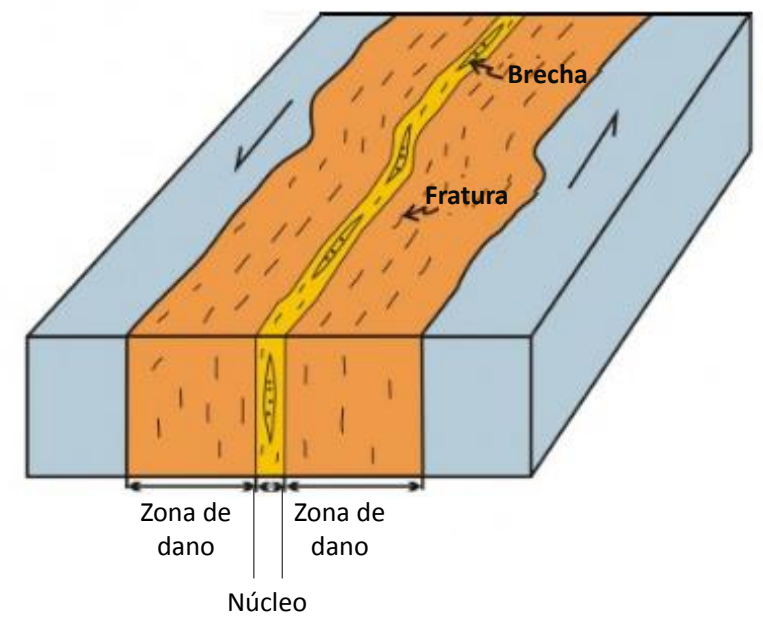

Figura 2-2 Núcleo e zona de dano em uma falha, adaptado de (Gudmundsson et al., 2010).

A zona de dano tem um papel importante para o desenvolvimento de caminhos preferenciais de fluxo porque a grande concentração de fraturas nessas zonas pode permitir a migração de fluidos (Koestler et al., 1992).

A estimativa da permeabilidade de zonas de falha não é simples, isto que os métodos convencionais para sua medição com amostras em laboratório submetidas a condições de tensões podem não ser aplicáveis às zonas de dano por causa da 
variação das propriedades ao longo da mesma (Mathias, 2012). O núcleo da falha é uma zona menos permeável com baixa porosidade, enquanto que a zona de dano é uma banda mais permeável com uma rede macroscópica de fraturas (Cappa \& Rutqvist, 2010). Dependendo da litologia da rocha adjacente ao reservatório e das dimensões e movimentos da falha, a permeabilidade da falha pode mudar drasticamente, fazendo que esta zona atue como barreira ou como conduto para o fluxo de fluidos (Caine et al., 1996).

A permeabilidade em fraturas e zonas de falha foram estudadas por alguns autores no contexto de integridade do trapeamento de hidrocarbonetos (Watts, 1987; Heggland, 1998; Talwani et al., 1999, Tadokoro et al., 2000; Faulkner and Rutter , 2000; Mildren et al., 2002; Rutquvist \& Tsang, 2002; Bretan and Yielding, 2005; Faulkner et al., 2010, Cappa \& Rutqvist, 2010). Nesses estudos foi observado que a permeabilidade na falha é função do estado de tensões que atua sobre ela e da geometria da mesma. Também estudaram a influência do material que se encontra na zona de falha nas micro e macro fraturas, o qual varia muito para diferentes rochas e diferente estado de tensões.

No trabalho de Evans et al., (1997) foram estudadas as permeabilidades para três tipos de amostras de uma rocha granítica, provenientes de afloramentos da falha East Fork no estado de Wyoming nos EUA. As amostras eram provenientes de o núcleo da falha, da zona de dano e da rocha integra. Os resultados obtidos para tensões confinantes variando entre 2 e $50 \mathrm{MPa}$, para as três regiões analisadas mostraram que para o núcleo da falha foram encontrados valores de permeabilidade entre $10^{-20} \mathrm{e} 10^{-17} \mathrm{~m}^{2}$, enquanto que a amostra da zona de dano apresentou valores de permeabilidade um pouco maiores oscilando entre $10^{-16}$ e $10^{-14} \mathrm{~m}^{2}$. Já o material da rocha integra apresentou valores de permeabilidade entre $10^{-18}$ e $10^{-17} \mathrm{~m}^{2}$. Valores similares são apresentados por Cappa \& Rutqvist (2010), na Figura 2-3 onde se vê como varia a permeabilidade e o módulo de elasticidade nas zonas adjacentes ao núcleo da falha e na zona de dano. 

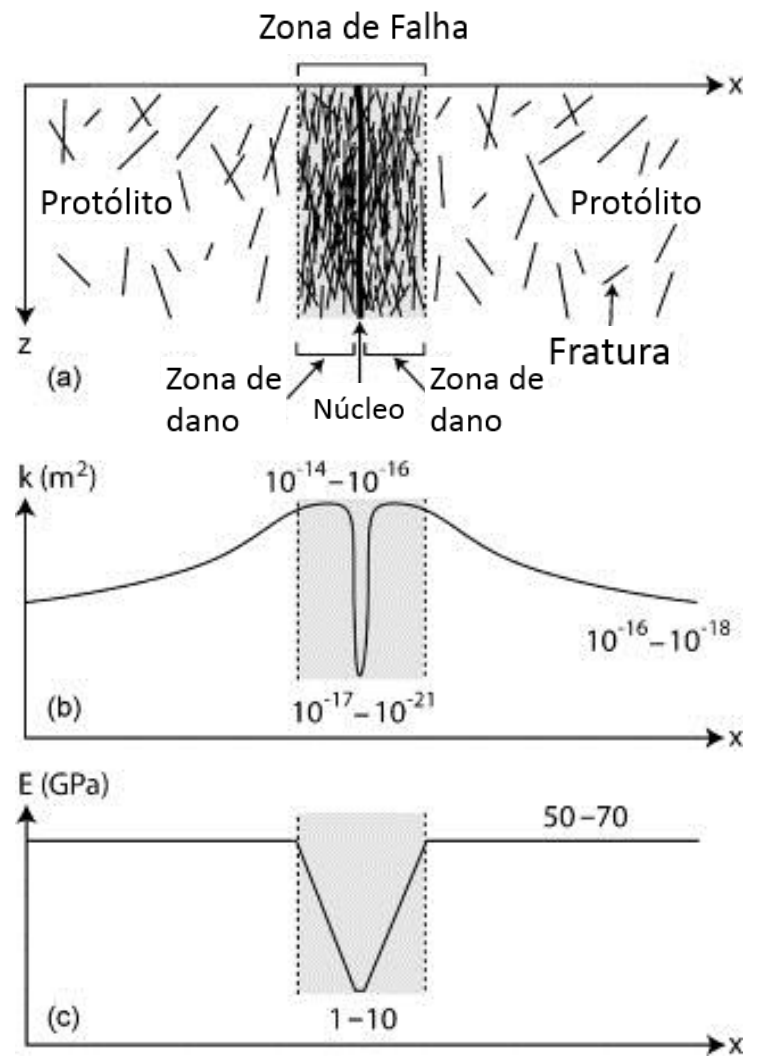

Figura 2-3 (a) Diagrama esquemático da estrutura transversal da zona da falha (b) permeabilidade (c) modulo de elasticidade. Cappa \& Rutqvist (2010)

\subsection{Análise de tendência de reativação de falhas}

O deslizamento e a reativação de falhas foram reconhecidos pela primeira vez como uma possível causa do fluxo de fluidos nas zonas de falha (Sibson, 1990; Rueda, 2013). Este fenômeno tem sido amplamente investigado: uma revisão detalhada foi fornecida por Zoback (2007). A tendência à reativação pode ser expressa através do critério de Mohr-Coulomb. Na literatura encontram-se três abordagens diferentes para a análise de reativação de falhas: analítica, semianalítica e numérica.

\subsubsection{Solução analítica e semianalítica}

A injeção de fluido no reservatório incrementa a pressão de poros e, consequentemente, altera o estado de tensões no reservatório e nas rochas adjacentes. Quando isso ocorre a tensão cisalhante atuante no plano de falha excede a tensão cisalhante resistente. Nessa condição a falha pode reativar o que significa que a falha teve uma movimentação produto da mudança no estado de tensões. 
Utilizando o critério de falha de Mohr-Coulomb e o princípio das tensões efetivas (Moeck et al., 2009; Neves et al., 2009; Streit et al., 2002; Bostrøm et al., 2004; Mendes et al., 2010) o critério de reativação é dado pela equação (2.1)

$$
\tau=c+\left(\sigma_{n}-P\right) \mu
$$

onde, $\tau$ é a tensão crítica cisalhante, $c$ é a coesão, $\mu$ é o coeficiente de atrito, propriedades equivalentes para a zona de falha, $\sigma_{n}$ é a tensão normal e $P$ é a poropressão. Muitos autores desprezam a coesão do material da falha. Nesse caso, a reativação ocorre quando a relação entre a tensão cisalhante e a tensão normal efetiva é igual ao coeficiente de atrito estático da falha:

$$
\frac{\tau}{\sigma_{n}-P}=\mu
$$

A Figura 2-4 apresenta as tensões e a influência do incremento da poropressão sobre a falha.

(a)

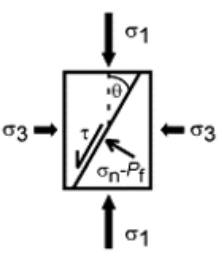

(b)

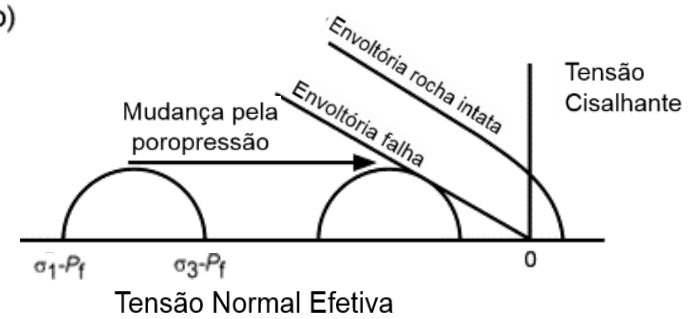

Figura 2-4 (a) Tensões atuantes na falha; (b) efeito pelo o incremento de poropressão na estabilidade da falha (Streit et al., 2004)

As tensões normal e cisalhante podem ser calculadas a partir das tensões principais conforme as seguintes equações:

$$
\begin{gathered}
\tau=\frac{1}{2}\left(\sigma_{1}-\sigma_{3}\right) \sin 2 \theta \\
\sigma_{n}^{\prime}=\frac{1}{2}\left({\sigma^{\prime}}_{1}+{\sigma^{\prime}}_{3}\right)+\frac{1}{2}\left({\sigma^{\prime}}_{1}-{\sigma^{\prime}}_{3}\right) \cos 2 \theta
\end{gathered}
$$

onde, $\sigma^{\prime}{ }_{1}$ e $\sigma_{3}^{\prime}$ são as tensões principais máxima e mínima efetivas atuando no plano de falha, $\theta$ é o ângulo entre o vetor normal ao plano de falha e a direção da tensão principal $\sigma_{1}$ atuante na falha. 
Entre as limitações da solução analítica tem se que é assumido que o estado de tensões in situ é constante durante o processo de injeção, o que não ocorre na pratica já que o estado de tensões poder variar no tempo e no espaço, controlado pela evolução da pressão de poro e pela temperatura (Rutqvist et al., 2007). Nas análises usando soluções analíticas, o reservatório é representado por um meio homogêneo composto por superfícies regulares, submetidos a poropressões constantes (Rutqvist et al., 2007; Rueda, 2013).

Altmann et al., (2013) em seu trabalho fornece uma abordagem analítica 3D para mudanças a longo prazo das componentes do tensor de tensão em função de mudanças da poropressão. Os resultados indicaram que para uma taxa constante de injeção ou depleção todos os componentes do tensor dependem da localização do reservatório em relação ao ponto donde é feito o processo de injeção/depleção. Além disso, os resultados preveem que as mudanças localizadas da tensão de cisalhamento podem conduzir a diferentes orientações de fratura do que as estimadas quando os efeitos poro-elásticos não são considerados. No trabalho Altmann et al., (2013) foi analisado um campo hipotético. Um esboço apresentado está na Figura 2-5. Nessa figura são identificados 3 pontos A, B, C, os quais estão localizados sobre os eixos principais de tensões, equidistantes ao ponto de injeção. A área sombreada na figura representa as mudanças da poropressão ao redor do ponto de injeção/depleção $\mathrm{P}$, o qual está localizado na origem do sistema de coordenadas. Altmann et al., (2013) analisaram o comportamento do reservatório para os processos de injeção e depleção, a estabilidade de poços e a reativação de falhas para três regimes de tensões: normal, reversa e transcorrente.

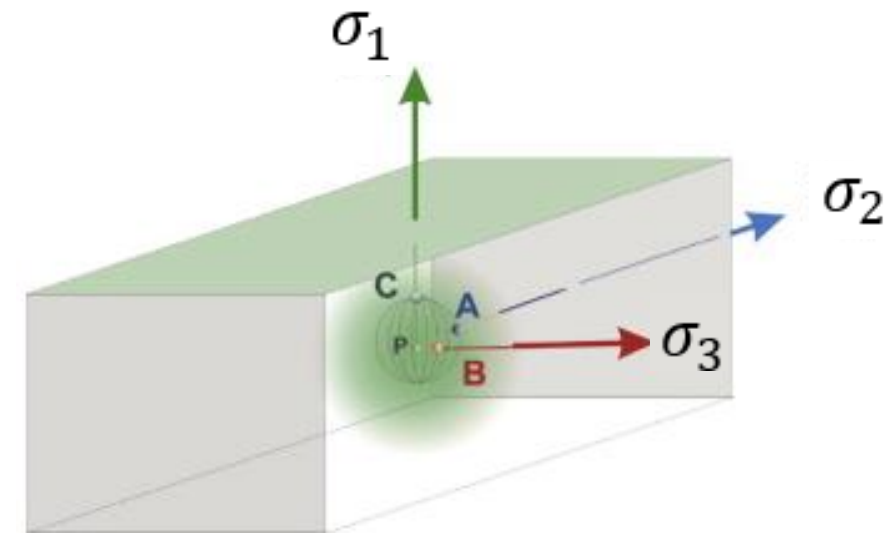

Figura 2-5 Esboço para explicar as posições dos pontos A, B, C. (Altmann et al., 2013) 
Dos resultados Altmann et al., (2013) concluiu que:

- As tensões induzidas pelas mudanças na poropressão modificam a tendência de reativação das falhas. Durante o processo de injeção nos regimes transcorrente e reverso a tendência de reativação da falha é maior ao longo da orientação da tensão $\mathrm{S}_{\mathrm{H},}$ enquanto que em regimes com falha normal, a reativação tende a ocorrer acima ou abaixo do ponto de injeção ao longo da orientação da tensão $S_{\mathrm{v}}$.

- Durante o processo de depleção nos regimes normal e transcorrente a reativação da falha é na orientação da tensão $S_{h}$, enquanto que no regime reverso a reativação ocorre na orientação de $S_{\mathrm{v}}$.

Altmann et al., (2013) afirma ainda que os resultados indicam a necessidade realizar estudos geomecânicos 3D com configurações de reservatórios mais realistas para estudar os efeitos 3D do acoplamento hidromecânico.

Como outra alternativa para estudar o problema de reativação de falhas se encontram as soluções semianalíticas as quais segundo Soltanzadeh \& Hawkes, (2008) consideram um acoplamento entre a pressão e o tensor de tensões. Uma prática comum em métodos semianalíticos é obter a distribuição da pressão dos poros e a evolução das tensões a partir das análises poro elástica, para usar como dados de entrada para as relações analíticas e semianalíticas.

No entanto, os modelos utilizados em seu trabalho têm limitações e não são adequados nos casos em que as propriedades mecânicas do reservatório são diferentes das rochas adjacentes (Soltanzadeh \& Hawkes, 2008).

\subsubsection{Soluções numéricas}

As abordagens numéricas são a melhor aproximação para a representação de reservatórios de petróleo, permitindo geometrias mais próximas ao problema real com campos de pressão e temperatura variáveis. Outras vantagens de usar abordagens numéricas é a possibilidade de utilização de modelos constitutivos mais complexos permitindo uma melhor representação do comportamento do material, Rueda (2013) em seu trabalho menciona os modelos de dano (Guimarães et al., 2009), de contato (Moeck et al., 2009; Bostrom \& Skomedal, 2004) e modelos elastoplásticos com anisotropia (Rutqvist et al., 2007). 


\subsubsection{Solução através do elemento continuo equivalente}

As falhas geológicas podem ser representadas explicitamente através de modelos discretos tais como uma superfície descontínua com deslocamentos relativos ou por bandas continuas com propriedades enfraquecidas, denominado continuo equivalente.

A formulação do elemento continuo equivalente se baseia no princípio dos deslocamentos equivalentes, o qual assume que para um dado estado de carregamento o deslocamento de uma massa de um continuo equivalente, é igual à deformação da rocha intata com uma falha (Zhu \& Zhao, 2004; Pezo et al., 2013; Rueda et al., 2014; Mejia et al., 2015). O deslocamento do continuo equivalente é dado pela seguinte equação:

$$
\delta_{i}=\delta_{i}^{R}+\delta_{i}^{F}
$$

onde $\delta_{i}^{R}$ é o deslocamento da rocha intata e $\delta_{i}^{F}$ é o deslocamento relativo no plano de falha.

A Figura 2-6 mostra o elemento do continuo equivalente (a) e a rocha intacta atravessada por uma falha (b).

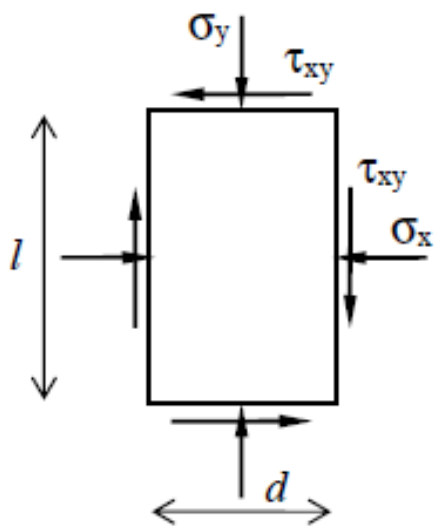

a)

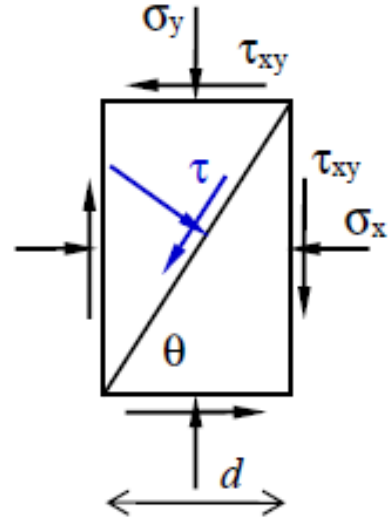

b)

Figura 2-6 Elemento 2D do continuo equivalente (a) rocha intata cruzada por uma falha (b).

Assumindo a rocha intata como isotrópica, sua correspondente matriz elástica é dada pela lei de Hooke como se mostra na equação (2.6)

$$
\varepsilon^{R}=C^{R} \cdot \boldsymbol{\sigma}
$$

onde, $\boldsymbol{C}^{R}$ é o correspondente matriz elástica, $\boldsymbol{\varepsilon}^{R}$ o vetor que contém as deformações e $\boldsymbol{\sigma}$ o correspondente vetor de tensões. 
Para a falha com ângulo de inclinação $\theta$, como apresentado na Figura 2-6 a tensão normal $\sigma_{n}$ e a tensão cisalhante $\tau$ no plano da falha são calculados pela seguinte equação:

$$
\left\{\begin{array}{c}
\sigma_{n} \\
\tau
\end{array}\right\}=\left\{\begin{array}{c}
\sigma_{x} \sin ^{2} \theta+\sigma_{y} \cos ^{2} \theta-\tau_{x y} \sin 2 \theta \\
\left(\sigma_{y}-\sigma_{x}\right) \cdot \sin \theta \cdot \cos \theta+\tau_{x y} \cos 2 \theta
\end{array}\right\}
$$

Assumindo um comportamento não acoplado entre tração-separação para a falha, os deslocamentos relativos no plano de falha em coordenadas globais são determinados de acordo com

$$
\left\{\begin{array}{l}
\delta_{x}^{F} \\
\delta_{y}^{F}
\end{array}\right\}=\left\{\begin{array}{l}
\frac{\sigma_{n}}{k_{N}} \sin \theta-\frac{\tau}{k_{S}} \cos \theta \\
\frac{\sigma_{n}}{k_{N}} \cos \theta+\frac{\tau}{k_{S}} \sin \theta
\end{array}\right\}
$$

onde, $k_{N}$ e $k_{S}$ são os coeficientes de rigidez normal e cisalhante da região da falha respetivamente, $\delta_{x}^{F}$ e $\delta_{y}^{F}$ os deslocamentos relativos nas direções $\mathrm{x}$ e $\mathrm{y}$, respetivamente. Os coeficientes de rigidez podem ser estimados a partir dos parâmetros elásticos das rochas adjacentes como (Priest, 1993)

$$
\begin{gathered}
k_{N}=\frac{E}{e} \\
k_{S}=\frac{G}{e}=\frac{E}{2(1+v) e}
\end{gathered}
$$

\subsubsection{Solução através de elementos sólidos com fraturas embutidas}

Nesta abordagem, a falha é representada através de elementos sólidos com permeabilidade dependente do estado de tensão/deformação. Esta metodologia foi utilizada por Olivella \& Alonso (2008) para simular a migração de gás através de meios fraturados. A análise é realizada através de uma formulação com acoplamento hidromecânico em que as equações de equilíbrio e de continuidade são solucionadas em um único sistema (acoplamento total).

Na produção de hidrocarbonetos nos campos de petróleo e gás novas fraturas podem surgir ou reativar devido às mudanças no estado de tensões. Pretende-se aqui simular o fluxo através das fraturas usando alguns modelos simples baseados na 
abertura da fratura com o fim de obter permeabilidades que representem melhor o fluxo através das descontinuidades.

A Figura 2-7 apresenta a seção transversal de uma rocha fraturada. $\mathrm{O}$ fluxo através desta seção é composto pelo fluxo que passa através do meio poroso e o fluxo que passa através das fraturas. Numa situação ideal, as fraturas podem ser representadas por um conjunto de fraturas de aberturas similares (b), e espaçamentos de tamanho similar (s), como se mostra do lado direito da figura.

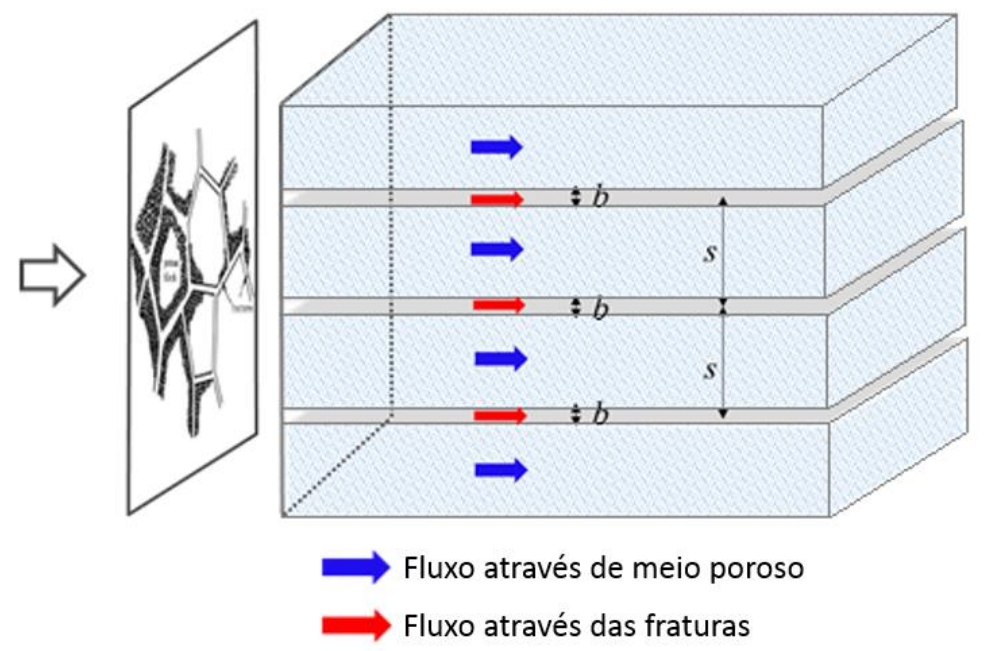

Figura 2-7 Representação do fluxo através de meios fraturados

Para o cálculo da permeabilidade intrínseca na direção paralela às fraturas se faz uso da seguinte equação

$$
k=k_{m}+\frac{b^{3}}{12 s}
$$

onde, $k_{m}$ é a permeabilidade do meio. Segundo Olivella \& Alonso (2008), a permeabilidade da matriz pode ser relevante somente para aberturas muito pequenas; caso contrário, a permeabilidade da fratura dominará a permeabilidade total e a permeabilidade da matriz será insignificante em termos comparativos. A dependência da permeabilidade dos efeitos mecânicos encontra-se no processo de formação da fratura e das mudanças na abertura. Logo, a abertura e separação associada a cada fratura podem ser estimadas como função da deformação perpendicular ao plano da fratura $\varepsilon$, de acordo com

$$
\begin{aligned}
& b=b_{0}+\left(\varepsilon-\varepsilon_{0}\right) \times s_{0} \\
& s=\left[1+\left(\varepsilon-\varepsilon_{0}\right)\right] \times s_{0}
\end{aligned}
$$


onde, $b_{0}$ e $s_{0}$ representam os valores iniciais da abertura e espaçamento da fratura, e $\varepsilon_{0}$ representa um valor associado com a iniciação da fratura. Este valor é zero se as fraturas já existem e têm uma abertura inicial $b_{0}$.

\subsubsection{Solução através de elementos de interface}

$\mathrm{Na}$ literatura empregam-se diferentes técnicas numéricas para avaliação de reativação de falhas. Dentre eles citam-se: o método dos elementos finitos (VidalGilbert, 2009; Zhang et al., 2009; Mendes, 2010; Wang et al., 2012; Rueda, 2013), método das diferenças finitas (Zhang et al., 2009; Fouladvand et al., 2009; Rutqvist et al., 2007; Lee et al.,2012), métodos dos elementos discretos (Zhang \& Sanderson, 1996; Langhi et al., 2009) e o método dos elementos de contorno (Safari \& Ghassemi, 2012).

Entre todos estes trabalhos, o método de elementos finitos empregando elementos de interface na sua representação tem se mostrado com grande potencial para avaliação de reativação de falhas geológicas (Zhang et al., 2009; Mendes, 2010; Wang et al., 2012; Rueda, 2013). Todos estes trabalhos levaram em consideração modelos 2D para análise de reativação de falhas geológicas na hipótese de estado plano de deformação. No entanto, esta hipótese pode não ser aplicável em alguns campos em função da configuração geométrica do reservatório e das falhas geológicas. Na literatura encontram-se alguns estudos de caso para análises com modelos 3D (Mulders, 2003, Fang et al., 2014; Vidal-Gibert et al., 2014, Serajian et al., 2016).

Vidal-Gilbert et al., (2009) realizaram uma análise geomecânica 3D modelando o armazenamento de $\mathrm{CO}_{2}$ em carbonatos da bacia de Paris. No trabalho é estudada a avaliação das deformações induzidas pelas mudanças das tensões in situ, e seus efeitos potenciais sobre as falhas. A análise geomecânica do sistema reservatório-rocha capeadora foi realizada usando informações de pressão através de um acoplamento "one way", onde as pressões estimadas com um simulador de reservatórios são introduzidas no modelo geomecânico como dados de entrada.

O modelo proposto por Vidal-Gilbert et al., (2009) é o campo de Saint-Martin de Bossenay (SMB), onde o petróleo está a uma profundidade de $1450 \mathrm{~m}$ com pressão e temperatura inicial no reservatório de $14,5 \mathrm{MPa}$ e $65^{\circ} \mathrm{C}$ respetivamente. $\mathrm{O}$ 
reservatório esta subdividido em 4 reservatórios calcários A, B, C, D. A Figura 2-8 apresenta a distribuição da falha SMB e o modelo com a malha de elementos finitos usada por Vidal-Gilbert et al., (2009).
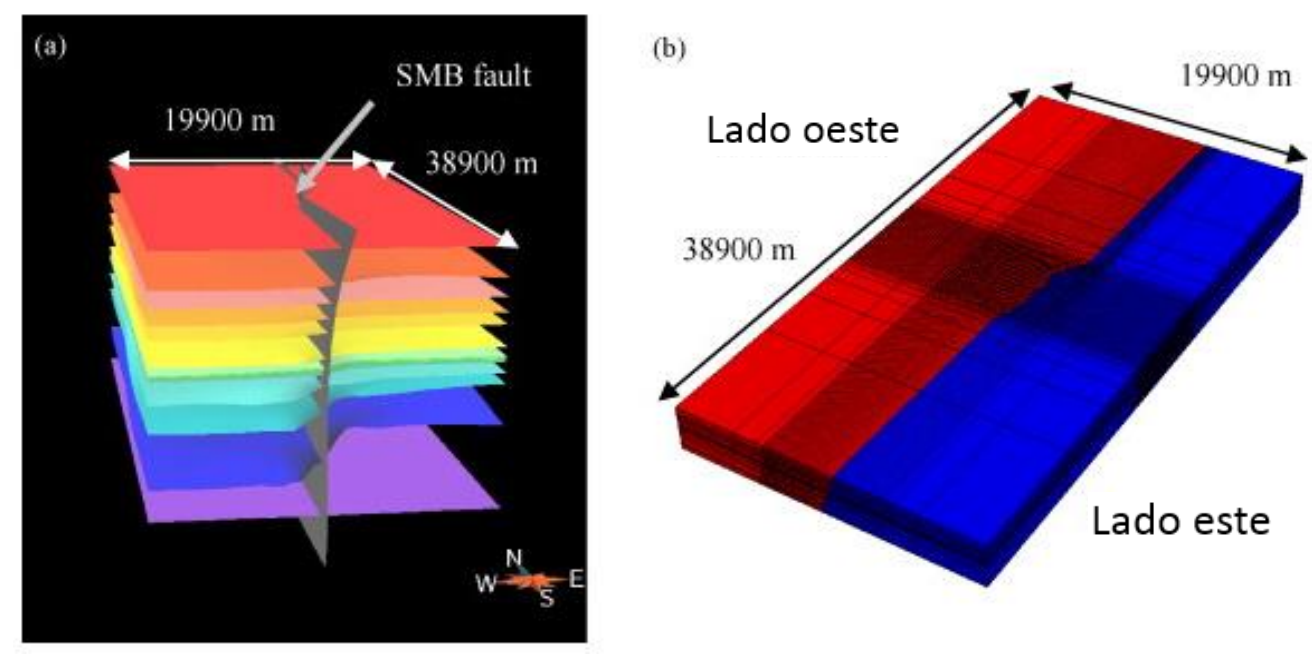

Figura 2-8 (a) Horizontes das superfícies que cortam a falha (SMB Fault) e (b) malha de elementos finitos (Vidal-Gilbert et al., 2009)

No modelo de Vidal-Gilbert et al., (2009) a falha é representada por elementos de interface entre a zona este e oeste. O critério de ruptura foi o critério de Mohr-Columb.

As mudanças da poropressão foram calculadas por um simulador de reservatórios desenvolvido no IFP com a seguinte história (Bossie-Codrenau, 2008). O campo de Saint-Martin de Bossen estava em produção desde 1958 até 1995 e ficou abandonado até o ano 2006. O campo foi examinado de novo e a produção recomeçou nos mesmos poços SMB17 e SBM15. Na simulação, VidalGilbert et al., (2009) injetaram $\mathrm{CO}_{2}$ nos dois poços para o reservatório D durante um período de 5 anos. A variação da poropressão aplicada nos poços é dada na Figura 2-9. 


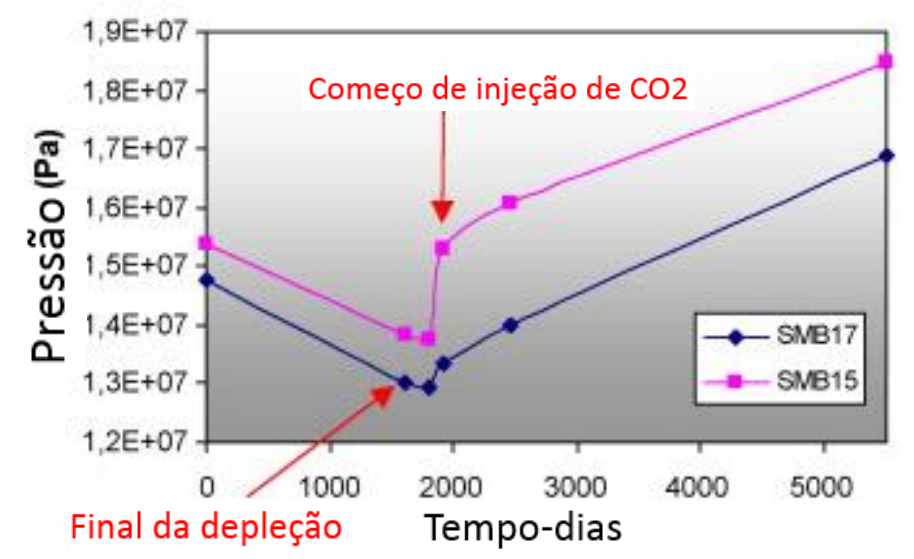

Figura 2-9 Evolução da poropressão nos poços injetores no reservatório D

A falha maior SMB está um pouco afastada do reservatório, mas existem outras falhas menores. Para essas falhas Vidal-Gilbert et al., (2009) realizaram estudos para avaliar a estabilidade das mesmas.

O risco de reativação foi calculado o critério de Mohr-Coulomb. A magnitude da tensão normal e tensão cisalhante através da falha foram calculadas por relações 3D estabelecidas para uma mudança de um sistema cartesiano para um tensor de uma falha qualquer. Vidal-Gilbert et al., (2009) observaram que para que ocorra a reativação da falha dentro do reservatório, deve ser aplicado um delta de poropressão igual a $13 \mathrm{MPa}$. Concluem ainda que o elemento de interface proporciona uma boa representação para o comportamento mecânico de uma falha geológica baseados em os resultados obtidos. 


\section{3 \\ Análise 3D de reativação de falhas pelo método dos elementos finitos}

Neste capítulo são apresentadas as implementações feitas neste trabalho: as formulações do elemento de interface com interpolação linear e quadrática para a representação das falhas geológicas. Foram implementados elementos de interface tipo linha para as análises $2 \mathrm{D}$ e elementos de interface triangulares e quadrilaterais para as análises 3D. O modelo constitutivo para a interface é o modelo elastoplástico de Mohr-Coulomb. O algoritmo implícito de integração das tensões em regime elasto-plástico foi também implementado no escopo deste trabalho.

\subsection{Relações constitutivas}

Para simular o comportamento físico da rocha é necessário ter um modelo no qual se relacionem as tensões e deformações. Este modelo deve levar em conta além das propriedades do material em questão, outras características do seu comportamento como não linearidade, plasticidade e dilatância.

Uma das hipóteses mais comuns sobre a quais estão formulados os modelos constitutivos em geotecnia é assumir que o solo ou rocha è um meio continuo. Por esse motivo deve-se atender as três equações básicas da mecânica dos meios contínuos (Malvern, 1969; Spencer 1980):

- Equação de equilíbrio de tensões.

- Equação de compatibilidade de deformações.

- Equação constitutiva que relaciona tensões e deformações.

\subsubsection{Lei de Hooke generalizada}

A lei de Hooke generalizada é utilizada para prever a mudança de tensões efetivas $\left(\Delta \sigma^{\prime}\right)$ produzidas em um dado material por uma de mudança arbitrária nas deformações $(\Delta \boldsymbol{\varepsilon})$ : 


$$
\Delta \boldsymbol{\sigma}^{\prime}=\mathbf{D} \Delta \boldsymbol{\varepsilon}
$$

em que, $\boldsymbol{\sigma}^{\prime}=\left\{\begin{array}{lll}\tau_{1} & \tau_{2} & \sigma^{\prime}\end{array}\right\}^{T}$ é o tensor das tensões efetivas com, $\tau_{1}$ e $\tau_{2}$ como as tensões cisalhantes no plano de falha e $\sigma_{n}^{\prime}$ definida como a tensão normal. D representa a matriz constitutive do material na falha e $\boldsymbol{\varepsilon}=\left\{\begin{array}{lll}\varepsilon_{s 1} & \varepsilon_{s 2} & \varepsilon_{n}\end{array}\right\}^{T}$ é o tensor das deformações no plano de falha.

\subsubsection{Definição da matriz constitutiva}

Diferentes teorias foram desenvolvidas na literatura para definir a matriz constitutiva D. Dentre estas, dois grupos principais têm sido utilizados em aplicações geomecânicas: teoria da elasticidade e teoria da plasticidade.

A matriz D pode tomar diferentes formas, mesmo se o material for elástico. Enquanto alguns autores assumem que a rocha apresenta um comportamento isotrópico, outros assumem que a rocha é anisotrópica. Outros autores assumem que a rocha tem um comportamento linear, outros estabelecem um comportamento não linear com parâmetros dependentes do estado de tensão-deformação (Zoback \& Zdravkovic, 2008). De acordo com Goodman et al. (1968), no plano de falha a matriz $\mathbf{D}$ é estabelecida através de:

$$
\mathbf{D}=\mathbf{D}^{e}=\left[\begin{array}{ccc}
k_{S} & 0 & 0 \\
0 & k_{S} & 0 \\
0 & 0 & k_{N}
\end{array}\right]
$$

em que $k_{S}$ e $k_{N}$ são os coeficientes de rigidez tangencial e normal por unidade de comprimento ao plano de falha, respectivamente. De forma geral esses parâmetros são obtidos em laboratório. Alternativamente, podem ser estimados a partir dos parâmetros elásticos das rochas adjacentes como (Priest, 1993)

$$
\begin{gathered}
k_{N}=\frac{E}{e} \\
k_{S}=\frac{G}{e}=\frac{E}{2(1+v) e}
\end{gathered}
$$

sendo $E$ o módulo de Young, $v$ coeficiente de Poisson, $e$ a espessura equivalente da falha geológica, e $G$ o modulo de cisalhamento. 
Enquanto esta teoria é relativamente simples, ela não é capaz de representar algumas características importantes do comportamento real das rochas. Algumas melhorias podem ser alcançadas utilizando a teoria da plasticidade.

A teoria da plasticidade começou orientada ao estudo do comportamento dos metais (Tresca, 1864) e sua formulação matemática se deve a Hill (1950). A partir de essas teorias iniciou-se o desenvolvimento de modelos para calcular deformações irreversíveis em solos e rochas. As primeiras aplicações foram feitas por Drucker et al. (1957), embora Coulomb (1773) já tivesse introduzido o conceito do comportamento à ruptura dos solos, que depois foi utilizado na teoria da plasticidade perfeita e nos métodos do equilíbrio limite.

De acordo com Potts \& Zdravkovic (1999), a teoria clássica da plasticidade está baseada em quatro conceitos fundamentais: coincidência dos eixos principais de tensões e deformações, função de escoamento, função do potencial plástico e lei de endurecimento/amolecimento.

A coincidência dos eixos, admite que os eixos principais dos incrementos de tensões coincidem com os eixos principais dos incrementos das deformações.

A função de escoamento, também conhecida como função de plastificação, estabelece o limite entre a região das tensões admissíveis e inadmissíveis (Figura 3-1), $F$ é uma função escalar de tensões expressa em termos das componentes de tensão ou em função dos invariantes de tensão e dos parâmetros de estado $\{k\}$ :

$$
F(\{\sigma\},\{k\})=0
$$

Onde:

$F$ : é a função de escoamento

$\sigma:$ é o componente de tensões

k: é o parâmetro de endurecimento/amolecimento 


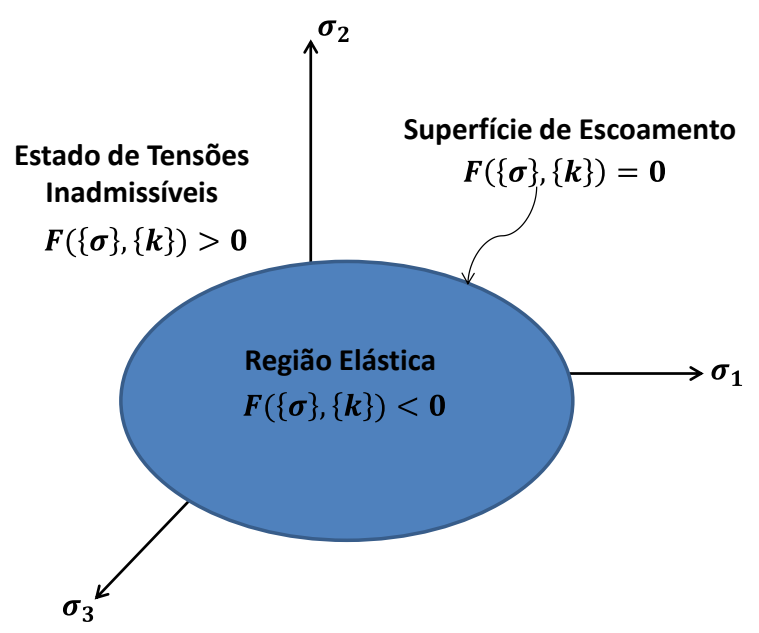

Figura 3-1 Representação da superfície de escoamento no sistema de eixos principais de tensões

Para um modelo perfeitamente plástico (Figura 3-2) o parâmetro $\{k\}$ é constante e representa a tensão de plastificação uniaxial equivalente. Considerandose endurecimento ou amolecimento plástico, o parâmetro $\{k\}$ varia com a deformação plástica ou com o trabalho plástico.

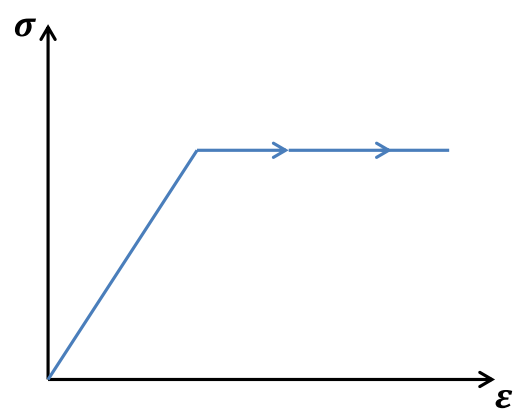

Figura 3-2 Comportamento perfeitamente plástico

$O$ valor de função $F$ é utilizado para saber qual é o comportamento do material. Para valores $F(\{\sigma\},\{k\})<0$ o estado de tensões é elástico e se encontra dentro da superfície de plastificação; para $F(\{\sigma\},\{k\})=0$ o material se comporta plasticamente; valores $\{\sigma\},\{k\})$ tais que $F(\{\sigma\},\{k\})>0$ são inadmissíveis (Figura 3-1).

A função de potencial plástico, $P(\{\sigma\},\{m\})$, define a direção e o incremento de deformação plástica. Para um estado geral de deformações a lei de fluxo não associada é dada pela Eq, (3.6)

$$
\Delta \varepsilon^{p}=\Lambda \frac{\partial P(\{\sigma\},\{m\})}{\partial \sigma}
$$


onde $\Lambda$ é um escalar que recebe o nome de multiplicador plástico, $m$ é o vetor dos parâmetros de estado e $\Delta \varepsilon^{p}$ é o incremento de deformação plástica.

A Figura 3-3 fornece a representação gráfica da equação (3.6), onde a superfície do potencial plástico está representada no espaço das tensões principais em duas dimensões.

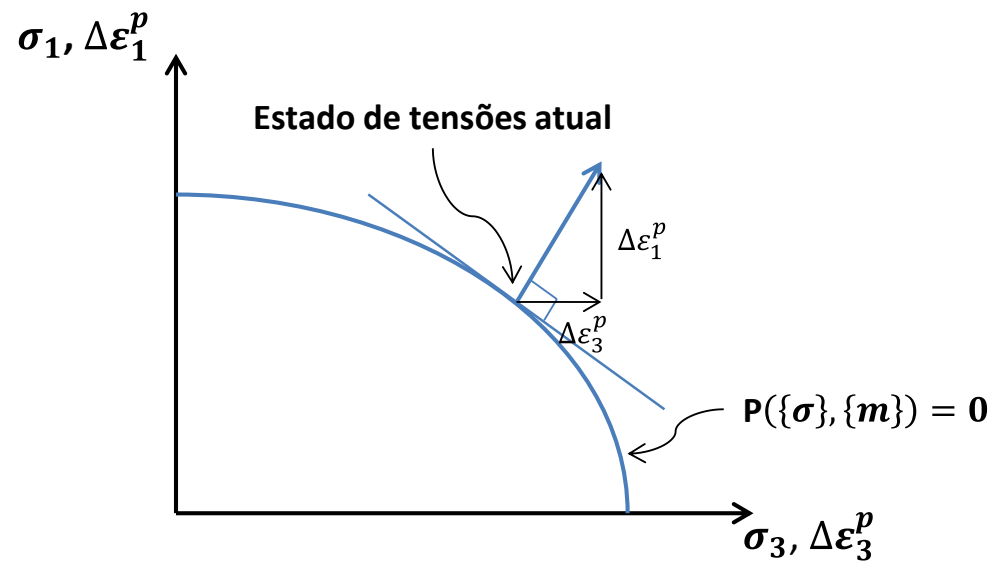

Figura 3-3 Superfície de potencial plástico

Denomina-se plasticidade associada quando a função de escoamento coincide com a função do potencial plástico, ou seja,

$$
F(\{\sigma\},\{k\})=P(\{\sigma\}, m) .
$$

Dá-se o nome de plasticidade não associada quando a função de escoamento difere da função do potencial plástico,

$$
F(\{\sigma\},\{k\}) \neq P(\{\sigma\}, m) .
$$

Finalmente, a regra de endurecimento/amolecimento é uma relação empírica, independente da trajetória de tensões, que define a variação da superfície de encruamento. Igualmente prescreve como os parâmetros $\{k\}$ variam com a deformação plástica. Quando não ocorre endurecimento nem amolecimento os parâmetros $\{k\}$ são constantes. Isso ocorre em trajetórias de tensões elásticas e para materiais com comportamento elasto-plástico perfeito como foi apresentado na Figura 3-2 .

A partir dos conceitos definidos aqui, a matriz elasto-plástica pode ser estabelecida pela seguinte expressão: 


$$
\mathbf{D}=\mathbf{D}^{e p}=\mathbf{D}^{e}-\frac{\mathbf{D}^{e}\left\{\frac{\partial P(\{\sigma\},\{m\})}{\partial \sigma}\right\}\left\{\frac{\partial F(\{\sigma\},\{k\})}{\partial \sigma}\right\}^{T} \mathbf{D}^{e}}{\left\{\frac{\partial F(\{\sigma\},\{k\})}{\partial \sigma}\right\}^{T} \mathbf{D}^{e}\left\{\frac{\partial P(\{\sigma\},\{m\})}{\partial \sigma}\right\}+A}
$$

onde

$$
A=-\frac{1}{\Lambda}\left\{\frac{\partial F(\{\sigma\},\{k\})}{\partial k}\right\}^{T}\{\Delta \mathrm{k}\}
$$

Dependendo do tipo de encruamento o parâmetro $A$ pode tomar diferentes valores. No caso de plasticidade perfeita o parâmetro $A$ tem um valor de zero isso ocorre porque a equação (3.11) é igual à zero.

$$
\left\{\frac{\partial F(\{\sigma\},\{k\})}{\partial k}\right\}^{T}=0
$$

\subsubsection{Modelo Constitutivo de Mohr-Coulomb com Cut-off}

O critério de ruptura de Mohr-Coulomb é amplamente usado para materiais geotécnicos, já que representa bem o comportamento desses materiais para várias trajetórias de tensões. Na literatura são diversos os problemas geotécnicos que fazem uso do critério de Mohr-Coulomb tais como a estabilidade de aterro (Sarma, 1975; Shen et al., 2012), capacidade de suporte em fundações (Bolton \& Lau, 1993; Conte et al., 2013), e a tendência à reativação de falhas (Pereira et al., 2014; Mejia et al., 2015) Como base teórica dessa formulação toma-se a dissertação de Rueda (2013).

O critério de plastificacão de Mohr-Coulomb é determinado em função da tensão normal efetiva $\sigma_{n}^{\prime}$ (compressão negativa) e a tensão cisalhante $\tau$ satisfazendo a expressão (3.12)

$$
\tau_{\text {res }}=c-\sigma_{n}^{\prime} \tan \phi
$$

onde $c$ e $\phi$ são a coesão e ângulo de atrito do material, respetivamente. A relação linear entre o esforço normal e cisalhante pode ser observada na Figura 3-4. 


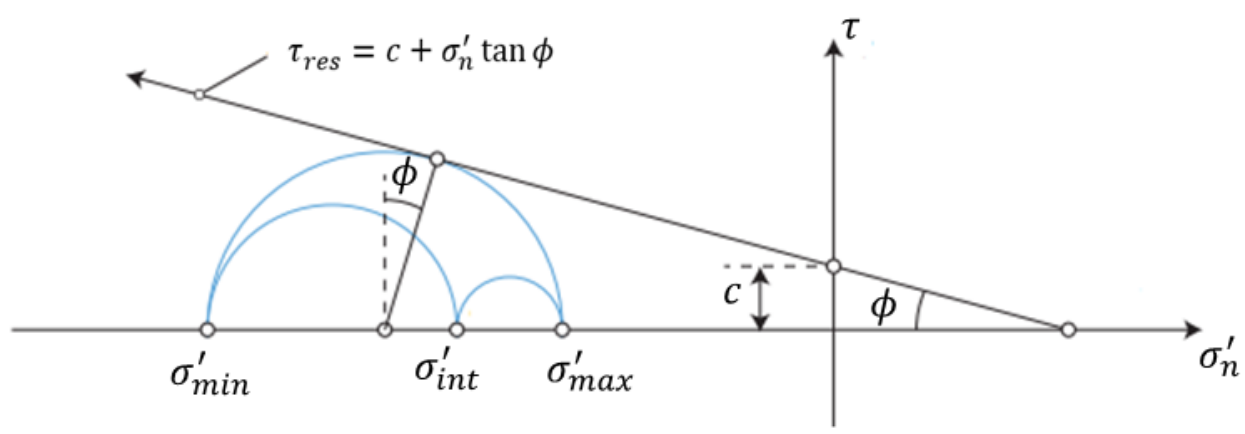

Figura 3-4 Envoltória de Mohr-Coulomb no espaço $\sigma_{\mathrm{n}}^{\prime}-\tau$ (adaptado de Sørensen 2012)

A função de plastificacão que define o limite entre o comportamento elástico e o comportamento elasto-plástico está dada pela equação (3.13),

$$
F_{1}=\tau-c+\sigma_{n}^{\prime} \tan \phi
$$

onde $\tau$ é componente cisalhante atuante no elemento, Figura 3-5, e o restante da expressão é a resistência ao cisalhamento no plano de falha.

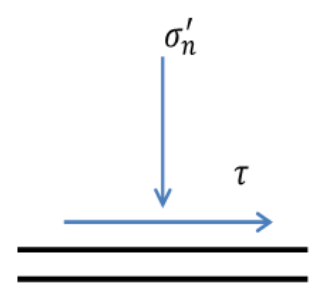

2D

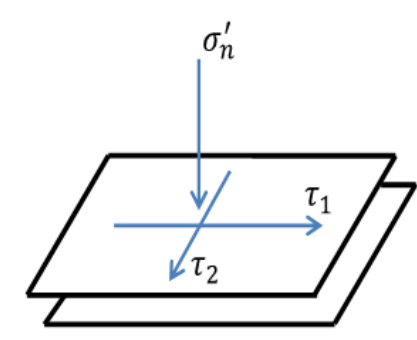

$3 \mathrm{D}$

Figura 3-5 Representação das componentes de tensão

Para as análises 3D define-se o $\tau$ atuante como a resultante das componentes $\tau_{1}$ e $\tau_{2}$ como se apresenta na equação (3.14). Para facilitar a formulação no espaço 3D introduz-se a variável $\beta$, segundo o apresentado na Figura 3-6

$$
\tau=\sqrt{\tau_{1}^{2}+\tau_{2}^{2}}
$$




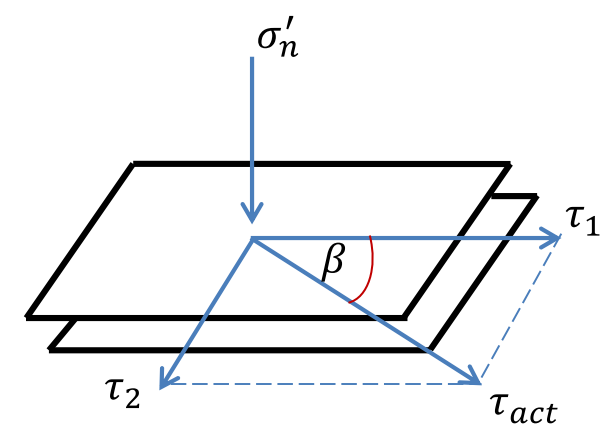

Figura 3-6 Definição ângulo $\beta$

onde,

$$
\begin{aligned}
& \sin \beta=\frac{\tau_{2}}{\tau} \\
& \cos \beta=\frac{\tau_{1}}{\tau}
\end{aligned}
$$

Logo, um estado de tensão no plano de falha pode atingir a envoltória de plastificação por cisalhamento, indicando a reativação da falha, ou por tração, indicando a abertura da falha. No caso da plastificação por cisalhamento, foi estabelecido um parâmetro que define a tendência de reativação da falha denominado índice de reativação (IR), definido pela (3.17), onde, $\tau_{r e s}$ é a tensão cisalhante resistente. Valores menores que 1 indicam que a falha é estável; já um valor igual a 1 , indica que uma falha foi reativada,

$$
I R=\frac{\tau}{\tau_{r e s}}
$$

Segundo Michal (2009) e Rueda (2013), é aconselhável evitar as tensões de tração ou limitar sua magnitude por um valor especifico, $T$, através de uma superfície adicional de corte, expressa pela equação (3.18), que representa a função de corte ("Cut-off").

$$
F_{2}=\sigma_{n}^{\prime}-T
$$

onde $T$ é a resistência à tração da falha, e $\sigma_{n}^{\prime}$ a tensão normal, como se apresenta na Figura 3-7 


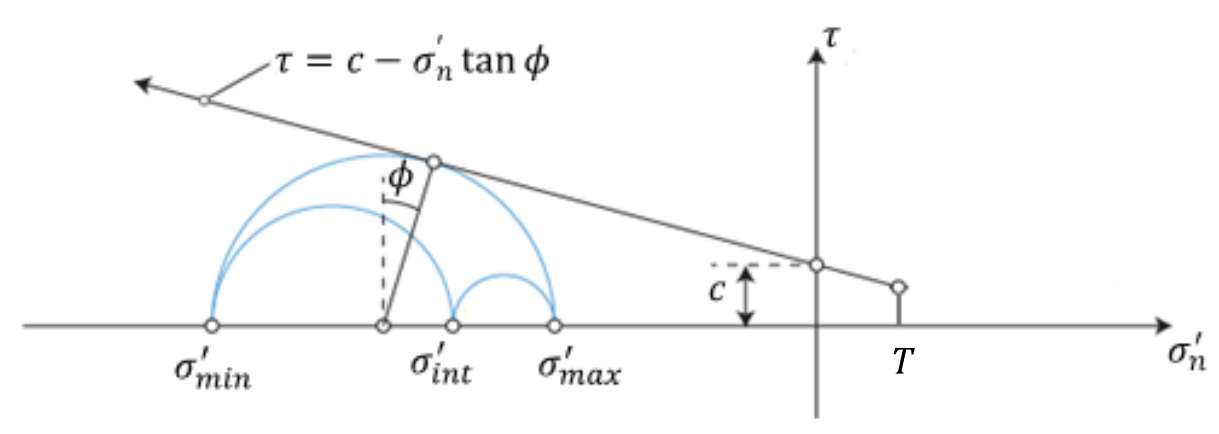

Figura 3-7 Envoltória de Mohr-Coulomb com cut-off no espaço $\sigma_{n}^{\prime}-\tau$

Para simular a migração de fluido através do plano da falha considerou-se que quando uma região de falha é reativada ou aberta, ocorre uma migração instantânea que transmite toda a pressão da zona adjacente, inicialmente pressurizada, para a nova zona reativada. Essa migração foi avaliada através de um parâmetro que mede uma condição de instabilidade $(C I)$, que pode adotar quatro valores inteiros entre 0 e 3. Para isto, assumiu-se que as falhas que se encontram fora do reservatório são inicialmente seladas, mas podem perder o selo em algum momento da análise quando a $C I$ tem um valor diferente de 0 . A Tabela 1 apresenta o significado de cada valor de $C I$.

Tabela 3.1. Condição de instabilidade

\section{Significado do valor da condição de instabilidade}

0 A falha não reativou nem abriu em nenhum momento da análise, conserva o selo.

1 A falha reativou em algum momento da análise, perdeu o selo.

2 A falha abriu em algum momento da análise, perdeu o selo.

A falha reativou e abriu em algum momento da análise, perdeu o selo. 


\subsubsection{Integração numérica das tensões}

Como foi descrito anteriormente o modelo implementado considera o retorno de tensões perpendicular à envoltória (fluxo associado), como proposto no trabalho de Rueda (2013) para modelos 2D com integração implícita (Backward Euler). Neste trabalho a formulação apresentada em Rueda é estendida para o caso 3D.

Para o modelo constitutivo implementado tem-se duas funções de escoamento $F_{1}$ e $F_{2}$ que definem o comportamento do material. A primeira é a superfície de Mohr-Coulomb e a segunda define a superfície de cut-off como foi mencionado nos parágrafos anteriores.

Para a obtenção do estado de tensões correspondente a um estado de deformação conhecido, adota-se uma estratégia do tipo preditor-corretor. A tensão preditora elástica conhecida como $\sigma^{\text {trial }}$ é calculada como segue:

$$
\left\{\sigma_{n+1}^{\text {trial }}\right\}=\{\sigma\}+\left\{\Delta \sigma^{\text {trial }}\right\}
$$

Segundo a trajetória de esforços a tensão preditora pode cair em três diferentes regiões como se pode ver na Figura 3-8 para o retorno perpendicular à superfície. Dependendo em qual região se localize a tensão preditora é selecionado o critério de retorno para a função de escoamento como se apresentara posteriormente.

A equação (3.19) define as tensões preditoras,

$$
\begin{gathered}
\left\{\begin{array}{c}
\tau_{1}^{\text {trial }} \\
\tau_{2}^{\text {trial }} \\
\sigma_{N}^{\text {trial }}
\end{array}\right\}=\left[\begin{array}{ccc}
k_{S} & 0 & 0 \\
0 & k_{S} & 0 \\
0 & 0 & k_{N}
\end{array}\right]\left\{\begin{array}{c}
\varepsilon_{S 1}^{e}+\Delta \varepsilon_{S 1} \\
\varepsilon_{S 2}^{e}+\Delta \varepsilon_{S 2} \\
\varepsilon_{N}^{e}+\Delta \varepsilon_{N}
\end{array}\right\} \\
=\left\{\begin{array}{c}
\tau_{1}{ }_{n} \\
\tau_{2}{ }_{n} \\
\sigma_{N}{ }_{n}
\end{array}\right\}+\left[\begin{array}{ccc}
k_{S} & 0 & 0 \\
0 & k_{S} & 0 \\
0 & 0 & k_{N}
\end{array}\right]\left\{\begin{array}{c}
\Delta \varepsilon_{S 1} \\
\Delta \varepsilon_{S 2} \\
\Delta \varepsilon_{N}
\end{array}\right\}
\end{gathered}
$$

onde o sub índice $n$ denota o passo atual da analise e os incrementos de das componentes de deformação $\Delta \varepsilon_{s}$ para as componentes cisalhantes e $\Delta \varepsilon_{N}$ para a componente normal..

Considerando uma lei de fluxo associada na Figura 3-8, quando o estado de tensão entra em plastificação $(\mathbf{Q})$, este pode estar localizado em uma das três regiões, (Região 1, 2 ou 3). Para seu retorno à superfície de escoamento, é necessário avaliar esta região a fim de selecionar o algoritmo de retorno adequado. 


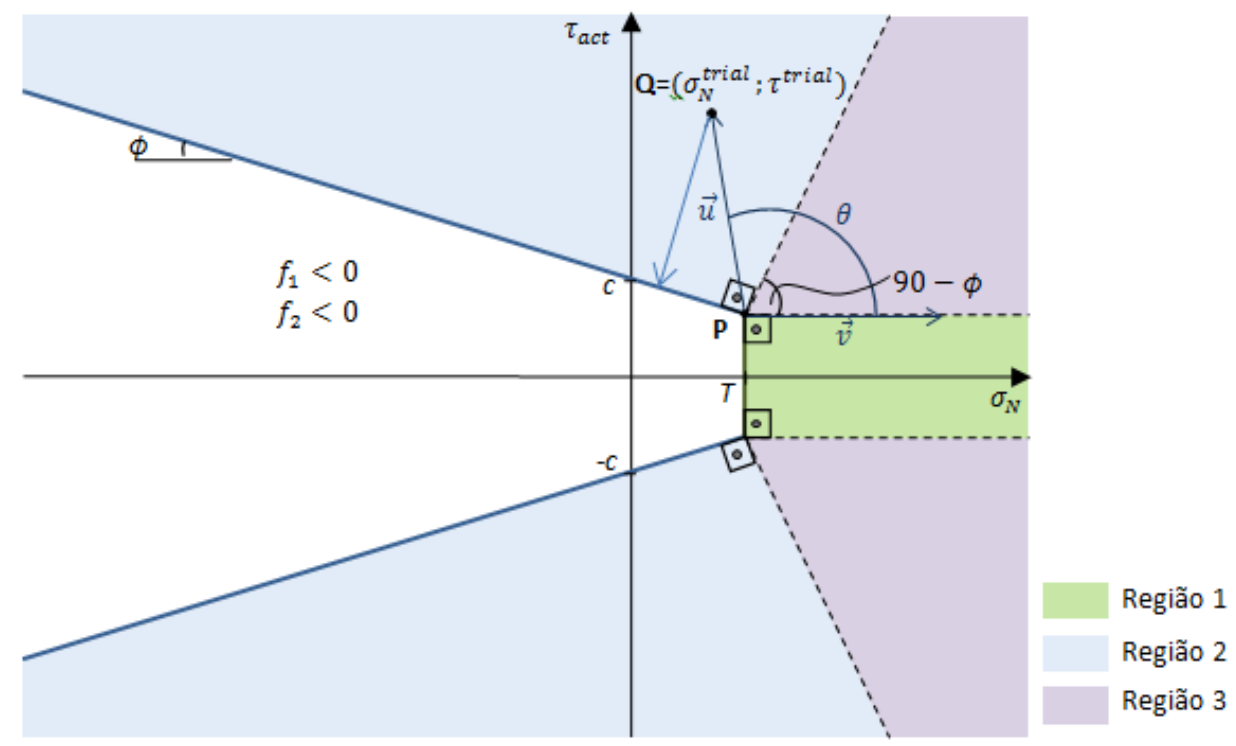

Figura 3-8 Regiões para o retorno perpendicular fonte: Manual de reativação de falhas Instituto Tecgraf 2014.

De acordo com o gráfico, o ponto $\mathrm{P}$, que define uma região em comum destas três regiões, pode ser estabelecido com base na seguinte relação:

$$
\mathbf{P}=(T ; \operatorname{sig}(\tau) \cdot(c-T \cdot \tan \phi)),
$$

em que $\operatorname{sig}(\tau)$ representa o sinal da tensão cisalhante atuante.

A tensão preditora $\mathbf{Q}$ pode ser utilizada para determinar uma função preditora para a envoltória de Mohr, $F_{1}^{\text {trial }}$, ou para a envoltória de cut-off, $F_{2}^{\text {trial }}$. Desta forma, se $F_{1}^{\text {trial }}<0$ e $F_{2}^{\text {trial }}<0$ o estado de tensão localiza-se na região elástica e caso contrário, os seguintes passos devem ser adotados.

\section{Região 1}

A tensão preditora se encontra na Região 1 só se cumprem as equações (3.22) e (3.23), ou seja, a plastificacão ocorre devido à tensão normal. Assim sendo o comportamento é elástico linear para as componentes cisalhantes.

$$
\begin{gathered}
\sigma_{N n+1}^{\text {trial }} \geq \mathbf{P}(1)=T \\
\left|\tau_{n+1}^{\text {trial }}\right| \leq|\mathbf{P}(2)|=c-T \cdot \tan \phi
\end{gathered}
$$

\section{Região 2}

A tensão preditora se encontra na Região 2 só se cumpre que $\mathbf{Q} \notin$ Região1 e

$$
\theta \geq 90^{\circ}-\phi
$$


com o ângulo $\theta$ medido entre um eixo horizontal e a trajetória que une a tensão preditora $\mathbf{Q}=\left(\sigma_{N n+1}^{\text {trial }} ; \tau_{n+1}^{\text {trial }}\right)$ com o ponto $\mathbf{P}$.

Por identidades trigonométricas a desigualdade apresentada na equação (3.24) pode se expressar como segue:

$$
\cos \theta \leq \sin \phi
$$

onde $\cos \theta$ está definido geometricamente da Figura 3-8 pela equação

$$
\frac{\sigma_{n+1}^{\text {trial }}-T}{\sqrt{\left(\sigma_{n+1}^{\text {trial }}-T\right)^{2}+\left(\tau_{n+1}^{\text {trial }}-\operatorname{sig}\left(\tau_{n+1}^{\text {trial }}\right) \cdot(c-T \cdot \tan \phi)\right)^{2}}}
$$

Pode-se afirmar que se $\mathbf{Q} \notin$ Região1 e a desigualdade (3.25) é verdadeira, a tensão cisalhante atingiu o valor da tensão de plastificação na componente cisalhante.

\section{Região 3}

A tensão preditora se encontra na Região 3 só se cumpre que $\mathbf{Q} \notin$ Região 1 e $\mathbf{Q} \notin$ Região 2, o que significa que a falha entrou em regime plástico nas componentes cisalhante e normal, ou seja, $F_{1}$ e $F_{2}$ são maiores ou iguais a zero.

\section{Derivadas das funções de plastificacão}

Assim, com $\frac{\partial F}{\partial \sigma}=\frac{\partial P}{\partial \sigma}$, temos as seguintes expressões,

$$
\begin{gathered}
\frac{\partial F_{1}}{\partial \tau_{1}}=\frac{\partial}{\partial \tau_{1}}\left(\sqrt{\tau_{1}^{2}+\tau_{2}^{2}}+\sigma_{n}^{\prime} \tan \phi-c\right)=\cos \beta \\
\frac{\partial F_{1}}{\partial \tau_{2}}=\frac{\partial}{\partial \tau_{2}}\left(\sqrt{\tau_{1}^{2}+\tau_{2}^{2}}+{\sigma^{\prime}}_{n} \tan \phi-c\right)=\sin \beta \\
\frac{\partial F_{1}}{\partial{\sigma_{n}^{\prime}}_{n}}=\frac{\partial}{\partial \sigma_{n}^{\prime}}\left(\sqrt{\tau_{1}^{2}+\tau_{2}^{2}}+{\sigma_{n}^{\prime}}_{n} \tan \phi-c\right)=\tan \phi \\
\frac{\partial F_{2}}{\partial \tau_{1}}=\frac{\partial}{\partial \tau_{1}}\left(\sigma_{n}^{\prime}-T\right)=0 \\
\frac{\partial F_{2}}{\partial \tau_{2}}=\frac{\partial}{\partial \tau_{2}}\left(\sigma_{n}^{\prime}-T\right)=0
\end{gathered}
$$




$$
\frac{\partial F_{2}}{\partial{\sigma_{n}^{\prime}}_{n}}=\frac{\partial}{\partial \sigma_{n}^{\prime}}\left({\sigma_{n}^{\prime}}_{n}-T\right)=1
$$

Obtendo assim os seguintes vetores:

$$
\begin{gathered}
\text { Cisalhamento: } \frac{\partial F_{1}}{\partial \sigma}=\frac{\partial P_{1}}{\partial \sigma}=\left\{\begin{array}{c}
\cos \beta \\
\sin \beta \\
\tan \phi
\end{array}\right\} \\
\text { Cut-off: } \frac{\partial F_{2}}{\partial \sigma}=\frac{\partial P_{2}}{\partial \sigma}=\left\{\begin{array}{l}
0 \\
0 \\
1
\end{array}\right\}
\end{gathered}
$$

Para determinação do parâmetro $\Lambda$ associado à superfície de plastificação de Mohr Coulomb e cut-off, parte-se do seguinte pressuposto:

$$
\left\{\Delta \varepsilon^{p}\right\}=\Lambda\left\{\frac{\partial P}{\partial \sigma}\right\}
$$

Uma vez que quando o material está sujeito a deformações plásticas tem-se $F=0$ nesse caso pode-se escrever que:

$$
\begin{gathered}
\{\Delta \sigma\}=\left[D^{e}\right]\{\Delta \varepsilon\}-\left[D^{e}\right]\left\{\Delta \varepsilon^{p}\right\} \\
\{\Delta \sigma\}=\left[D^{e}\right]\{\Delta \varepsilon\}-\left[D^{e}\right] \Lambda\left\{\frac{\partial P}{\partial \sigma}\right\}
\end{gathered}
$$

Obtendo-se para cada uma das funções de plastificacão o multiplicador plástico:

$$
\begin{gathered}
\text { Cisalhamento: } \Lambda_{1}=\frac{F_{1}\left(\sigma^{\text {trial }}\right)}{k_{S}+k_{N} \cdot \tan ^{2} \phi} \\
\text { Cut-off: } \Lambda_{2}=\frac{F_{2}\left(\sigma^{\text {trial }}\right)}{k_{N}}
\end{gathered}
$$

Assim, se a tensão preditora se encontra na Região 1, a tensão corrigida após o retorno à superfície é dada por:

$$
\left\{\sigma_{n+1}\right\}=\left\{\sigma^{\text {trial }}\right\}-\left[D^{e}\right] \Lambda_{2}\left\{\begin{array}{l}
0 \\
0 \\
1
\end{array}\right\}=\left\{\begin{array}{c}
\tau_{1}^{\text {trial }} \\
\tau_{2}^{\text {trial }} \\
T
\end{array}\right\}
$$

Da equação (3.9) e considerando que o comportamento da falha é perfeitamente plástico, a matriz elastoplástica para a Região 1 é definida pela seguinte expressão: 


$$
\begin{aligned}
& {\left[D^{e p}\right]=\left[D^{e}\right]-\frac{[D]\left\{\frac{\partial P_{2}}{\partial \sigma}\right\}\left\{\frac{\partial F_{2}}{\partial \sigma}\right\}^{T}\left[D^{e}\right]}{\left\{\frac{\partial F_{2}}{\partial \sigma}\right\}^{T}\left[D^{e}\right]\left\{\frac{\partial P_{2}}{\partial \sigma}\right\}}} \\
& {\left[D^{e p}\right]=\left[\begin{array}{ccc}
k_{S} & 0 & 0 \\
0 & k_{S} & 0 \\
0 & 0 & 0
\end{array}\right]}
\end{aligned}
$$

Assim, se a tensão preditora se encontra na Região 2, a tensão corrigida pelo retorno à superfície de plastificação é dada por

$$
\left\{\sigma_{n+1}\right\}=\left\{\sigma^{\text {trial }}\right\}-\left[D^{e}\right] \Lambda_{1}\left\{\begin{array}{c}
\cos \beta \\
\sin \beta \\
\tan \phi
\end{array}\right\}=\left\{\begin{array}{c}
\tau_{1}^{\text {trial }}\left(1-\frac{\Lambda_{1} \cdot k_{s}}{\tau^{\text {trial }}}\right) \\
\tau_{2}^{\text {trial }}\left(1-\frac{\Lambda_{1} \cdot k_{s}}{\tau^{\text {trial }}}\right) \\
\sigma^{\prime}{ }_{N}{ }^{\text {trial }}-\Lambda_{1} \cdot k_{N} \cdot \tan \phi
\end{array}\right\}
$$

Fazendo uso também da equação (3.9) temos que para a Região 2 a matriz elastoplástica é definida por:

$$
\begin{gathered}
{\left[D^{e p}\right]=\frac{k_{S}}{k_{S}+k_{N} \cdot \tan ^{2} \phi} \times} \\
\times\left[\begin{array}{ccc}
k_{S} \cdot \sin ^{2} \beta+k_{N} \cdot \tan ^{2} \phi & -k_{S} \cdot \sin \theta \cdot \cos \beta & -k_{N} \cdot \cos \beta \cdot \tan \phi \\
-k_{S} \cdot \sin \beta \cdot \cos \beta & k_{S} \cdot \cos ^{2} \beta+k_{n} \cdot \tan ^{2} \phi & -k_{N} \cdot \sin \beta \cdot \tan \phi \\
-k_{S} \cdot \cos \beta \cdot \tan \phi & -k_{N} \cdot \sin \theta \cdot \tan \phi & k_{N}
\end{array}\right]
\end{gathered}
$$

Se a tensão preditora se encontra na Região 3, o que significa que ultrapassou as duas superfícies de plastificação, o incremento de deformação plástica é definido segundo Potts e Zdrakovic (1999) pela equação (3.46)

$$
\left\{\Delta \varepsilon^{p}\right\}=\Lambda_{3}\left\{\frac{\partial P_{1}}{\partial \sigma}\right\}+\Lambda_{4}\left\{\frac{\partial P_{2}}{\partial \sigma}\right\}
$$


Substituindo (3.46) em (3.36) obtemos

$$
\{\Delta \sigma\}=\left[D^{e}\right]-\left[D^{e}\right]\left\{\Delta \varepsilon^{p}\right\}=\left[D^{e}\right]\{\Delta \varepsilon\}-\left[D^{e}\right]\left(\Lambda_{3}\left\{\frac{\partial P_{1}}{\partial \sigma}\right\}+\Lambda_{4}\left\{\frac{\partial P_{2}}{\partial \sigma}\right\}\right)
$$

Substituindo obtemos os seguintes multiplicadores plásticos:

$$
\begin{aligned}
& \Lambda_{3}=\frac{F_{1 n+1}^{\text {trial }}-F_{2 n+1}^{\text {trial }} \tan \phi}{k_{S}} \\
& \Lambda_{4}=-\Lambda_{3} \tan \phi+\frac{F_{2 n+1}^{\text {trial }}}{k_{N}}
\end{aligned}
$$

onde a tensão após o retorno é dada pela seguinte expressão:

$$
\left\{\sigma_{n+1}\right\}=\left\{\sigma^{\text {trial }}\right\}-\left[D^{e}\right] .\left\{\Delta \varepsilon^{p}\right\}=\left\{\begin{array}{c}
c-T \cdot \tan \phi \frac{\tau_{1}^{\text {trial }}}{\tau^{\text {trial }}} \\
c-T \cdot \tan \phi \frac{\tau_{2}^{\text {trial }}}{\tau^{\text {trial }}} \\
T
\end{array}\right\}
$$

Para esta região as duas superfícies de plastificação foram ultrapassadas e o cálculo da matriz elastoplastica segundo o Potts \& Zdravkovic (1999) é dado por:

$$
\left[D^{e p}\right]=\left[D^{e}\right]-\frac{\left[D^{e}\right]}{A}\left(\left\{\frac{\partial P_{1}}{\partial \sigma}\right\}\left\{b_{1}\right\}^{T}+\left\{\frac{\partial P_{2}}{\partial \sigma}\right\}\left\{b_{2}\right\}^{T}\right)\left[D^{e}\right]
$$

com

$$
\begin{gathered}
\left\{b_{1}\right\}=L_{22}\left\{\frac{\partial F_{1}}{\partial \sigma}\right\}-L_{12}\left\{\frac{\partial F_{2}}{\partial \sigma}\right\} \\
\left\{b_{2}\right\}=L_{11}\left\{\frac{\partial F_{2}}{\partial \sigma}\right\}-L_{21}\left\{\frac{\partial F_{1}}{\partial \sigma}\right\} \\
L_{11}=\left\{\frac{\partial F_{1}}{\partial \sigma}\right\}^{T}\left[D^{e}\right]\left\{\frac{\partial P_{1}}{\partial \sigma}\right\}
\end{gathered}
$$




$$
\begin{aligned}
& L_{12}=\left\{\frac{\partial F_{1}}{\partial \sigma}\right\}^{T}\left[D^{e}\right]\left\{\frac{\partial P_{2}}{\partial \sigma}\right\} \\
& L_{22}=\left\{\frac{\partial F_{2}}{\partial \sigma}\right\}^{T}\left[D^{e}\right]\left\{\frac{\partial P_{2}}{\partial \sigma}\right\} \\
& L_{21}=\left\{\frac{\partial F_{2}}{\partial \sigma}\right\}^{T}\left[D^{e}\right]\left\{\frac{\partial P_{1}}{\partial \sigma}\right\} \\
& A=L_{11} \cdot L_{22}-L_{12} \cdot L_{21}
\end{aligned}
$$

Uma vez feitas todas as operações chega-se que a expressão (3.51) é igual a

$$
\left[D^{e p}\right]=\left[\begin{array}{ccc}
k_{S} \cdot \sin ^{2} \beta & -k_{S} \cdot \sin \beta \cdot \cos \beta & 0 \\
-k_{S} \cdot \sin \beta \cdot \cos \beta & k_{S} \cdot \cos ^{2} \beta & 0 \\
0 & 0 & 0
\end{array}\right]
$$

\section{2. \\ Formulação pelo método dos elementos finitos}

\subsubsection{Equação de equilíbrio}

Considerando que uma quantidade elementar de um meio poroso se deforma estaticamente devido a uma variação de poropressão conhecida, o equilíbrio pode ser representado pela seguinte equação:

$$
\nabla_{u}^{\mathrm{T}}\left(\boldsymbol{\sigma}^{\prime}+\alpha p \boldsymbol{m}\right)=0
$$

em que $p$ representa a poropressão, $\alpha$ é o coeficiente de Biot, $\nabla_{u}$ é um operador diferencial em relação aos deslocamentos e $\mathbf{m}$ é um vetor que introduz a influência da poropressão na direção normal do tensor de tensões. Fazendo uso de procedimentos padrão do método dos elementos finitos, a seguinte equação global pode ser estabelecida:

$$
\mathbf{K} \cdot \Delta \mathbf{u}=\Delta \mathbf{F}_{\text {ext }}
$$

Sendo 


$$
\begin{gathered}
\mathbf{K}=\Sigma \int_{\Omega_{\mathrm{e}}} \mathbf{B}^{\mathrm{T}} \mathbf{D B} d \Omega_{e} \\
\Delta \mathbf{F}_{\mathrm{ext}}=-\mathbf{L} \Delta \mathbf{p}=-\Sigma \int_{\Omega_{\mathrm{e}}} \mathbf{B}^{\mathrm{T}} \alpha \mathbf{m} \mathbf{N}_{\boldsymbol{p}} \mathrm{d} \Omega_{\mathrm{e}} \cdot \Delta \boldsymbol{p}
\end{gathered}
$$

Em que $\Delta \mathbf{u}$ representa os incrementos dos deslocamentos nodais e $\mathbf{K}$ é a matriz de rigidez global. A matriz $\mathbf{N}_{\boldsymbol{p}}$ é aquela que contém as funções de interpolação do elemento finito para descrição da variação da poropressão dentro do elemento e, a matriz $\mathbf{B}$ é aquela que relaciona os deslocamentos nodais $\mathbf{u}$ com as deformações. O domínio do elemento de interface, $\Omega_{e}$, é definido pelo comprimento do elemento em análises $2 \mathrm{D}$ e pela área superficial do elemento em análises 3D. O vetor de forças externas, $\Delta \mathbf{F}_{\text {ext }}$, é gerado pela mudança nas poropressões conhecidas. Este vetor é definido pelo produto da matriz de acoplamento mecânico-hidráulica $\mathbf{L}$ e o incremento de poropressões nodais $\Delta \mathbf{p}$. Observe que neste trabalho, estes incrementos de poropressão são considerados conhecidos a priori. Por este motivo, não se faz necessário avaliar a equação de continuidade.

\subsubsection{Discretização espacial}

Para a representação do comportamento geomecânico das falhas geológicas comumente empregam-se elementos especiais chamados elementos de interface. Rueda (2013) descreve os diferentes tipos de elementos de interface utilizados para as análises 2D, tais como os elementos de Goodman (1967), Ghaboussi et. al, (1973), Panda \& Sharma(1979), Day \& Potts (1994). Rueda (2013) implementou os elementos de interface 2D através da sub-rotina UEL para o software comercial ABAQUS. Neste trabalho, tanto esses elementos 2D quanto os elementos de interface 3D foram implementados dentro de um software in-house desenvolvido no Instituto Tecgraf.

Os elementos de interface 2D foram denominados INT2D4 e INT2D6. Na sua formulação em termos das poropressões considerou-se uma interpolação linear para os graus de liberdade localizados nos cantos do elemento. Para os deslocamentos 
considerou-se uma interpolação linear para o elemento INT2D4 e uma interpolação quadrática para o elemento INT2D6 como se apresenta na Figura 3-9.

Elemento INT2D4

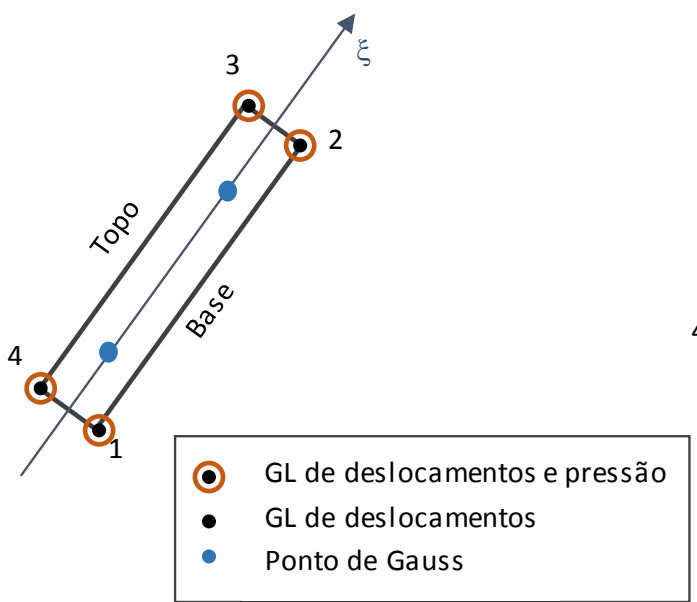

Figura 3-9 Elementos de interface 2D
Elemento INT2D6

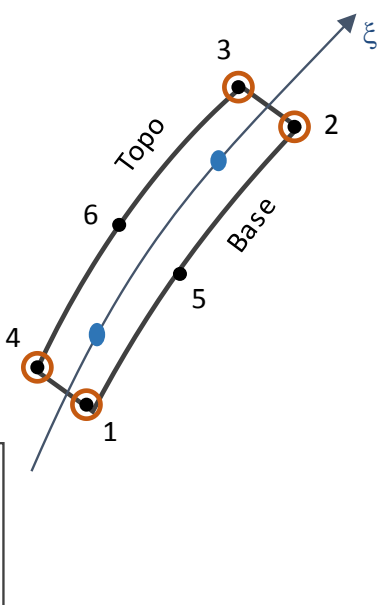

Os elementos de interface 3D foram divididos em 2 grupos em função do tipo de elemento sólido utilizado na representação da rocha adjacente ao plano de falha.

Quando o elemento continuo é de forma tetraédrica, o elemento de interface é definido pela face deste elemento na forma triangular. Nesta situação, os elementos de interface foram denominados INT3D6 e INT3D12. Na sua formulação em termos das poropressões considerou-se uma interpolação linear para os graus de liberdade localizados nos cantos do elemento. Já para os deslocamentos considerou-se uma interpolação linear para o elemento INT3D6 e uma interpolação quadrática para o elemento INT3D12 como se apresenta na Figura 3-10. 


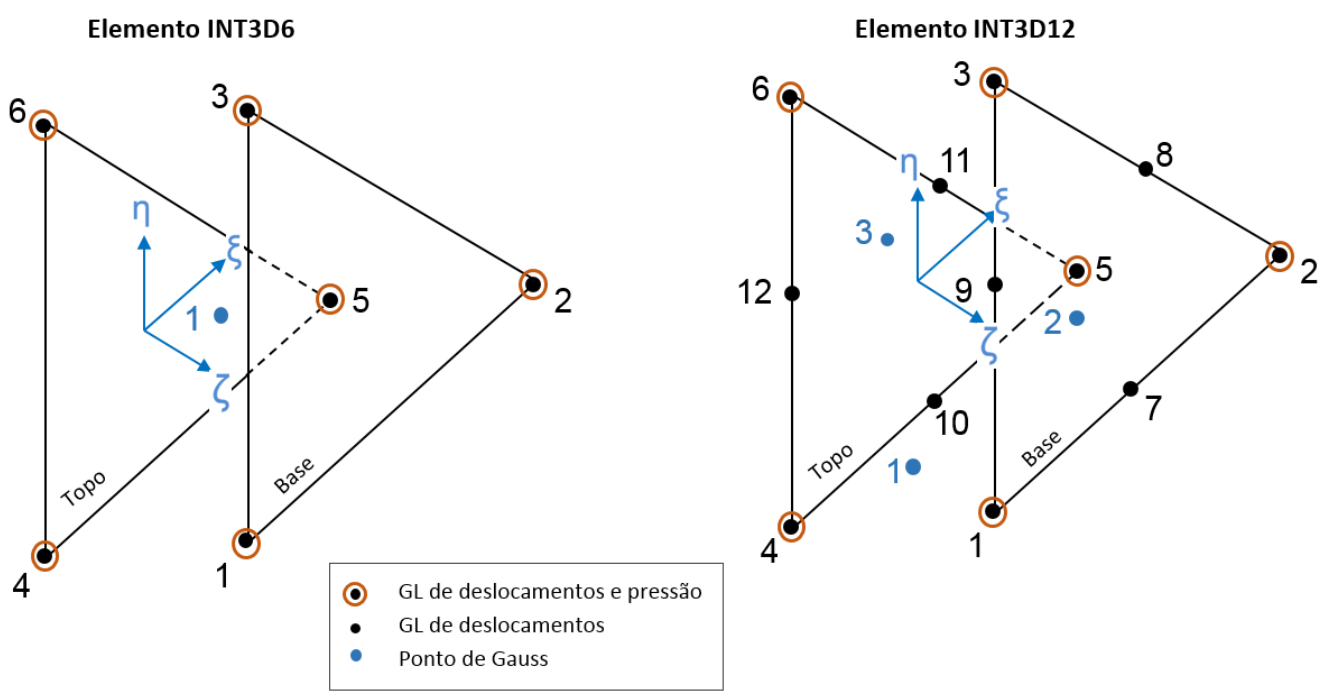

Figura 3-10 Elementos de Interface triangulares

Já quando o elemento continuo é de forma hexaédrica, o elemento de interface é definido pela face deste elemento na forma quadrilateral. Nesta situação, os elementos de interface foram denominados INT3D8 e INT3D16. Nesse caso para as poropressões considerou-se uma interpolação linear para os graus de liberdade localizados nos cantos do elemento, e para os deslocamentos considerou-se uma interpolação linear para o elemento INT3D8 e uma interpolação quadrática para o elemento INT3D16 como se apresenta na Figura 3-11.
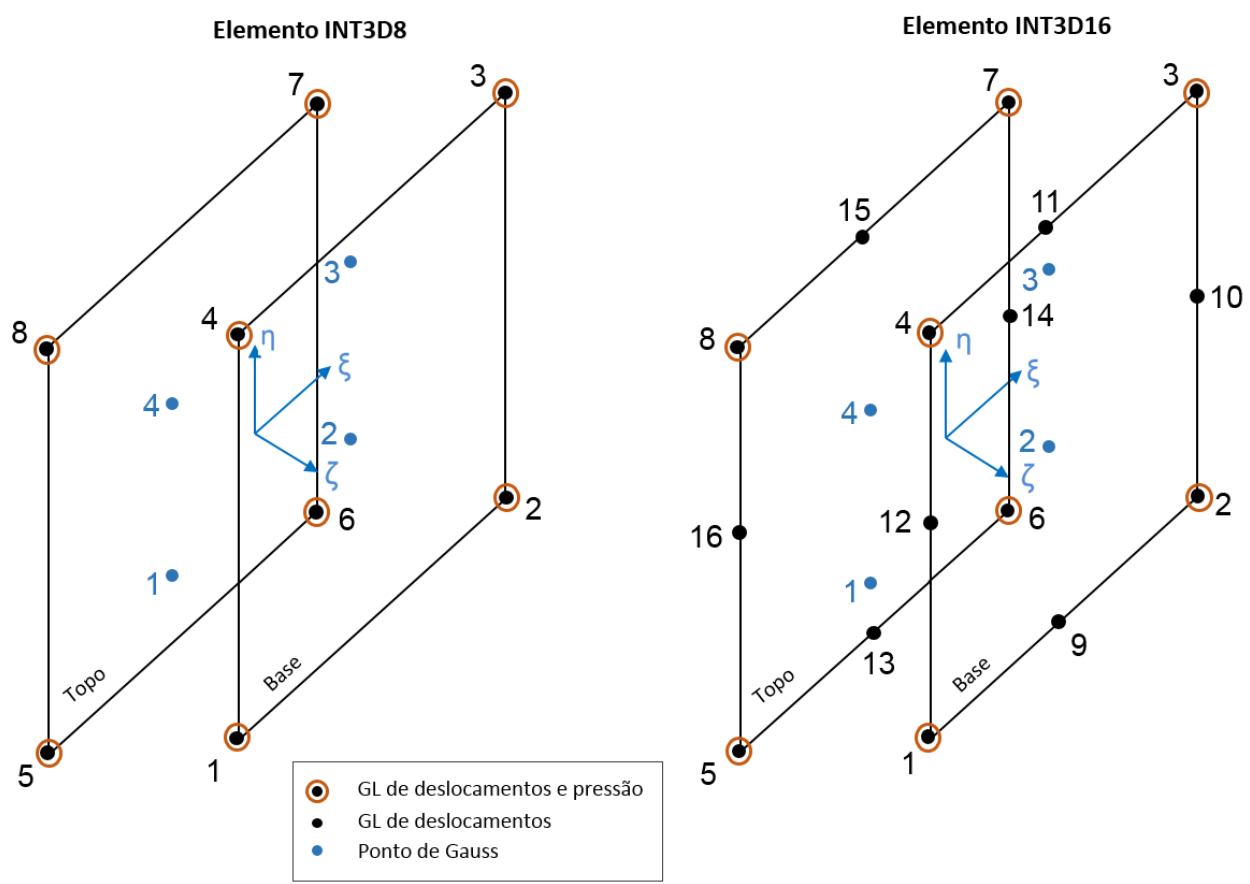

Figura 3-11 Elementos de Interface quadrilaterais. 
As funções de forma correspondentes a todos estes elementos, tanto 2D quanto 3D, estão apresentadas no Apêndice A desta dissertação.

\subsubsection{Avaliação dos deslocamentos}

Os deslocamentos são divididos em dois, um no topo e outro na base do elemento de interface. As equações (3.64) e (3.65) apresentam sua determinação a partir das funções de forma e dos deslocamentos nodais. Observe que para o caso 2D a componente em $\mathrm{z}$ some destas equações. Estes deslocamentos são determinados no sistema de coordenadas global. As equações(3.66) e (3.67) apresentam sua determinação a nível local do elemento,

Deslocamentos globais:

$$
\begin{aligned}
& \mathbf{u}_{G}^{\text {topo }}=\left\{\begin{array}{l}
u_{X}^{\text {topo }} \\
u_{Y}^{\text {topo }} \\
u_{z}^{\text {topo }}
\end{array}\right\}=\left\{\begin{array}{c}
\Sigma N_{i} u_{X i} i^{\text {topo }} \\
\Sigma N_{i} u_{y i}{ }^{\text {topo }} \\
\Sigma N_{i} u_{z i} i^{\text {topo }}
\end{array}\right\} \\
& \mathbf{u}_{G}^{\text {base }}=\left\{\begin{array}{l}
u_{X}^{\text {base }} \\
u_{Y}^{\text {base }} \\
u_{z}^{\text {base }}
\end{array}\right\}=\left\{\begin{array}{c}
\Sigma N_{i} u_{X i^{\text {base }}} \\
\Sigma N_{i} u_{y i}{ }^{\text {base }} \\
\Sigma N_{i} u_{z i}{ }^{\text {base }}
\end{array}\right\}
\end{aligned}
$$

Deslocamentos locais:

$$
\begin{gathered}
\mathbf{u}_{L}^{\text {topo }}=\left\{\begin{array}{l}
u_{x}^{\text {topo }} \\
u_{y}^{\text {topo }} \\
u_{z}^{\text {topo }}
\end{array}\right\}=\mathbf{R} \mathbf{u}_{G}^{\text {topo }} \\
\mathbf{u}_{L}^{\text {base }}=\left\{\begin{array}{l}
u_{x}^{\text {base }} \\
u_{y}^{\text {base }} \\
u_{z}^{\text {base }}
\end{array}\right\}=\mathbf{R} \mathbf{u}_{G}^{\text {base }}
\end{gathered}
$$

A matriz $\mathbf{R}$ representa a matriz de rotação do sistema de coordenadas global para o local.

\subsubsection{Avaliação das deformações}

A deformação é definida pelos deslocamentos relativos entre o topo e base do elemento como mostra a equação (3.68).

$$
\boldsymbol{\varepsilon}=\mathbf{u}_{L}^{\text {topo }}-\mathbf{u}_{L}^{\text {base }}=\mathbf{R}\left\{\mathbf{u}_{G}^{\text {topo }}-\mathbf{u}_{G}^{\text {base }}\right\}
$$


Esta equação também pode ser reescrita como

$$
\boldsymbol{\varepsilon}=\mathbf{B}\{\mathbf{u}\}
$$

em que B é a matriz que relaciona os deslocamentos nodais ( $\mathbf{u})$ com as deformações (ع) , definida na equação (3.70) e u é o vetor dos deslocamentos nodais em coordenadas globais expressos pela equação (3.71). Nestas equações, Nnoel representa o número total de nós do elemento de interface.

B

$$
\begin{aligned}
& =\mathbf{R}\left[\begin{array}{ccccccccc}
-N_{1} & 0 & 0 & -N_{2} & 0 & 0 & N_{\text {Nnoel }} & 0 & 0 \\
0 & -N_{1} & 0 & 0 & -N_{2} & 0 & \ldots & 0 & N_{\text {Nnoel }} \\
0 & 0 & -N_{1} & 0 & 0 & -N_{2} & 0 & 0 & N_{\text {Nnoel }}
\end{array}\right] \\
& \mathbf{u}^{\mathrm{T}}=\left\{\begin{array}{lllllll}
u_{X 1} & u_{Y 1} & u_{Z 1} & \ldots \ldots & u_{X N \text { noel }} & u_{Y N \text { Noel }} & u_{Z N n o e l}
\end{array}\right\} \\
& \text { onde, }
\end{aligned}
$$

$N_{i}$ São as funções de interpolação para os graus de liberdade de deslocamento para o topo e base do elemento de interface.

\subsubsection{Avaliação da matriz de rotação}

Para o caso 2D a avaliação da matriz de rotação é dada simplesmente pela definição do ângulo de inclinação da falha em relação ao plano horizontal $(\theta)$. Esta matriz é dada por:

$$
\mathbf{R}=\left[\begin{array}{cc}
\cos \theta & \sin \theta \\
-\sin \theta & \cos \theta
\end{array}\right]
$$

Já para o caso 3D, a avaliação desta matriz não é tão simples. Para um caso geral no espaço 3D, a matriz de rotação é definida não apenas por um ângulo, mas por três. Existem diferentes convenções para a definição destes ângulos. Neste trabalho, optou-se pelo uso dos ângulos de Euler, apresentados na Figura 3-12. 

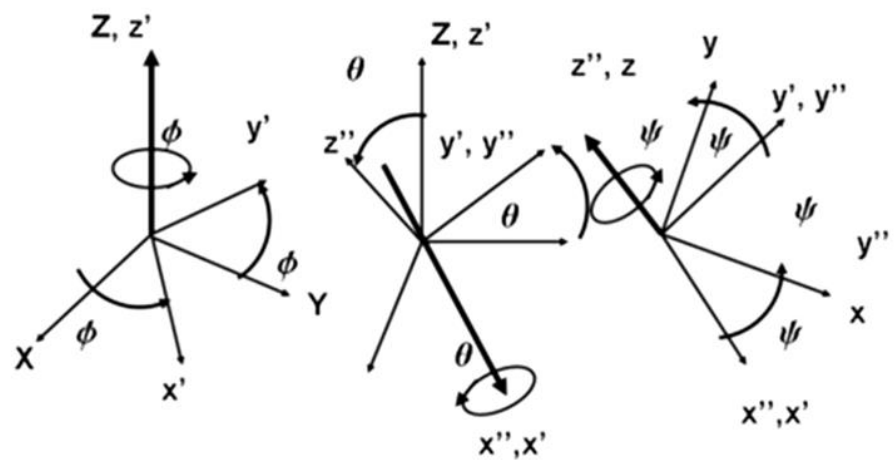

Figura 3-12 Ângulos de Euler para definir a matriz de rotação no espaço 3D. Fonte: S. Widnall 16.07 Dynamics Fall 2009

A matriz de transformação do sistema global $(\mathrm{X}, \mathrm{Y}, \mathrm{Z})$ para o sistema local (x”,y”,z”) é dada pela seguinte equação:

$$
\mathbf{R}=\mathbf{T}_{1} \mathbf{T}_{2} \mathbf{T}_{3}
$$

onde $\mathbf{T}_{1}, \mathbf{T}_{2}$ e $\mathbf{T}_{3}$ são as matrizes de transformação para cada ângulo de Euler. Estas matrizes são definidas como:

$$
\begin{aligned}
& \mathbf{T}_{1}=\left[\begin{array}{ccc}
\cos \phi & \sin \phi & 0 \\
-\sin \phi & \cos \phi & 0 \\
0 & 0 & 1
\end{array}\right] \\
& \mathbf{T}_{2}=\left[\begin{array}{cccc}
1 & 0 & 0 \\
0 & \cos \theta & \sin \theta \\
0 & -\sin \theta & \cos \theta
\end{array}\right] \\
& \mathbf{T}_{3}=\left[\begin{array}{ccc}
\cos \psi & \sin \psi & 0 \\
-\sin \psi & \cos \psi & 0 \\
0 & 0 & 1
\end{array}\right]
\end{aligned}
$$

Para o caso de falhas, é necessário apenas definir dois ângulos, sendo o terceiro nulo $(\psi=0)$. Desta forma, a matriz $\mathbf{T}_{3}$ torna-se igual à matriz identidade. Para determinar os ângulos $\phi$ e $\theta$ são utilizados ângulos comumente utilizados na geologia, chamados de direção de mergulho e mergulho. Ambos os ângulos são apresentados na Figura 3-13. O ângulo de direção de mergulho (dd) é um ângulo horizontal medido a partir da direção norte enquanto que o ângulo mergulho (d) é um ângulo vertical medido a partir de um plano horizontal. 

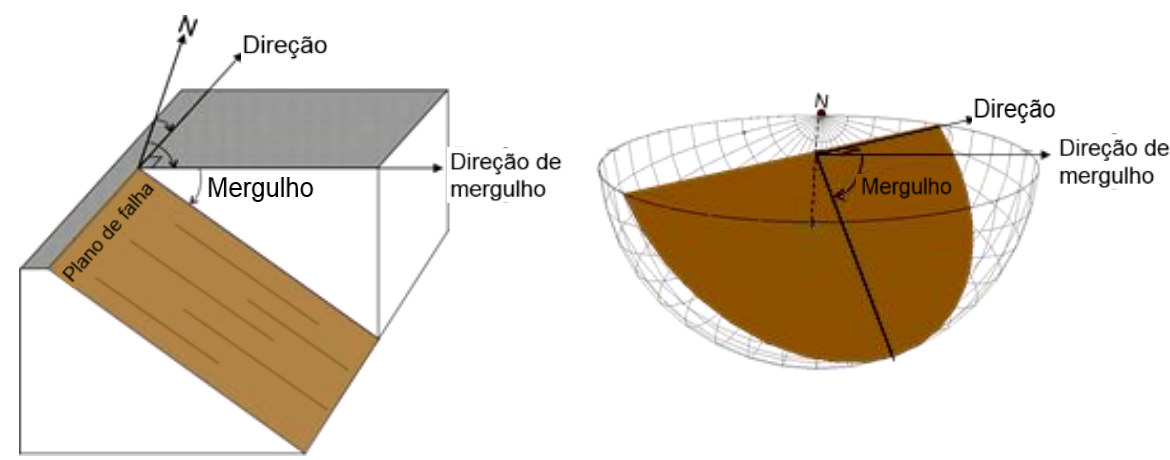

Figura 3-13 Definição geométrica de strike, dip e dip direction.

A Figura 3-14 apresenta o processo de rotação do sistema global $(\mathrm{X}, \mathrm{Y}, \mathrm{Z})$ para o sistema local da falha (x",y",z") considerando os ângulos dd e d.

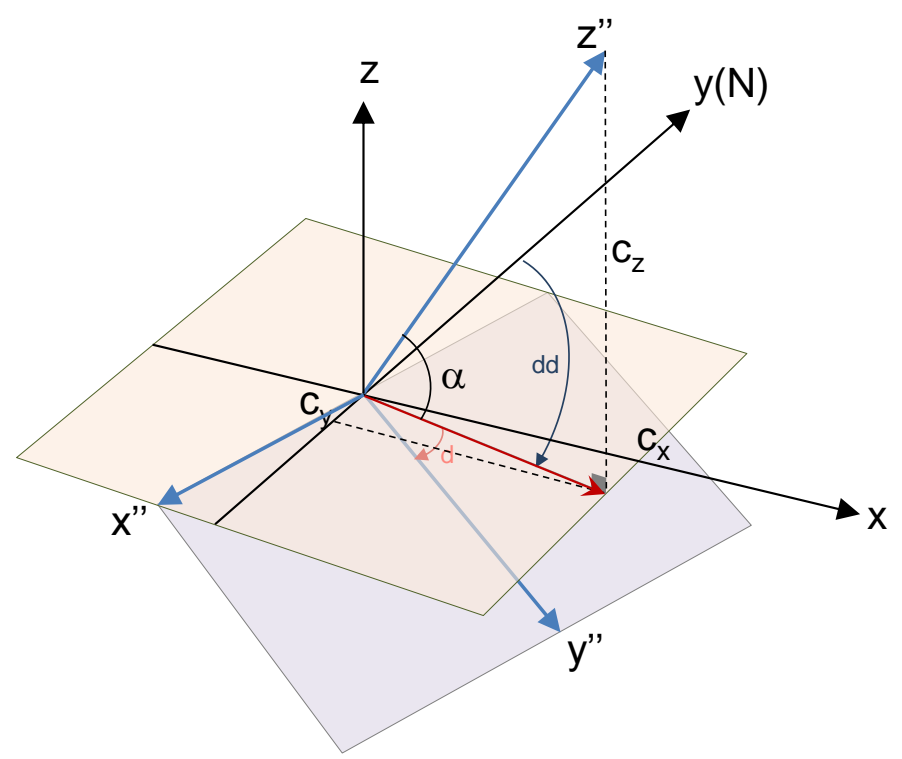

Figura 3-14 Vetores no plano de falha

Nesta figura, $C_{x}, C_{y}$ e $C_{z}$ são as componentes do vetor $Z^{\prime \prime}$, a linha vermelha é a projeção de $Z^{\prime \prime}$ no plano XY, $\alpha$ é o ângulo entre o vetor normal $Z^{\prime \prime}$ ao plano de falha e o vetor projeção no plano XY. Assim:

$$
\tan d d=\frac{C_{x}}{C_{y}}=\frac{\sin d d}{\cos d d}
$$

Se $C_{y}$ for igual a zero, então $\cos d d=0$ o que quer dizer que, $\alpha=90^{\circ}$, caso contrario:

$$
d d=\tan ^{-1} \frac{C_{x}}{C_{y}}
$$

Conhecido o valor de $d d$, o ângulo de mergulho é determinado como 


$$
\tan \alpha=\frac{\left|C_{z}\right|}{\sqrt{C_{x}^{2}+C_{y}^{2}}}=\frac{\sin \alpha}{\cos \alpha}
$$

Se $\sqrt{C_{x}^{2}+C_{y}^{2}}$ for igual a zero, então $\cos \alpha=0$, o que quer dizer que $\alpha=90^{\circ}$.

Finalmente, levando em consideração a convenção de rotações na Figura 3-14, os ângulos de Euler são dados por

$$
\begin{aligned}
& \phi=-d d \\
& \theta=-d i p
\end{aligned}
$$

\subsubsection{Avaliação da matriz de rigidez}

A matriz de rigidez $\mathbf{K}$ é aquela que relaciona os deslocamentos nodais com respeito ao vetor de forças nodais, a nível do elemento pode se apresentar como:

$2 \mathrm{D}$

$$
\mathbf{K}=\int_{-1}^{1} \mathbf{B}^{\mathrm{T}} \mathbf{D B} \quad|J| e d \xi
$$

$3 \mathrm{D}$

$$
\mathbf{K}=\int_{-1}^{1} \int_{-1}^{1} \mathbf{B}^{\mathrm{T}} \mathbf{D B} \quad|J| e d \xi d \eta
$$

onde $|J|$ é o determinante Jacobiano, dado pela equação (3.83)para o caso $2 \mathrm{D}$ e pela equação (3.86) para o caso dos elementos 3D. A integração numérica para calcular a matriz de rigidez é feita pela regra de integração de Gauss.

2D

$$
|J|=\sqrt{\left(\frac{d x}{d \xi}\right)^{2}+\left(\frac{d y}{d \xi}\right)^{2}}
$$

onde

$$
\frac{d x}{d \xi}=\sum_{i=1}^{\text {Nnoel }} \frac{d N_{i}}{d \xi} X_{i}
$$




$$
\frac{d y}{d \xi}=\sum_{i=1}^{N \text { noel }} \frac{d N_{i}}{d \xi} Y_{i}
$$

3D

$$
|J|=\sqrt{\operatorname{det} J_{1}^{2}+\operatorname{det} J_{2}^{2}+\operatorname{det} J_{2}^{2}}
$$

com

$$
\begin{aligned}
& \operatorname{det} J_{1}=\frac{d x}{d \xi} \cdot \frac{d y}{d \eta}-\frac{d x}{d \eta} \cdot \frac{d y}{d \xi} \\
& \operatorname{det} J_{2}=\frac{d x}{d \xi} \cdot \frac{d z}{d \eta}-\frac{d x}{d \eta} \cdot \frac{d z}{d \xi} \\
& \operatorname{det} J_{3}=\frac{d y}{d \xi} \cdot \frac{d z}{d \eta}-\frac{d y}{d \eta} \cdot \frac{d z}{d \xi}
\end{aligned}
$$

sendo:

$$
\begin{aligned}
& \frac{d x}{d \xi}=\sum_{i=1}^{N n o e l} \frac{d N_{i}}{d \xi} X_{i} \\
& \frac{d y}{d \xi}=\sum_{i=1}^{N \text { Noel }} \frac{d N_{i}}{d \xi} Y_{i} \\
& \frac{d z}{d \xi}=\sum_{i=1}^{N n o e l} \frac{d N_{i}}{d \xi} Z_{i} \\
& \frac{d x}{d \eta}=\sum_{i=1}^{N n o e l} \frac{d N_{i}}{d \eta} X_{i}
\end{aligned}
$$




$$
\begin{aligned}
& \frac{d y}{d \eta}=\sum_{i=1}^{\text {Nnoel }} \frac{d N_{i}}{d \eta} Y_{i} \\
& \frac{d z}{d \eta}=\sum_{i=1}^{N \text { Noel }} \frac{d N_{i}}{d \eta} Z_{i}
\end{aligned}
$$

\subsection{Validação em modelos 3D}

\subsubsection{Elemento de interface sob tração}

Para a avaliação da integração das tensões empregou-se um modelo o qual é composto de dois elementos sólidos elásticos com um elemento de interface de espessura nula de interpolação quadrática entre eles, como se apresenta na Figura 3-15, o solido da parte superior foi submetido a um deslocamento prescrito de $0,1 \mathrm{~m}$ de tal forma que a interface plastifica devido à tensão normal atuante.

$\mathrm{Na}$ Tabela 3.2 se apresentam as propriedades associadas aos elementos sólidos e ao elemento de interface. Para a análise se considerou o comportamento dos elementos sólidos no regime elástico.

Tabela 3.2. Propriedades do modelo sintético para avaliação das tensões

\begin{tabular}{cccccccc}
\hline Elemento & $\begin{array}{c}\mathrm{E} \\
\mathrm{GPa}\end{array}$ & $v$ & $\begin{array}{c}\mathrm{Ks} \\
\mathrm{kN} / \mathrm{m}\end{array}$ & $\begin{array}{c}\mathrm{Kn} \\
\mathrm{KN} / \mathrm{m}\end{array}$ & $\begin{array}{c}\mathrm{C} \\
\mathrm{MPa}\end{array}$ & $\phi$ & $\begin{array}{c}\text { Cutoff } \\
\mathrm{MPa}\end{array}$ \\
\hline Solido & $5 \times 10^{6}$ & 0.26 & - & - & - & - & - \\
Interface & - & - & $1980 \times 10^{3}$ & $5000 \times 10^{3}$ & 0,5 & 15 & 1,5 \\
\hline
\end{tabular}




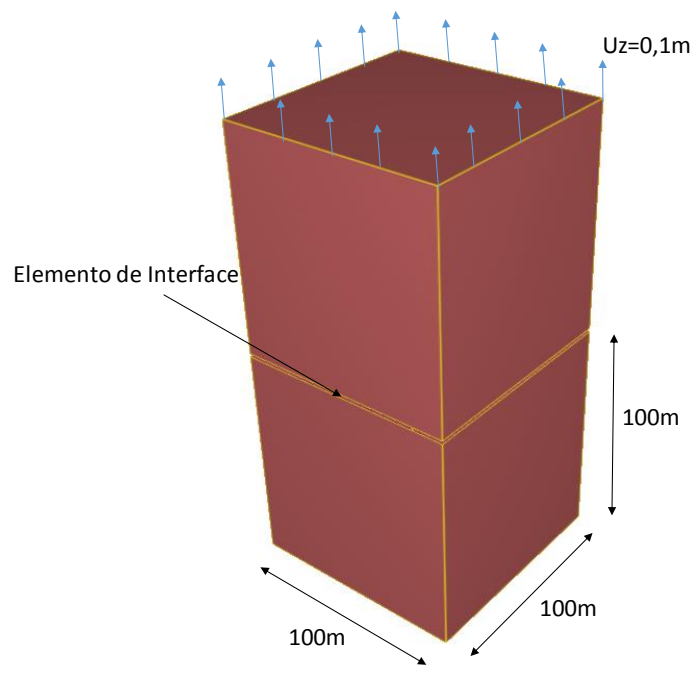

Figura 3-15 Modelo sintético submetido à tração

A Figura 3-16 se apresenta a trajetória de tensões para o elemento de interface.. Como esperado, a tensão cisalhante sobre a interface é igual a zero, já que os elementos só foram submetidos à tração. Na figura, a seta indica a direção da trajetória das tensões. Como não foram consideras condições inicias de tensões, a trajetória começa na origem de coordenadas.

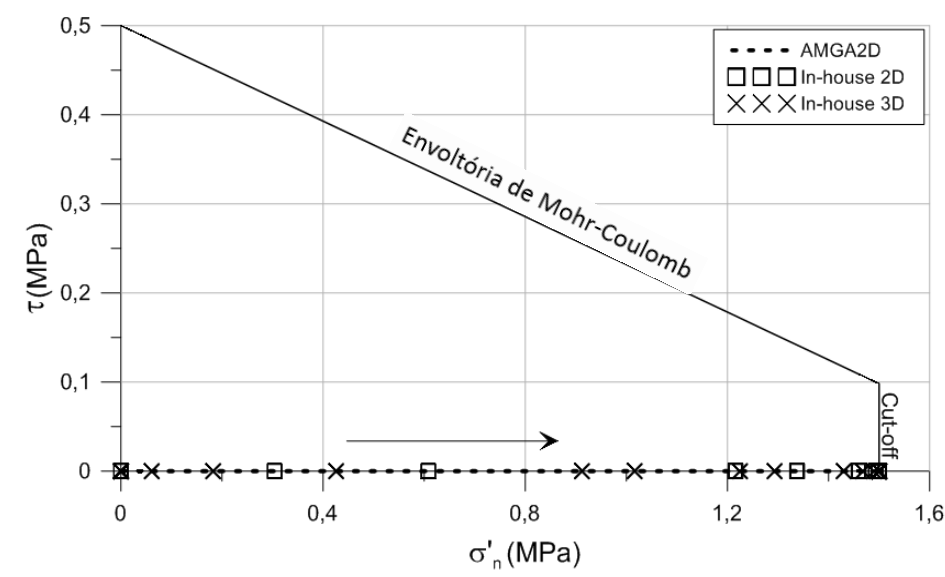

Figura 3-16 Trajetória de tensões para elemento de interface sometido a tensão normal

\subsubsection{Elemento de interface sob cisalhamento}

Para avaliação da tensão cisalhante sobre elemento de interface foram usados dois blocos sólidos com um elemento de interface entre eles como se pode ver na Figura 3-17. No modelo para o elemento solido que se encontra na parte superior foram impostos deslocamentos na direção horizontal com um valor de $0,001 \mathrm{~m}$ causando a plastificacão no elemento de interface. 


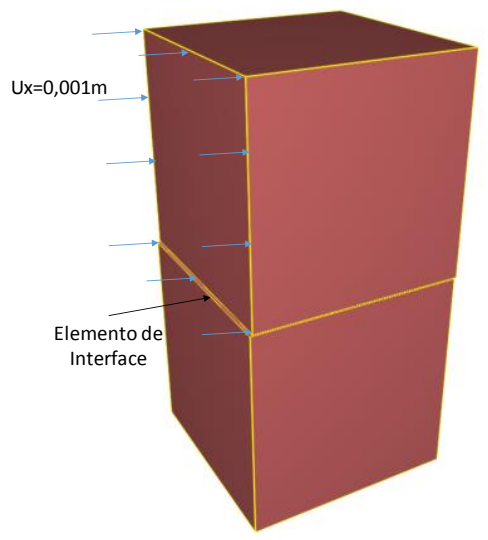

Figura 3-17 Elemento de interface sometido a tensão cisalhante

$\mathrm{Na}$ Tabela 3.2 se apresentam as propriedades associadas aos elementos sólidos e o elemento de interface. Para a análise se considerou o comportamento dos elementos sólidos no regime elástico.

Os resultados obtidos para as analises 2D e 3D foram comparadas com o código AMGA, implementado por Rueda(2013) para o ABAQUS como se apresenta na Figura 3-18.

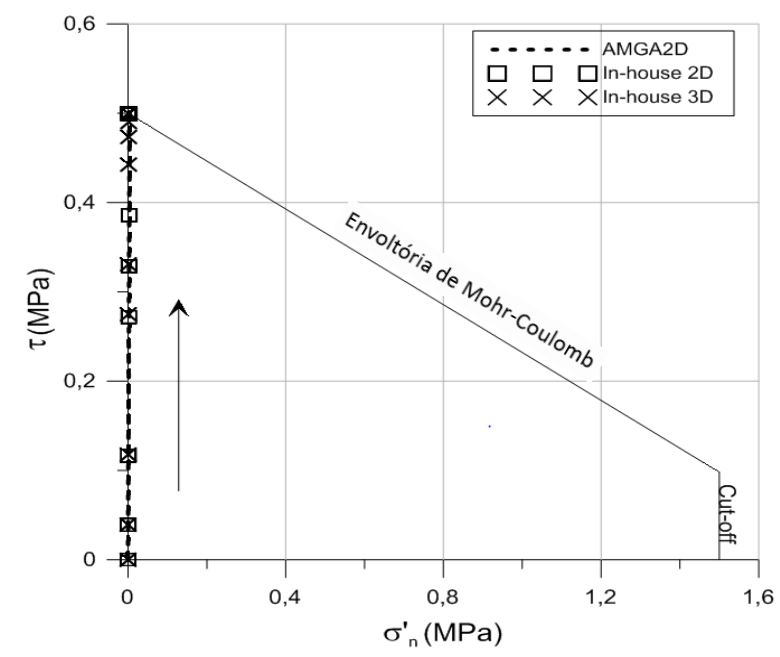

Figura 3-18 Trajetória de tensões para elemento de interface sometido a esforços cisalhantes.

Da Figura 3-18 pode se ver como para os três modelos os resultados são os mesmos

\subsubsection{Elemento de interface sob tração e cisalhamento}

Para a avaliação da integração das tensões empregou-se um modelo o qual é composto de dois elementos sólidos com um elemento de interface de espessura nula e interpolação quadrática entre eles, como se apresenta na Figura 3-19. No modelo para o elemento solido da direita foram impostos dois deslocamentos um 
na direção vertical de $0,0173 \mathrm{~m}$ e outro na direção horizontal com um valor de $0,01 \mathrm{~m}$ causando a plastificacão no elemento de interface.

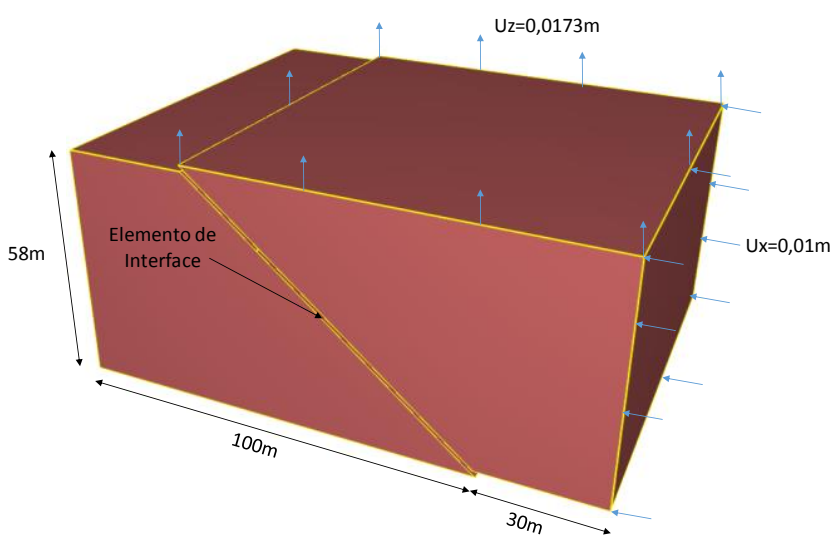

Figura 3-19 Modelo sintético com falha inclinada

$\mathrm{Na}$ Tabela 3.2 se apresentam as propriedades assignadas para os elementos sólidos e o elemento de interface. Para a análise se considerou o comportamento dos elementos sólidos no regime elástico.

Os resultados obtidos para as analises 2D e 3D foram comparadas com o código AMGA, implementado por Rueda(2013) para o ABAQUS, como se apresenta na Figura 3-20.

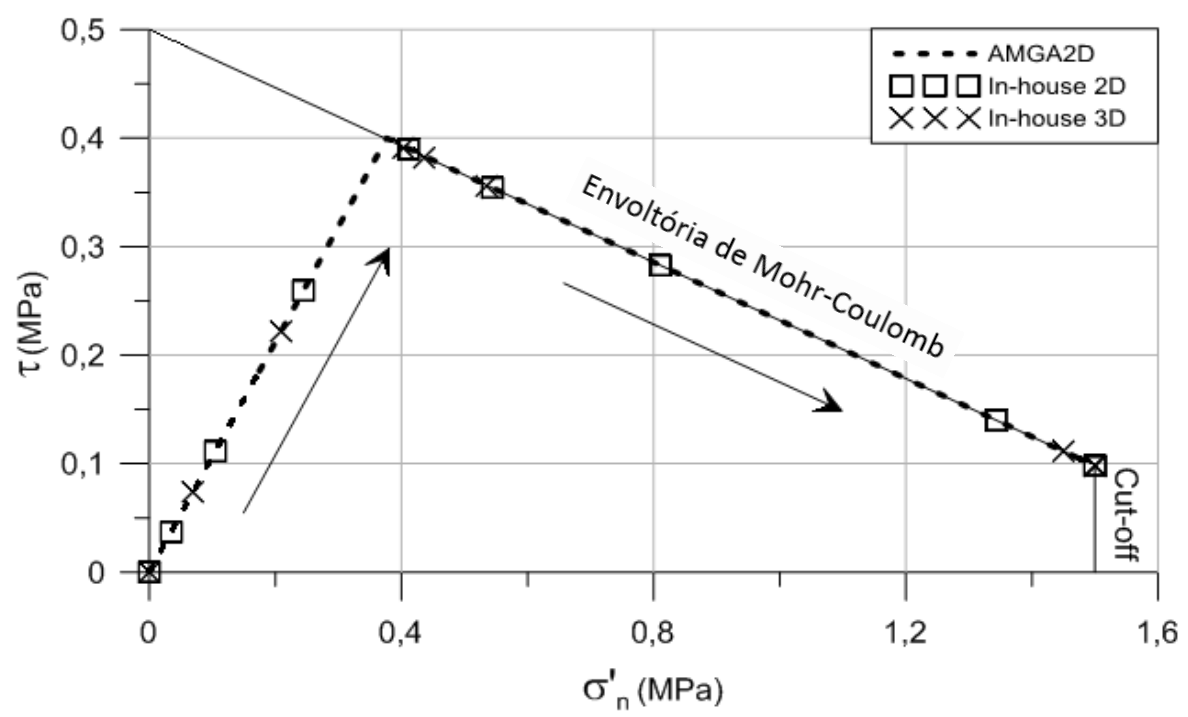

Figura 3-20 Trajetória de tensões

Da Figura 3-20 pode-se observar que os resultados são iguais para as três analises, também pode se ver que a trajetória das tensões começa desde a origem, isso porque não foi considerado um estado de esforços inicias. 


\section{Exemplos de aplicação}

Nos capítulos prévios foi introduzida a metodologia para a avaliação de reativação de falhas geológicas presentes em campos de hidrocarbonetos. Esta metodologia foi implementada em um simulador in-house de elementos finitos 2D/3D com processamento paralelo. Apresenta-se neste capítulo uma série de simulações 2D e 3D de cenários de avaliação de estabilidade de falhas geológicas. Na geração dos modelos foi utilizado o pré-processador GID v.12 (CIMNE, 2012) e para a visualização de resultados empregaram-se os softwares Sigma 2D e Pos3D, estes últimos desenvolvidos no Instituto Tecgraf.

\subsection{Simulações 2D}

Neste apartado se apresenta o modelo 2D para estudar a reativação de falhas geológicas.

\subsubsection{Descrição dos modelos}

O modelo 2D utilizado nestas simulações foi proposto por Cappa e Rutqvist (2010). Estes autores compararam os resultados numéricos de reativação de falhas através de um acoplamento iterativo entre um simulador de fluxo e um mecânico. O modelo é apresentado na Figura 4-1 que consiste em um reservatório de 100m de espessura inserido em duas camadas de $150 \mathrm{~m}$ de espessura de rochas de baixa permeabilidade, no topo e na base do reservatório. Adicionalmente, duas camadas com espessuras de $800 \mathrm{~m}$ foram representadas no modelo, uma na parte superior e outra na parte inferior. Uma falha geológica com uma inclinação de $80^{\circ}$ em relação a um plano horizontal cruza o modelo desde a base até a superfície. As propriedades utilizadas nas camadas e na falha geológica encontram-se listadas na Tabela 4.1. A arquitetura da falha está composta pelo núcleo da falha e a zona de dano como foi apresentado no capitulo 2. No entanto para as análises aqui apresentadas 
considerou-se a zona de falha como meio homogêneo. A falha foi representada através de três tipos de elementos: elemento de interface apresentado no capitulo 3, elemento de continuo equivalente (Mejia et al., 2015) discutido no Capítulo 2, e elemento sólido com fraturas embutidas (Olivella \& Alonso, 2008), Figura 4-3.

$\mathrm{Na}$ modelagem com elementos de interface tem-se um comportamento mecânico em que a ação do fluido é simplificada pela prescrição de poropressão nos elementos localizados dentro do reservatório e pela migração da mesma com a reativação ou abertura da falha. Nesta abordagem, os elementos de interface foram assumidos com rigidez normal e cisalhante com valor de $5000 \mathrm{MPa} / \mathrm{m}$; a falha é considerada sem coesão e com um ângulo de atrito de $25^{\circ}$, conforme apresentado na referência (Cappa \& Rutqvist, 2010).

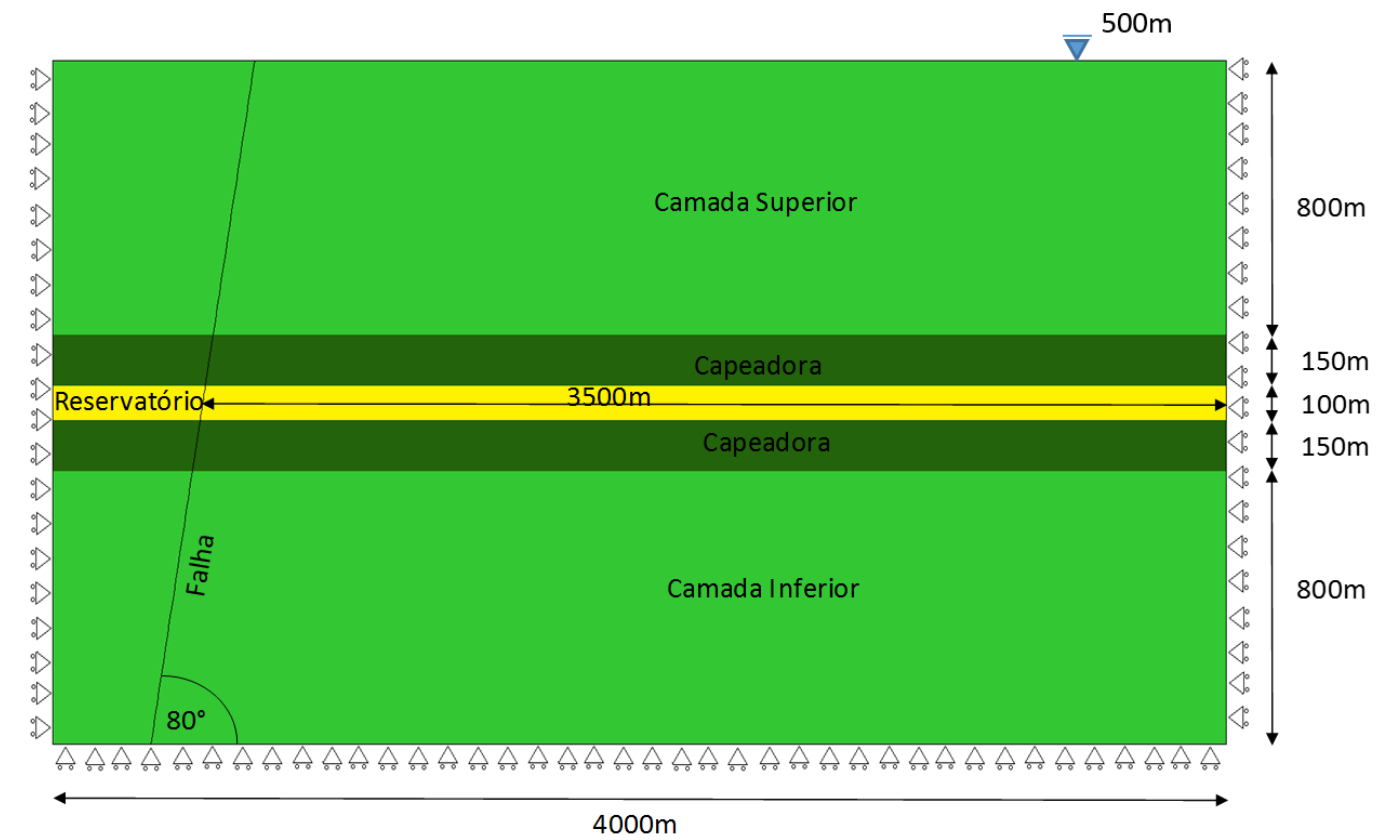

Figura 4-1 Geometria do modelo 2D com falha inclinada.

Tabela 4.1 Propriedades utilizadas nos modelos 2D (Cappa \& Rutqvist, 2010)

\begin{tabular}{lcccc}
\hline \multicolumn{1}{c}{ Camada } & $\begin{array}{c}\mathrm{E} \\
(\mathrm{MPa})\end{array}$ & $\begin{array}{c}v \\
(-)\end{array}$ & $\begin{array}{c}\text { Porosidade } \\
(-)\end{array}$ & $\begin{array}{c}\text { Permeabilidade } \\
\left(\mathrm{m}^{2}\right)\end{array}$ \\
\hline Camada superior & 10000 & 0,25 & 0,10 & $1,00 \mathrm{E}-14$ \\
Capeadora & 10000 & 0,25 & 0,01 & $1,00 \mathrm{E}-19$ \\
Reservatório & 10000 & 0,25 & 0,10 & $1,00 \mathrm{E}-13$ \\
Camada inferior & 10000 & 0,25 & 0,01 & $1,00 \mathrm{E}-16$ \\
Falha & 5000 & 0,25 & 0,10 & $1,00 \mathrm{E}-16$ \\
\hline
\end{tabular}


O estado de tensão inicial foi definido através de um gradiente vertical de tensão total no valor de $22,17 \mathrm{kN} / \mathrm{m}^{3}$. Para definição das tensões horizontais foi considerado um regime de falha normal, $\sigma_{h}=\sigma_{H}=0,7 \sigma_{V}$. As poropressões iniciais foram definidas por meio de um gradiente hidrostático de $10 \mathrm{kN} / \mathrm{m}^{3}$. Tudo isso para uma inicialização de zero deslocamento.

A Figura 4-2 apresenta a malha para o modelo com representação da falha através do elemento de interface.

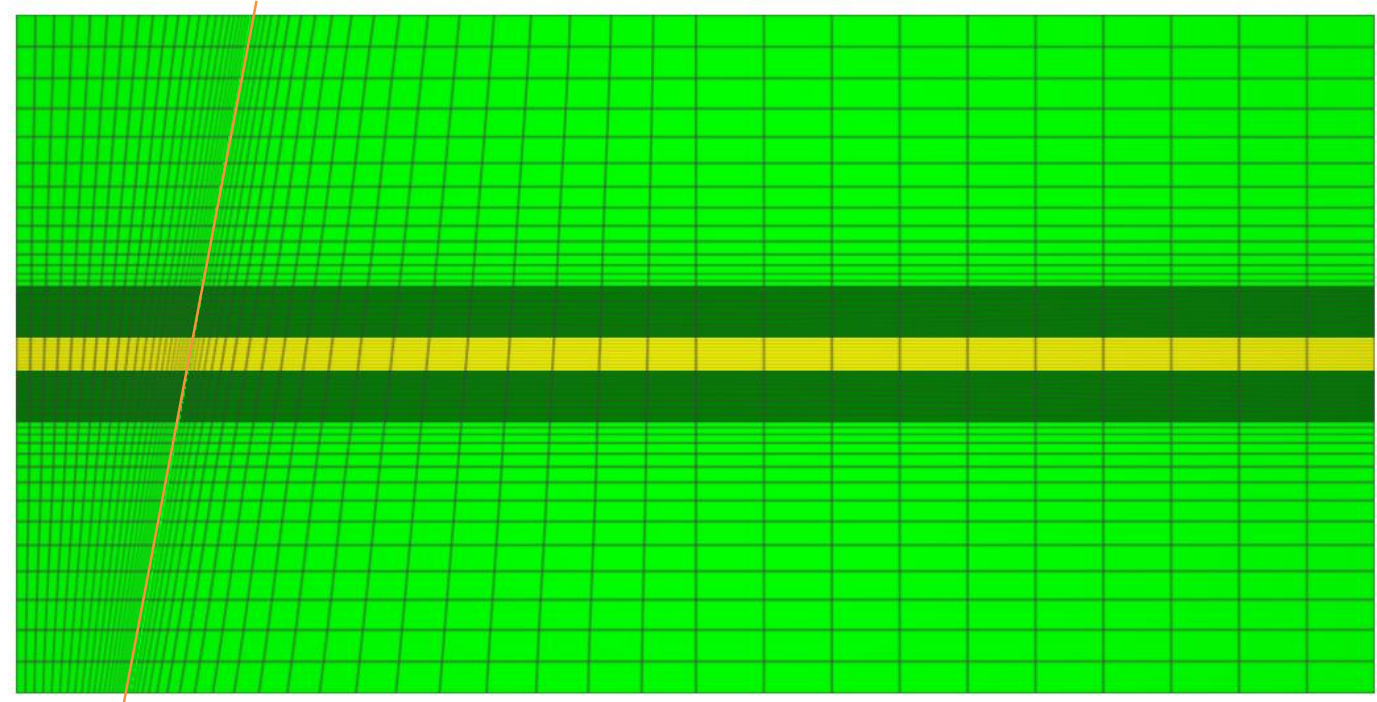

Figura 4-2 Malha para o modelo com representação da falha por meio de elementos de interface

No elemento de contínuo equivalente tem-se apenas o efeito mecânico, sem migração de poro. Nesta abordagem, também foram utilizados os mesmos parâmetros de resistência do elemento de interface, ou seja, coesão nula e ângulo de atrito de $25^{\circ}$.

Já os elementos com fratura embutida apresentam comportamento hidromecânico (acoplamento). Nesta última abordagem, os elementos sólidos dentro da falha foram modelados segundo os critérios adotados por Cappa \& Rutqvist (2010). Na modelagem acoplada, estes autores representaram a falha através de elementos de junta ubíquos com espessuras de $10 \mathrm{~m}$ dentro dos quais foram embutidos planos enfraquecidos com um espaçamento entre fraturas de $0,20 \mathrm{~m}$. 

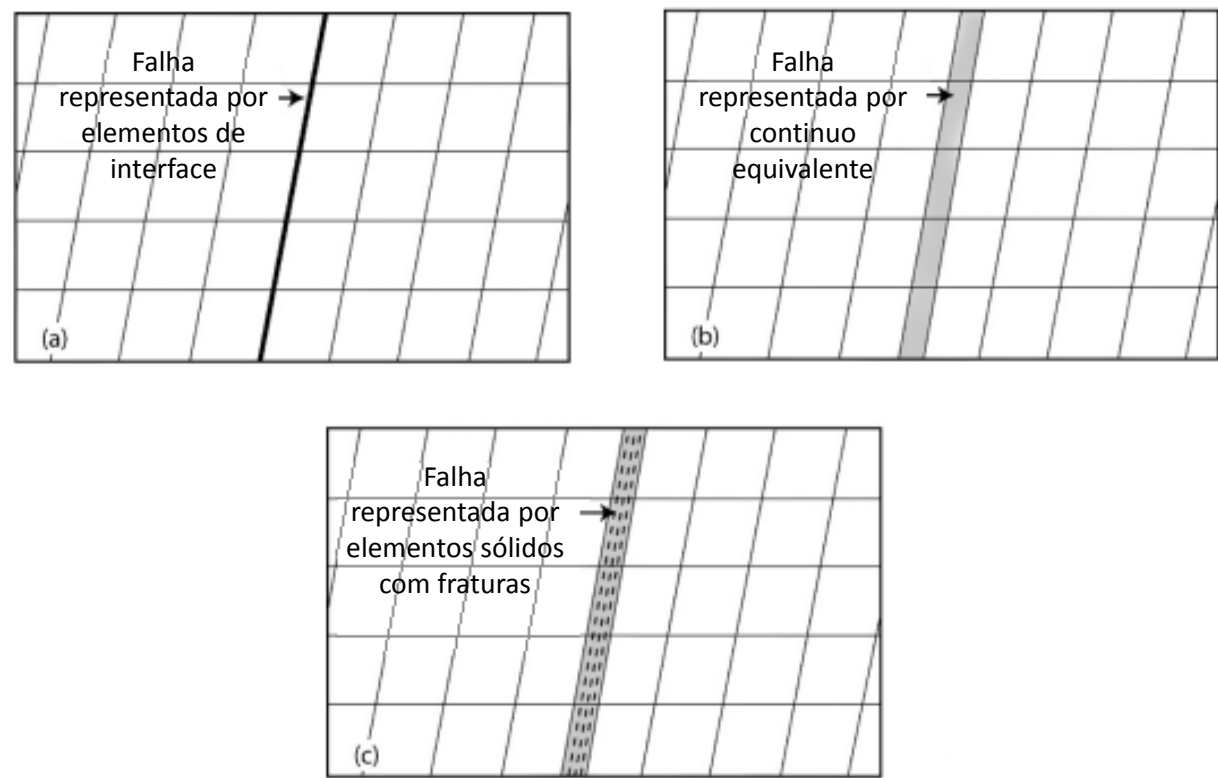

Figura 4-3 Representação das falhas com os diferentes tipos de elementos (adaptado de Cappa and Rutqvist, 2010).

Como se sabe, o movimento relativo nos planos de falha é fortemente influenciado pelas tensões iniciais. Para Cappa \& Rutqvist (2010), as direções das tensões iniciais verticais $\left(\sigma_{V}=\sigma_{1}\right)$ e horizontais $\left(\sigma_{H}=\sigma_{3}\right)$ foram consideradas como principais durante toda a análise.

Para os modelos aqui apresentados foram adotadas as seguintes hipóteses:

- Nas análises com representação da falha por elementos com fraturas embutidas, dois modelos foram avaliados: um adotando o mesmo critério assumido por Cappa \& Rutqvist 2010 em que $\sigma_{V}=\sigma_{1}$ e $\sigma_{H}=\sigma_{3}$, e outro levando em conta a rotação das tensões principais pelo desenvolvimento de tensões cisalhantes.

- Para as análises com representação da falha através de elementos de interface e de elementos de continuo equivalente, foram consideradas todas as componentes de tensão no cálculo sobre o plano de falha.

- Neste estudo, o fluxo na falha foi considerado apenas para os modelos com representação do elemento solido com fraturas, através da equação da continuidade, e com elementos de interface, através dos critérios de instabilidade descritos anteriormente.

- Salienta-se que a simulação acoplada com elementos sólidos com fraturas embutidas, contêm algumas simplificações em relação ao modelo apresentado por Cappa \& Rutqvist (2010). Estas simplificações envolvem: fluxo monofásico sem consideração dos efeitos de capilaridade e de temperatura, e com permeabilidade 
alterada pelo efeito das fraturas embutidas. Por outro lado, na formulação acoplada de Cappa \& Rutqvist (2010), o efeito mecânico da fratura é levado em conta através dos coeficientes de rigidez normal e cisalhante da mesma. Nesta abordagem, o acoplamento hidromecânico é iterativo e realizado entre os simuladores "TOUGH" e "FLAC".

Nas simulações realizadas neste trabalho aplicou-se um incremento total de pressão $(\Delta \mathrm{P})$ de $15 \mathrm{MPa}$ em todo o reservatório para um tempo total de 5 anos. $\mathrm{O}$ processo incremental se deu com incrementos definidos de forma automática pelo programa. As análises se concentraram na avaliação das tensões no plano da falha devido ao processo de injeção.

A malha da simulação com elementos de interface é composta por 9706 nós, 3120 elementos sólidos e 60 elementos de interface. A malha da simulação com elemento de contínuo equivalente é constituída por 18321 nós e 6000 elementos sólidos. A malha da simulação com elementos sólidos com fraturas é constituída por 10573 nós e 3440 elementos sólidos.

\subsubsection{Análise e discussão de resultados}

Os tempos computacionais gastos em cada simulação foram 205s, 2754s e 19243s para os modelos com elementos de interface, elementos de continuo equivalente e elemento solido com fraturas embutidas, respectivamente.

Inicialmente são analisados os resultados para os primeiros pontos de reativação da falha nos diferentes modelos. Na Tabela 4.2 é apresentado o valor do incremento de poropressão que é constante em todo o reservatório com o que inicia a reativação da falha em cada simulação. Observa-se que as três simulações forneceram resultados similares, com valores acima de $4 \mathrm{MPa}$.

Tabela 4.2 Resultados comparativos de pressão de reativação na falha.

\begin{tabular}{lccc}
\hline $\begin{array}{c}\text { Representação da } \\
\text { falha }\end{array}$ & $\begin{array}{c}\Delta \mathrm{P} \text { para a reativação } \\
(\mathrm{MPa})\end{array}$ & $\begin{array}{c}\text { Número de } \\
\text { incrementos }\end{array}$ & $\begin{array}{c}\text { Tempo } \\
\text { (Meses) }\end{array}$ \\
\hline $\begin{array}{l}\text { Elemento de } \\
\text { interface }\end{array}$ & 4,14 & 3 & - \\
$\begin{array}{l}\text { Continuo } \\
\text { equivalente }\end{array}$ & 4,50 & 9 & - \\
Sólido com fraturas & 4,11 & - & 0,6 \\
\hline
\end{tabular}


A Figura 4-4 apresenta a variação das tensões cisalhante e normal efetiva ao longo da falha quando ocorre o início da reativação. A linha vermelha destaca o topo e a base do reservatório. Na Figura 4-4 pode-se observar que nas três simulações a evolução da tensão cisalhante tem o mesmo comportamento, mostrando assim que para a avaliação do início da reativação da falha, qualquer uma das três abordagens pode ser adotada. Nesta figura, também pode se apreciar que ocorre uma variação da tensão cisalhante superior $(1,9 \mathrm{MPa})$ na base do reservatório, onde ocorrem os primeiros pontos de reativação.

A Figura 4-4 também apresenta a comparação da variação da tensão normal efetiva no início da reativação na falha. Observa-se que os resultados das três simulações também foram similares, principalmente aqueles do elemento de interface e do continuo equivalente. Isto porque em ambas simulações, a tensão normal é governada pelo coeficiente de rigidez normal $k_{n}$. Por outro lado, na simulação com elemento sólido com fraturas embutidas, que apresentou maiores diferenças, a tensão normal é governada pelo módulo de elasticidade. Contudo a diferença máxima encontrada dentro do reservatório foi inferior a 0,65 $\mathrm{MPa}$, o que representa cerca de $20 \%$ do valor resultante com o continuo equivalente. Nessa figura não são apresentados os resultados de Cappa \& Rutqvist (2010) já que no trabalho deles as respostas são apresentadas para o final da análise quando é aplicado um incremento da poropressão de $15 \mathrm{MPa}$. 

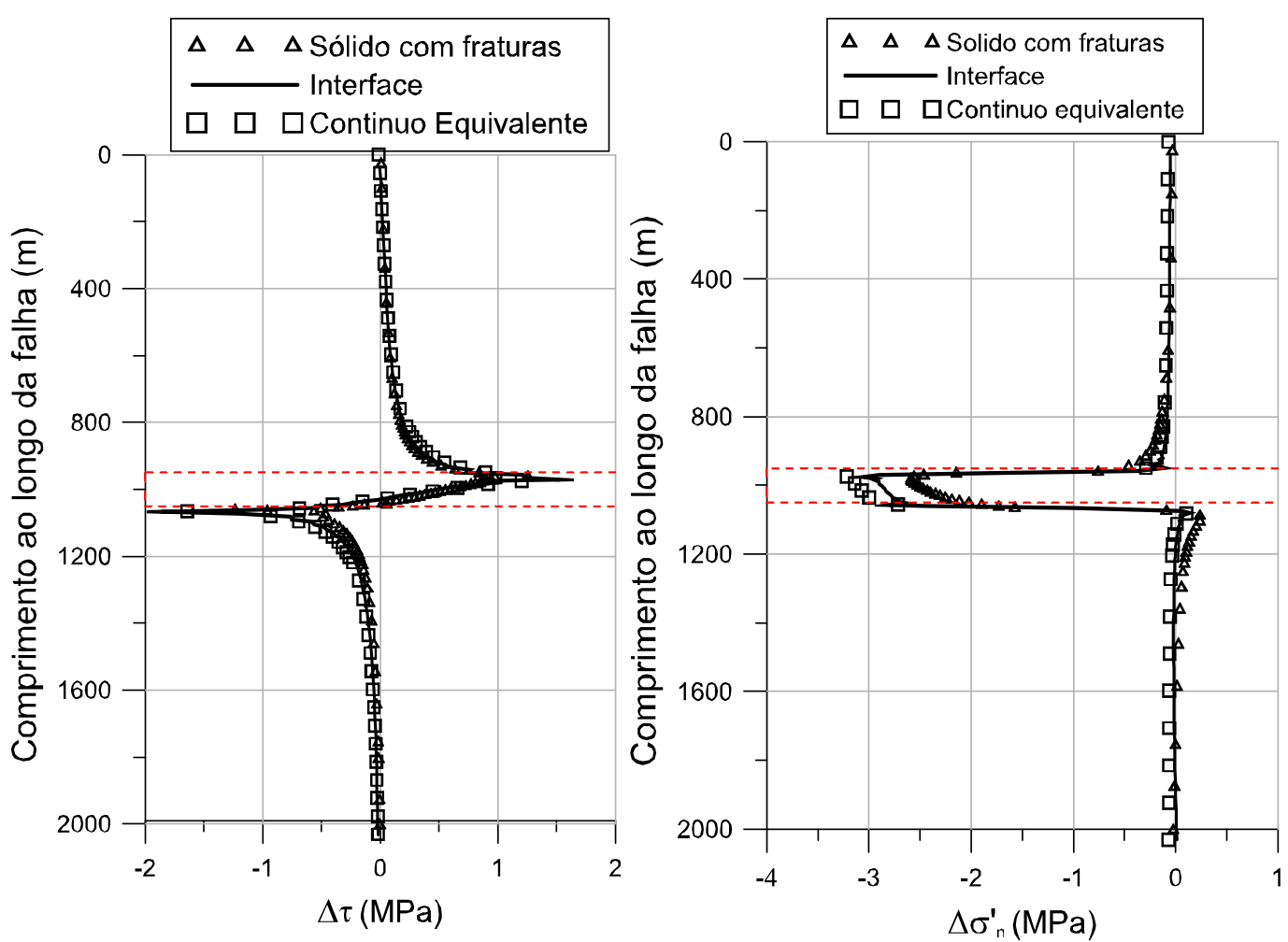

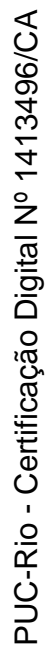

Figura 4-4 Variação das tensões ao longo do comprimento da falha no início do processo da reativação.

A Figura 4-4 apresenta a trajetória de tensões efetivas para dois pontos, um que se encontra na base do reservatório (ponto inferior) e outro no topo (ponto superior). Pode se ver como o ponto localizado na parte inferior do reservatório atinge primeiro a superfície de plastificação, onde ocorrem os primeiros pontos de reativação. 


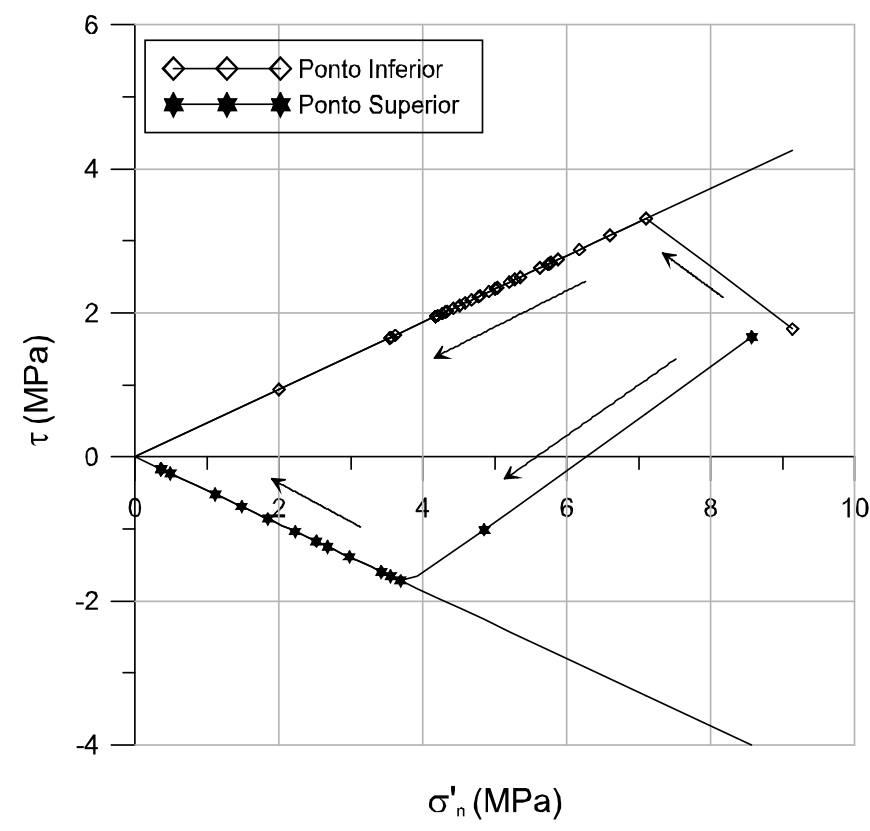

Figura 4-5 Trajetória de tensões para os pontos inferior (base do reservatório) e superior (topo do reservatório).

A Figura 4-6 apresenta a variação da tensão cisalhante e da tensão normal efetiva no final das simulações quando é aplicado um incremento na poropressão de $15 \mathrm{MPa}$. Do gráfico que compara a variação das tensões cisalhantes, pode-se observar que houve um comportamento similar entre os resultados com elementos de interface e sólidos com fraturas. Por outro lado, os resultados com o continuo equivalente apresentaram diferenças significativas, principalmente dentro do reservatório. Isto porque esta formulação não considera os efeitos da migração da poropressão após a reativação. Já nas outras simulações, que sim consideram este efeito, a evolução das tensões cisalhantes é similar. Do gráfico que compara a variação da tensão normal pode se apreciar que todas as simulações, inclusive a do continuo equivalente, forneceram resultados similares. No entanto, algumas diferenças podem ser apreciadas, principalmente nas regiões adjacentes ao reservatório. Acima do reservatório não se identificaram elementos de interface reativados, por tanto, não houve propagação nem migração de fluido. Isto pode explicar os resultados similares com a simulação com o continuo equivalente. Por outro lado, na simulação com elementos sólidos com fratura houve migração de fluido nesta região e consequentemente, o perfil de tensão efetiva resultou diferente. Abaixo do reservatório, há elementos de interface reativados. Pode se observar que as tensões efetivas são similares àquelas do elemento sólido com fraturas. Como explicado anteriormente, o resultado com o elemento de continuo equivalente 
resultou diferente, pois esta abordagem não permite identificar o comportamento após a reativação.
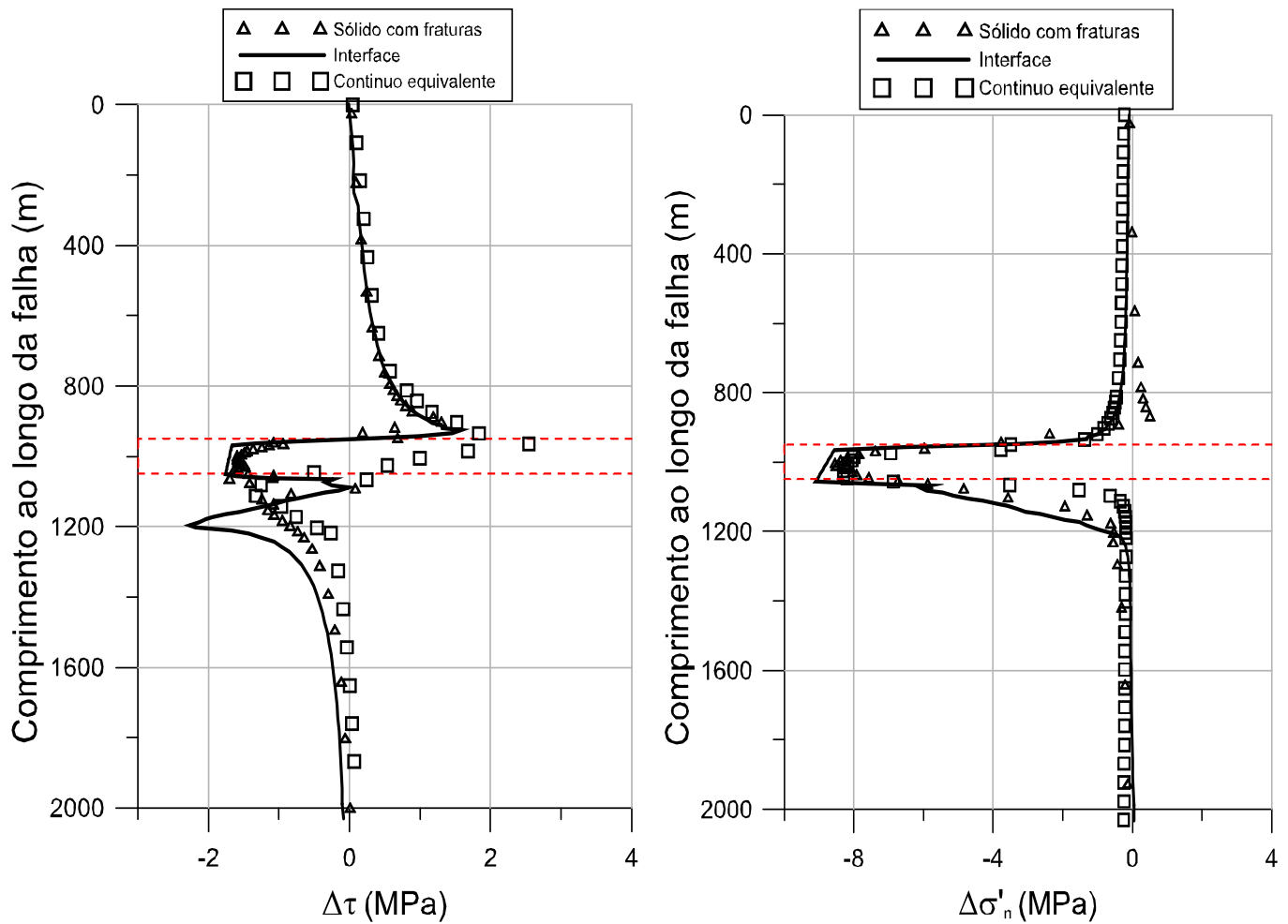

Figura 4-6 Resultados ao longo do comprimento da falha no final das simulações

A Figura 4-7 apresenta a variação da poropressão ao longo da falha no final da simulação, isto é, quando a variação de pressão dentro do reservatório atinge o valor máximo de $15 \mathrm{MPa}$. Para comparação, nesta figura foram colocados os resultados das simulações acopladas com o elemento sólido com fraturas embutidas e aqueles obtidos por Cappa e Rutqvist (2010). Observa-se que a migração do fluido através da falha foi similar em ambos os resultados. No entanto, aprecia-se que na simulação de Cappa \& Rutqvist (2010) ocorre uma transição suave de poropressão entre os elementos com migração e sem migração de poropressão. Já no caso da simulação com elementos sólidos com fraturas embutidas essa transição é brusca. 


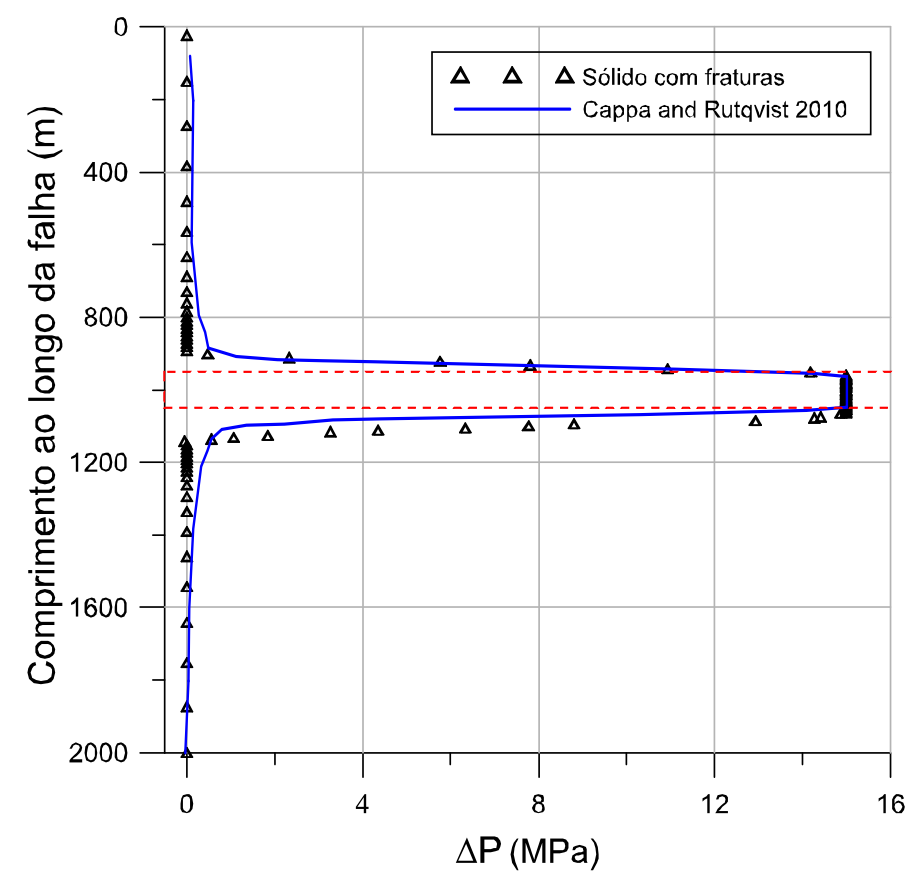

Figura 4-7 Variação da poropressão ao longo do comprimento da falha.

A Figura 4-8 apresenta a variação das tensões, cisalhante e normal efetiva, ao longo da falha no final da simulação. Nestes gráficos foram colocados os resultados das simulações acopladas com o elemento sólido com fraturas embutidas e aqueles obtidos por Cappa e Rutqvist (2010). Na geração destas tensões resultantes no plano de falha foram utilizadas apenas as componentes de tensão vertical e horizontal e foram desconsideradas as tensões cisalhantes, como propuseram Cappa e Rutqvist (2010). Observa-se um perfil de tensão completamente diferente daquele obtido quando são considerados todas as componentes do tensor na avaliação das tensões sobre o plano de falha (Figura 4-6). Da comparação da variação das tensões cisalhantes na Figura 4-8, observa-se que dentro do reservatório estas decrescem até um valor de aproximadamente 1,60 MPa. Pode-se ver que ambas as curvas têm tendências similares. No trabalho de Cappa \& Rutqvist 2010, a tensão cisalhante varia quase de forma simétrica no topo e na base do reservatório. Já no modelo acoplado com elementos sólidos com fratura, as tensões cisalhantes na base são diferentes daquelas no topo do reservatório. Isto se dá porque ocorre migração de fluido na base do reservatório enquanto que no topo, a falha se mantem estável. Estas diferenças não são tão significativas no gráfico que compara as tensões normais na falha. Pode-se observar que a tensão normal efetiva decresce de um valor aproximado de 9MPa no final da análise. Dentro do reservatório ambos os resultados são similares. Já fora do reservatório os resultados apresentados por 
Cappa \& Rutqvist (2010) apresentam uma maior variação por causa da maior migração de fluido que ocorre no modelo proposto por esses autores.

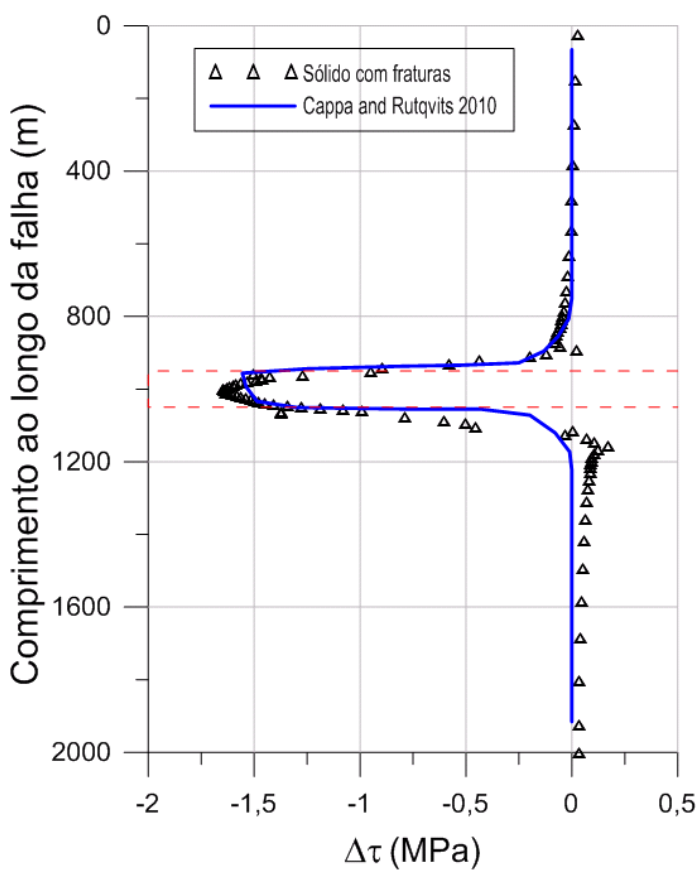

a)

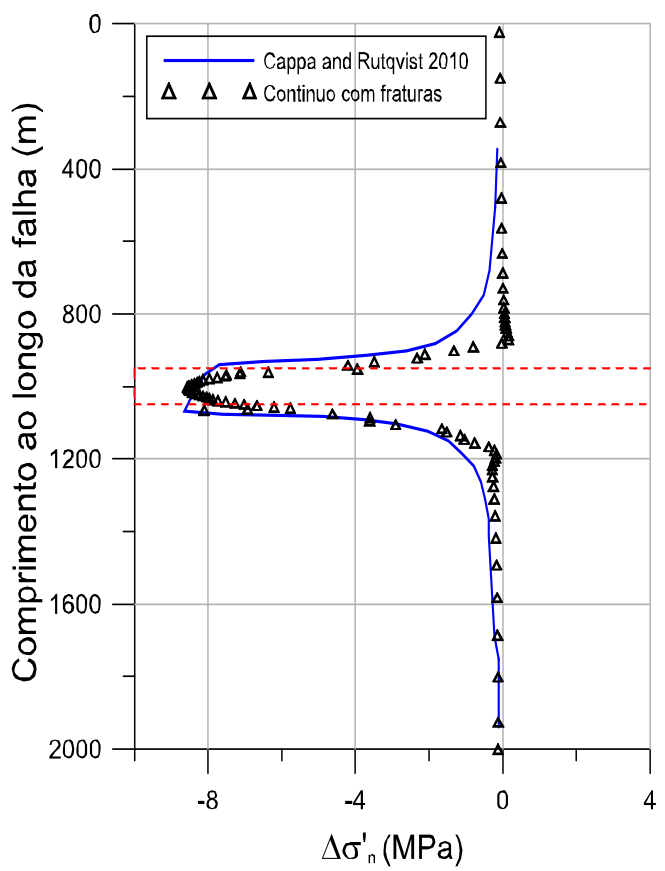

b)

Figura 4-8 Variação das tensões ao longo do comprimento da falha sem consideração de rotação das tensões principais. 


\subsection{Simulações 3D}

\subsubsection{Descrição dos modelos}

Para as análises 3D, empregou-se a geometria de um campo hipotético composto por 7 camadas e 3 falhas geológicas, como apresentado na Figura 4-9. Observa-se que esta estrutura geológica apresenta uma série de rejeitos na interface entre as camadas e as falhas geológicas. Isto foi contemplado no modelo a fim de representar condições tipicamente encontradas em campo. A zona de injeção foi estabelecida em parte da camada $\mathrm{C} 4$, como mostra a Figura 4-9. As três falhas consideradas no modelo foram denominadas F1, F2 e F3. Estas falhas foram incluídas dentro do modelo, sem atingir o topo, a base e as bordas laterais. Distancias mínimas de $300 \mathrm{~m}$, 900m e $1000 \mathrm{~m}$ foram empregadas para separar as falhas do topo, da base e dos contornos laterais, respectivamente. A Figura 4-9 também apresenta a posição das falhas em relação à zona de injeção. Observa-se que a zona de injeção inclui apenas uma parte das 3 falhas.

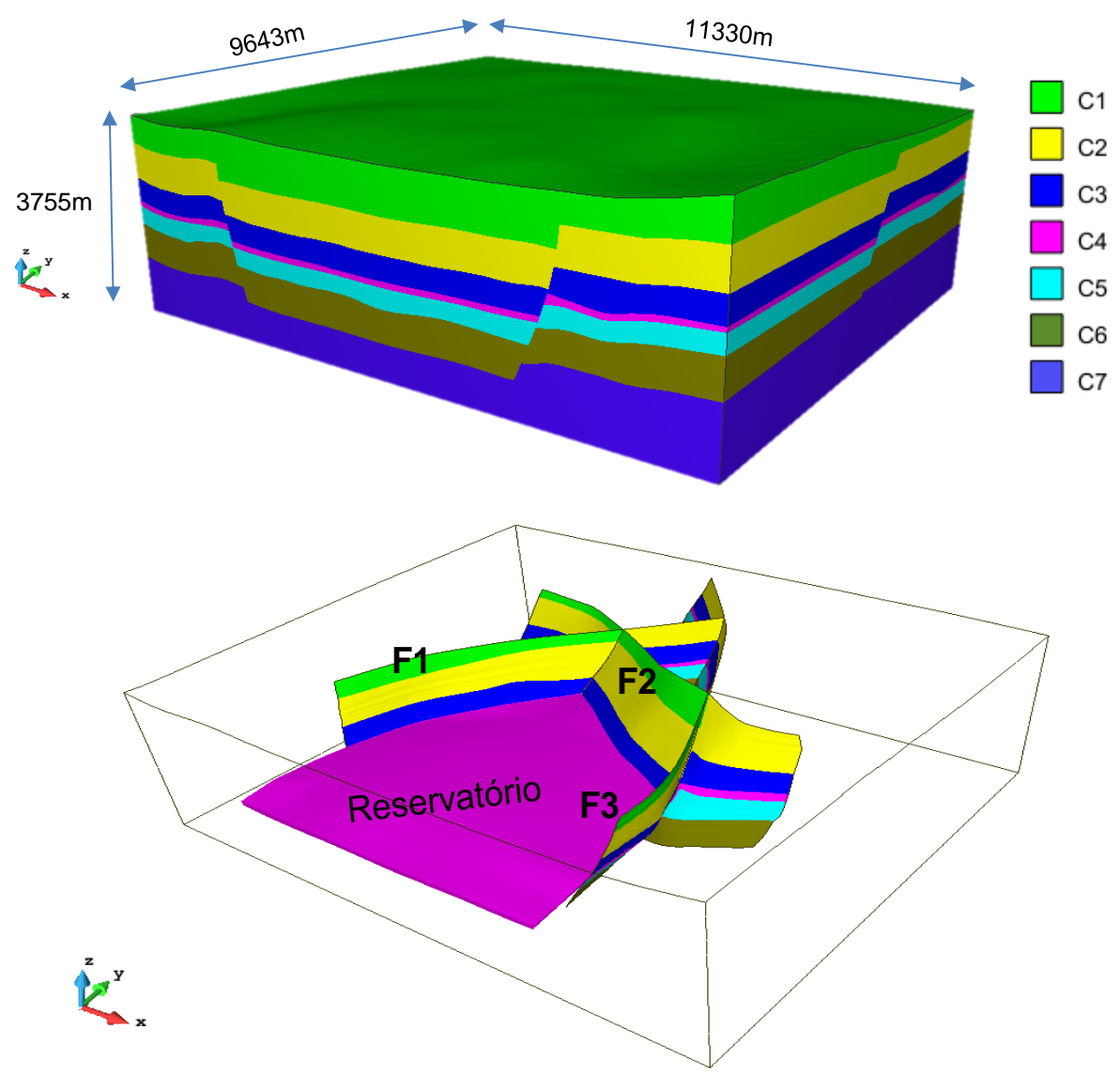

Figura 4-9 Descrição das camadas e das falhas geológicas para as simulações 3D. 
As propriedades das camadas e das falhas geológicas encontram-se listadas na Tabela 4.3 e na Tabela 4.4, respectivamente. Estes valores foram adotados com base em trabalhos prévios reportados na literatura (Mendes et al., 2010, e Rueda 2013). A resistência à tração das falhas nestas simulações foi considerada com valor nulo, isto é, cut-off $=0$.

Tabela 4.3. Propriedades da rocha para os elementos sólidos

\begin{tabular}{ccccc}
\hline Camada & $\begin{array}{c}\mathrm{E} \\
(\mathrm{MPa})\end{array}$ & $v$ & $\begin{array}{c}\mathrm{c} \\
(\mathrm{MPa})\end{array}$ & $\begin{array}{c}\phi \\
\left({ }^{\circ}\right)\end{array}$ \\
\hline C1 & 4000 & 0,38 & 2,25 & 28,5 \\
$\mathrm{C} 2$ & 5500 & 0,37 & 2,50 & 29,0 \\
C3 & 6000 & 0,36 & 2,75 & 29,5 \\
C4 & 7000 & 0,35 & 3,00 & 30,0 \\
C5 & 8000 & 0,34 & 3,25 & 30,5 \\
C6 & 8500 & 0,33 & 3,50 & 31,0 \\
C7 & 9000 & 0,32 & 4,00 & 31,5 \\
\hline
\end{tabular}

Tabela 4.4. Propriedades da falha para os elementos de interface

\begin{tabular}{ccccc}
\hline Camada & $\begin{array}{c}\mathrm{Kn} \\
(\mathrm{MPa} / \mathrm{m})\end{array}$ & $\begin{array}{c}\mathrm{Ks} \\
(\mathrm{MPa} / \mathrm{m})\end{array}$ & $\begin{array}{c}\mathrm{c} \\
(\mathrm{MPa})\end{array}$ & $\begin{array}{c}\phi \\
\left({ }^{\circ}\right)\end{array}$ \\
\hline FC1 & 8000 & 1450 & 0,50 & 20,0 \\
FC2 & 11000 & 2010 & 0,50 & 20,0 \\
FC3 & 12000 & 2210 & 0,50 & 20,0 \\
FC4 & 14000 & 2590 & 0,50 & 20,0 \\
FC5 & 16000 & 2990 & 0,50 & 20,0 \\
FC6 & 17000 & 3200 & 0,50 & 20,0 \\
FC7 & 18000 & 3410 & 0,50 & 20,0 \\
\hline
\end{tabular}

$\mathrm{Na}$ definição do estado de tensão vertical inicial adotou-se um gradiente vertical de tensão efetiva de $12,50 \mathrm{kPa} / \mathrm{m}$. Na definição das tensões efetivas horizontais empregou-se um coeficiente lateral de 0,53.

A partir da geometria apresentada na Figura 4-9, dois modelos foram gerados. O primeiro empregando elementos hexaédricos BRICK20, para representação das camadas, e elementos de interface INT3D16, para representação das falhas. No segundo modelo foram empregados elementos tetraédricos para as camadas e elementos de interface INT3D12 para as falhas. Desta forma, pretende-se comparar os resultados entre ambos os modelos a fim de verificar a sensibilidade da resposta em função dos tipos de elementos utilizados nas malhas de elementos finitos. 
A malha do modelo 1 é apresentada na Figura 4-10. Esta é composta por 230.608 elementos hexaédricos BRICK20 e por 7.392 elementos de interface INT3D16. No total a malha é formada por 976.152 nós.
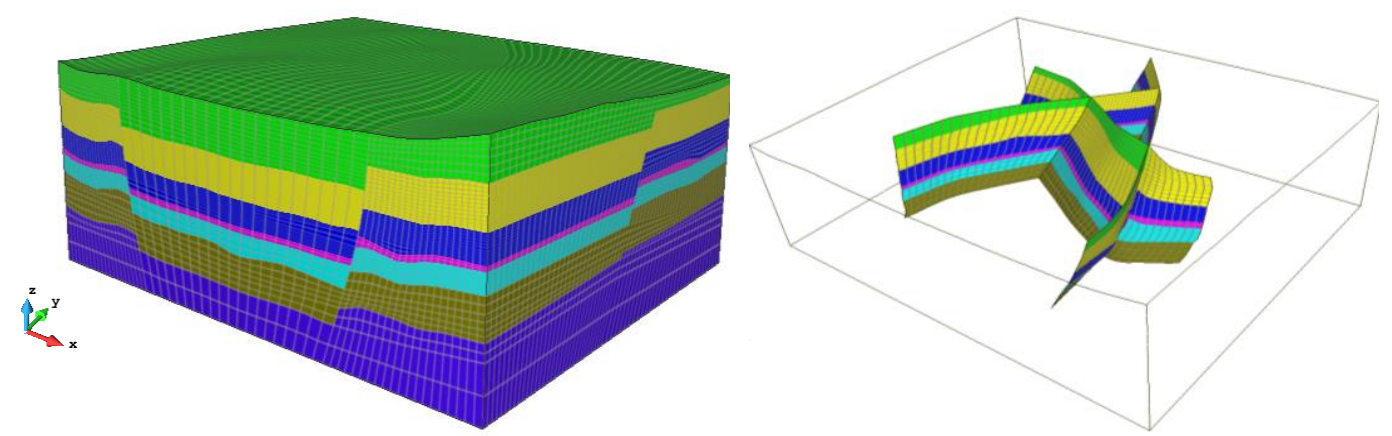

Figura 4-10 Malha de elementos finitos empregada no modelo 1.

A malha do modelo 2 é apresentada na Figura 4-11. Esta é composta por 580.970 elementos tetraédricos TETR10 e por 15.807 elementos de interface INT3D12. No total a malha possui 826.394 nós.

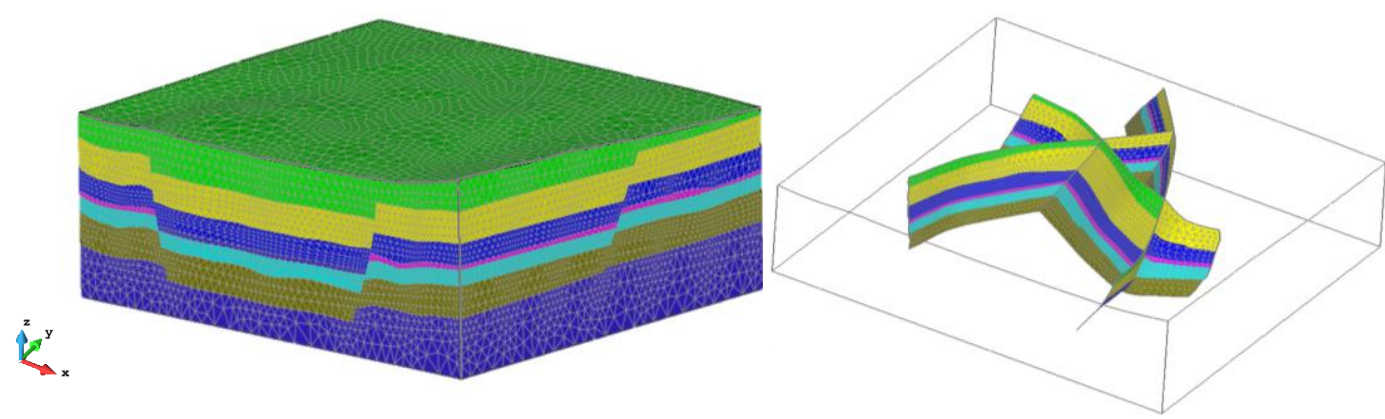

Figura 4-11 Malha de elementos finitos empregada no modelo 2.

Em ambos modelos aplicou-se um incremento de poropressão equivalente a $20 \mathrm{MPa}$ na região do reservatório.

As seguintes hipóteses foram adotadas nestes modelos:

- As falhas foram consideradas inicialmente seladas dentro e fora do reservatório.

- A migração da poropressão através da falha ocorre uma vez que o selo seja perdido quer pela reativação, quer pela abertura da falha.

- O incremento de poropressão foi aplicado uniformemente dentro da região do reservatório e nas regiões de falha adjacentes a este. 


\subsubsection{Análise e discussão de resultados}

Todas as simulações foram executadas em um CPU com processador Intel® Core $^{\mathrm{TM}}$ i7 e memória RAM de 32 GB. Os tempos computacionais gastos nas simulações foram de 50 horas e 17 horas para os modelos 1 e 2 , respectivamente. A Figura 4-12 apresenta as regiões correspondentes aos primeiros pontos de reativação em ambos os modelos. Desta figura pode ser observado que o processo de reativação da falha inicia dentro da região inferior do reservatório após um incremento de poropressão de $2,5 \mathrm{MPa}$.

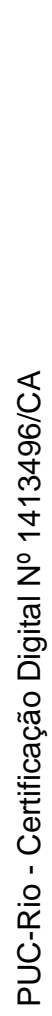
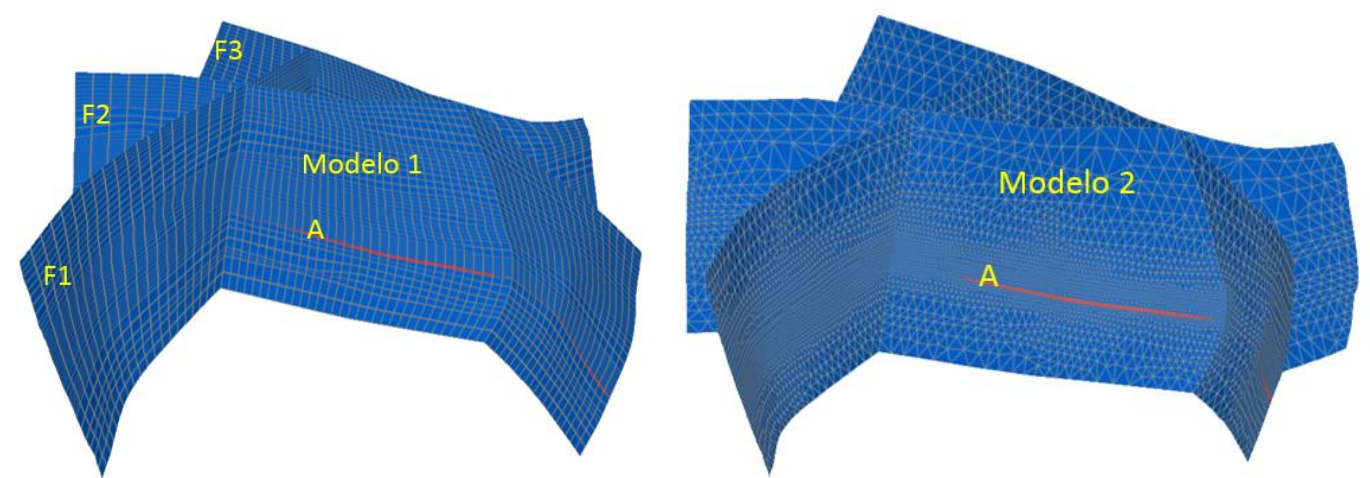

Figura 4-12. Primeiros pontos de reativação nas simulações 3D após um incremento de poropressão de $2,5 \mathrm{MPa}$.

A Figura 4-13 mostra a comparação da evolução do índice de reativação (IR - descrito no capítulo 3) com o incremento de pressão aplicado no ponto A, localizado na falha F2. Observa-se que ambos modelos forneceram respostas similares.

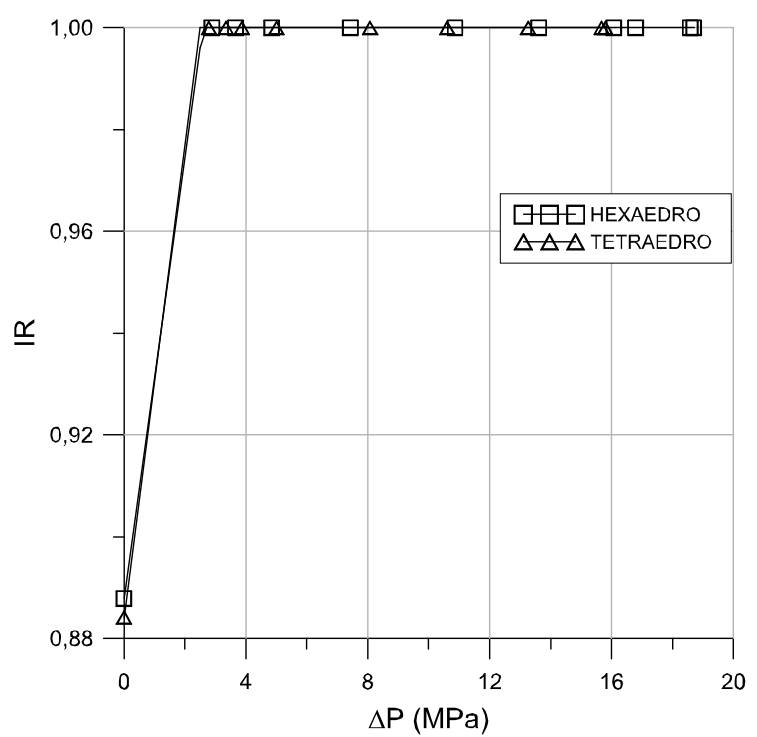

Figura 4-13 Evolução do índice de reativação com o incremento de poropressão no ponto A para os modelos 1 e 3 . 
A Figura 4-14 apresenta a evolução das tensões cisalhante e normal efetiva com a poropressão para o ponto A. Como pode ser observado, a tensão cisalhante começa a decrescer com o aumento da poropressão até atingir o valor mínimo de 0,5MPa que é exatamente o valor da coesão na falha. Isso acontece quando a tensão normal efetiva é anulada como pode ser apreciado no gráfico que mostra a evolução da tensão normal efetiva normal. Pode-se notar que esta evolução também foi similar em ambos modelos. No modelo 1, a anulação das tensões normais efetivas ocorre com um incremento da poropressão de $12,7 \mathrm{MPa}$ enquanto que no modelo 2, com 12,3Mpa. Nesta situação, inicia-se o processo de abertura na falha 2.
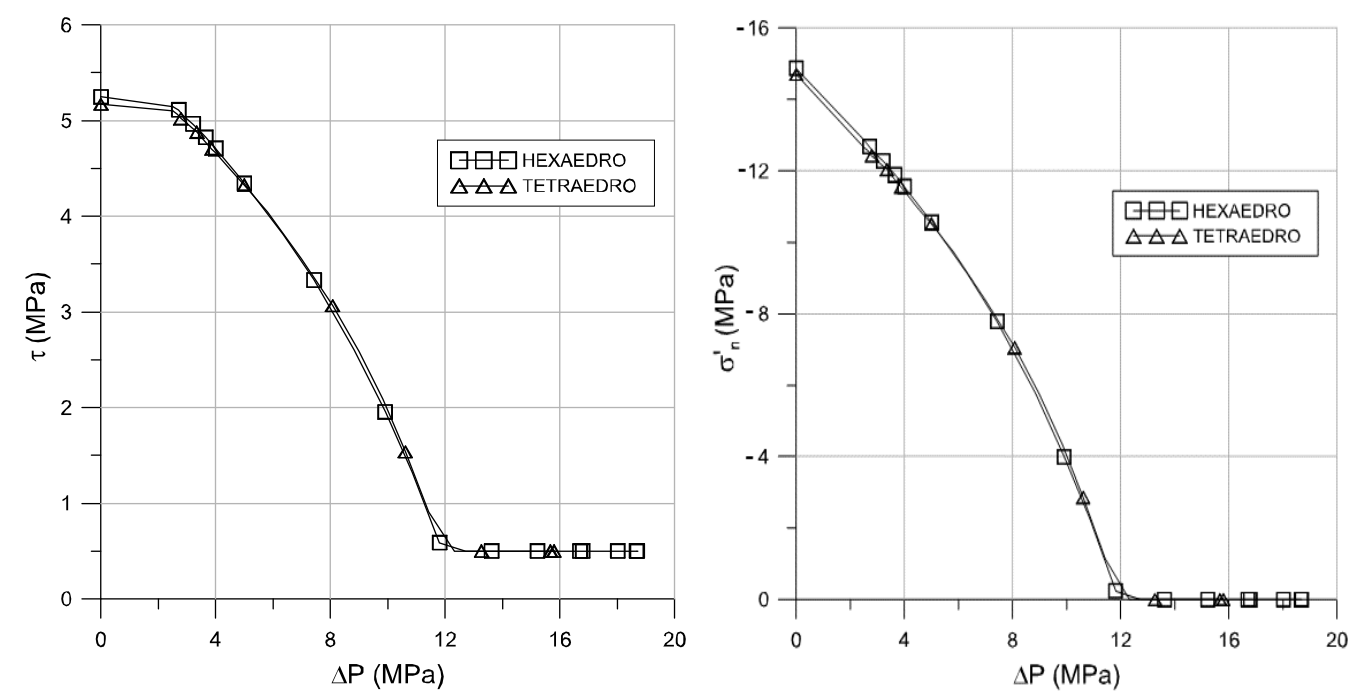

Figura 4-14 Evolução das tensões, normal efetiva e cisalhante, com o incremento de poropressão no ponto A para os modelos 1 e 3 .

A Figura 4-15 apresenta as regiões que reativaram em ambos os modelos após um incremento de poropressão de 4,5MPa. Pode-se observar que ambas as falhas 2 e 3 sofreram reativação em todo o trecho do reservatório. Também pode-se observar que alguns elementos fora do reservatório também foram reativados na região do rocha capeadora inferior da falha 3.
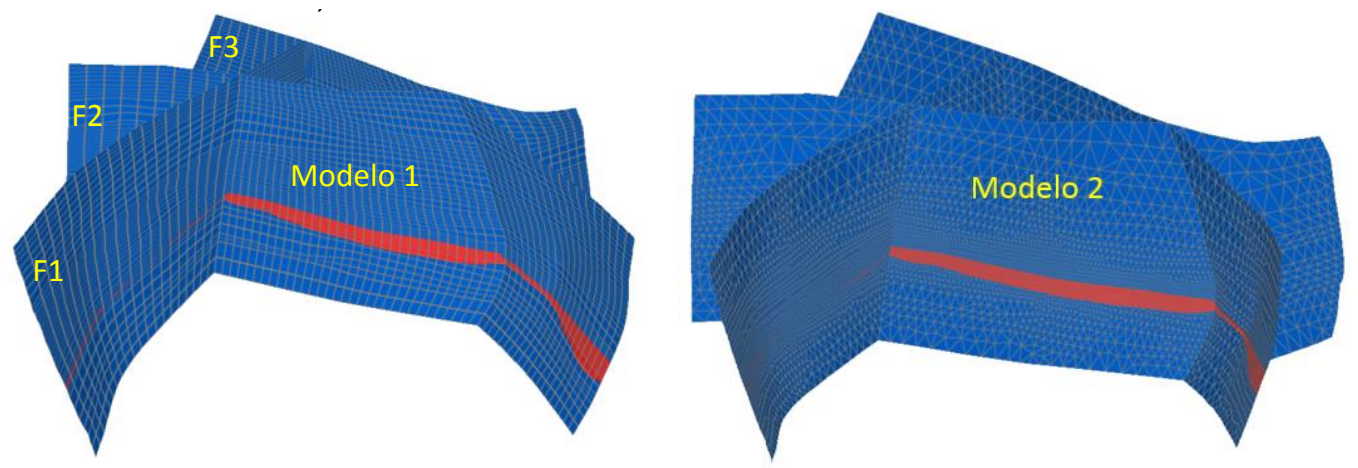

Figura 4-15 Regiões que indicam os primeiros pontos de reativação nos modelos 1 e 2 . 
A Figura 4-16 apresenta o efeito da migração do fluido, fazendo uso do critério de instabilidade de falha, para diferentes pressões de injeção nos modelos 1 e 2. Como pode ser apreciado, inicialmente o fluido migra para baixo e depois para cima. Isto pode ser explicado pelas inclinações das falhas modeladas. Estas têm inclinações mais próximas da crítica nas regiões da capeadora inferior. Consequentemente, o fluido migra antes nesse sentido apesar de encontrar uma maior resistência pela elevada tensão normal efetiva.

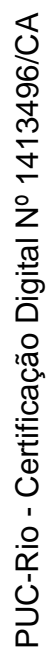
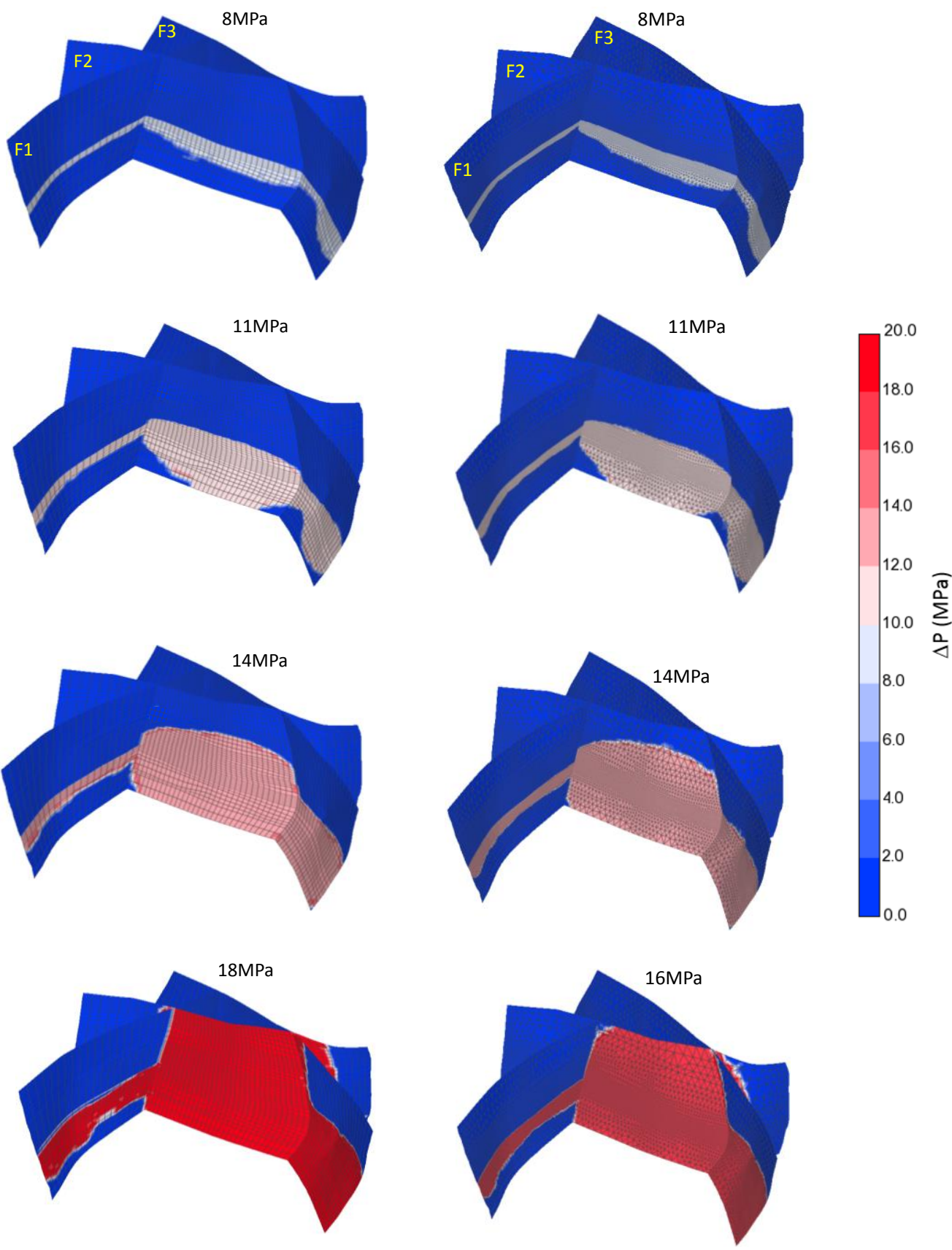

Figura 4-16 Evolução da migração da poropressão em todo o modelo 1 (esquerda) e em todo o modelo 2 (direita) 


\subsection{Comparação entre simulações $2 \mathrm{D}$ e 3D}

Neste item são comparados os resultados obtidos por um modelo 2D, na hipótese de estado plano de deformação, e o modelo 1 apresentado nas simulações 3D. Para isto, extraiu-se uma seção da geometria 3D apresentada no item anterior. Esta seção é mostrada na Figura 4-17 e foi selecionada porque intersecta tanto o reservatório pressurizado como as três falhas (F1, F2 e F3), e ainda passa pelo ponto A utilizado na discussão de resultados 3D. As propriedades geomecânicas, condições iniciais e a pressurização imposta são as mesmas daquelas detalhadas nas simulações 3D do item anterior. Na malha desta seção foram empregados 3.600 elementos quadrilaterais QUAD8 para representação das camadas, e 150 elementos de interface INT2D6 para representação das falhas; no total a malha possui 11.338 nós. O tempo computacional gasto nesta simulação foi de 18 minutos. Observe que este tempo foi consideravelmente inferior daquele gasto na simulação 3D (50 horas no modelo 1).
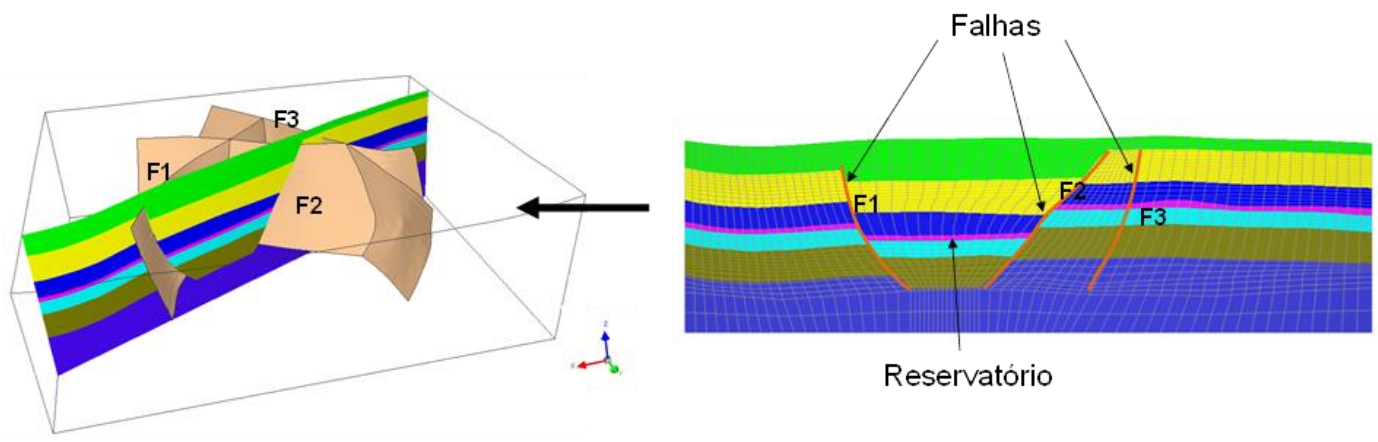

Figura 4-17 Geometria e malha de elementos finitos para a modelo 2D.

A Figura 4-18 apresenta a região correspondente aos primeiros pontos de reativação na seção para o ponto $\mathrm{A}$. Como no modelo 3D, estes pontos apareceram dentro da região inferior do reservatório para uma poropressão de 2,8MPa.

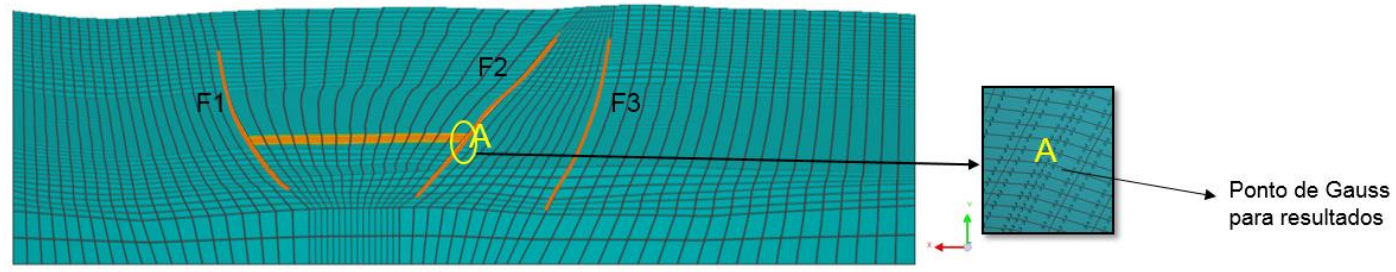

Figura 4-18 Regiões que indicam os primeiros pontos de reativação no modelo 2D

A Figura 4-19 mostra uma comparação da evolução do índice de reativação (IR) com o incremento de pressão para o ponto A localizado na falha F2. Observa- 
se que ambas as análises, 2D e 3D, forneceram tendências bastante similares. No entanto, na análise $3 \mathrm{D}$, o primeiro ponto de reativação na falha ocorre para um incremento de pressão na injeção de 2,5MPa enquanto que na análise 2D para um valor de $2,8 \mathrm{MPa}$. Salientasse que para essa seção o primeiro ponto de reativação acontece para a falha 1 quando é aplicada uma poropressão de 2,5MPa.

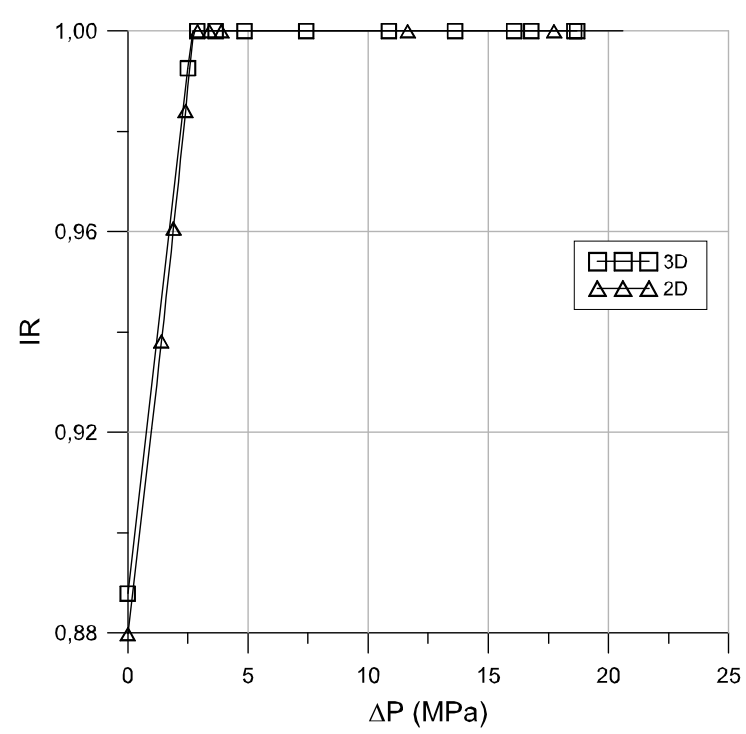

Figura 4-19 Evolução do índice de reativação com o incremento de poropressão no ponto A.
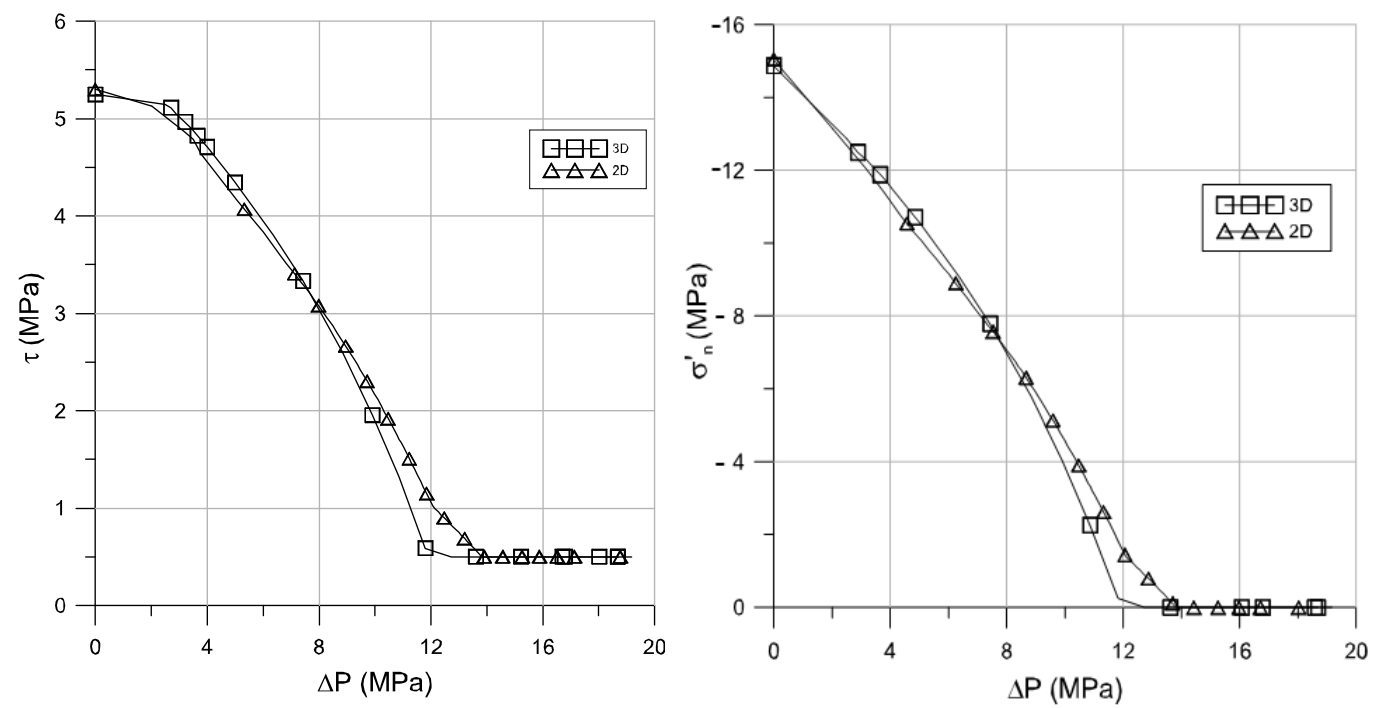

Figura 4-20 Evolução das tensões, cisalhante e normal efetiva, com o incremento de poropressão no ponto A

A Figura 4-20 apresenta a evolução das tensões cisalhante e normal efetiva com o incremento de poropressão no ponto A. Como pode ser observado, a tensão cisalhante começa a decrescer com o aumento da poropressão até atingir o valor mínimo de $0,5 \mathrm{MPa}$, que é exataamente o valor da coesão na falha. Isso acontece 
para um incremento de poropressão na injeção de 12,7MPa na análise 3D e de 14MPa na análise 2D. Pode-se notar que ambas as análises também forneceram tendências similares para a anulação das tensões normais efetivas, o que ocorre para um incremento de poropressão na injeção de 12,7MPa na análise 3D e de $14 \mathrm{MPa}$ na análise 2D.

A Figura 4-21 apresenta o efeito da migração do fluido fazendo uso do critério de instabilidade de falha para diferentes pressões de injeção. Assim como no caso 3D, a migração do fluido começa para baixo e posteriormente para cima. No entanto, observa-se que com um incremento de poropressão de $18 \mathrm{MPa}$ a propagação é maior no overburden. Isto indica que, embora a migração se inicie no underburden, após a quebra do selo do primeiro ponto no overburden, o processo de reativação se dá preferencialmente em sentido ascendente.

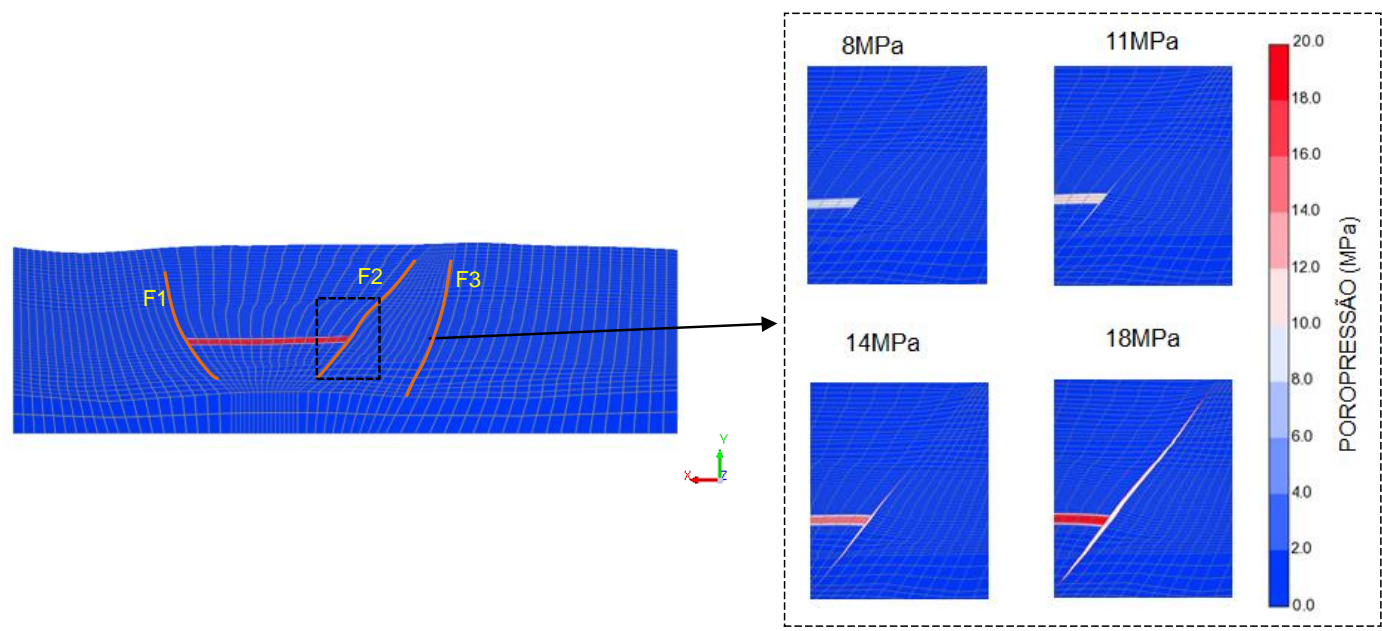

Figura 4-21 Evolução da migração da poropressão em todo o modelo 2D. Malha deformada em 60 vezes.

Na Figura 4-22 observa-se como uma região da falha F2, sem contato com a região pressurizada do reservatório, também apresentou incrementos de pressão pelos critérios de instabilidade. Este resultado não poderia ser reproduzido através de uma análise 2D pois não haveria um contato entre essa região da falha e a zona de injeção. 


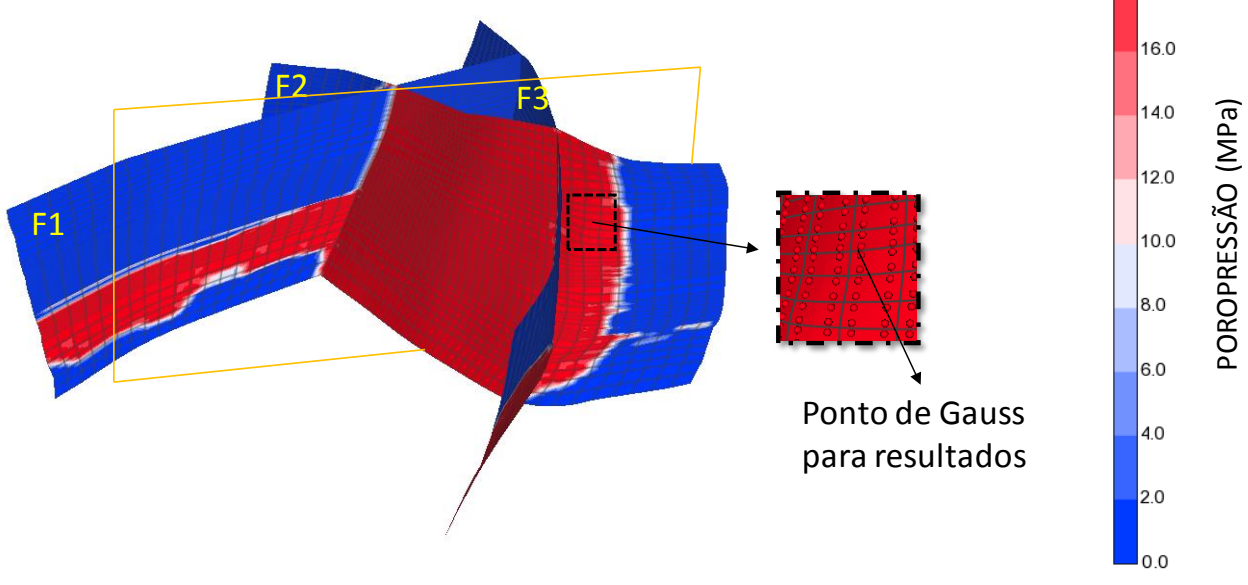

Figura 4-22 Migração de fluido através da falha F2 no final da simulação do modelo 3D.

A Figura 4-23 mostra a evolução do IR e da tensão normal efetiva de um ponto identificado na Figura 4-22. Observa-se que a falha é reativada após a injeção de $15 \mathrm{MPa}$ enquanto que as tensões normais efetivas são anuladas com quase 19 MPa.

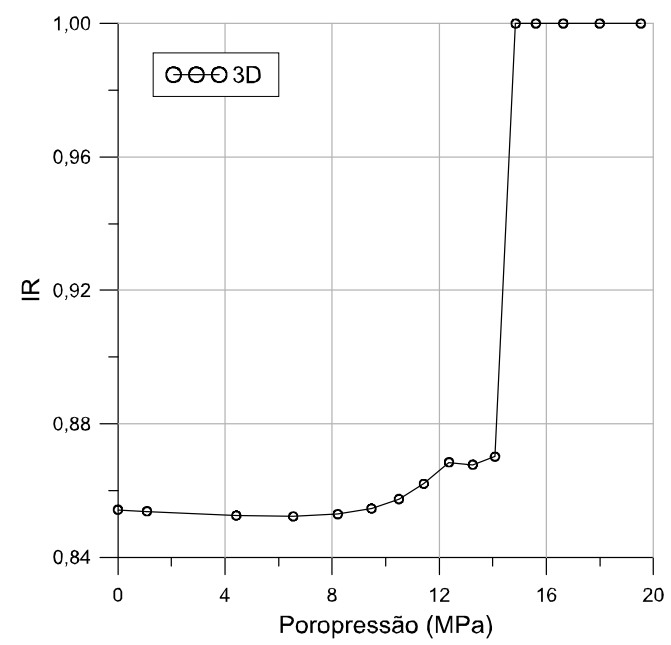

a)

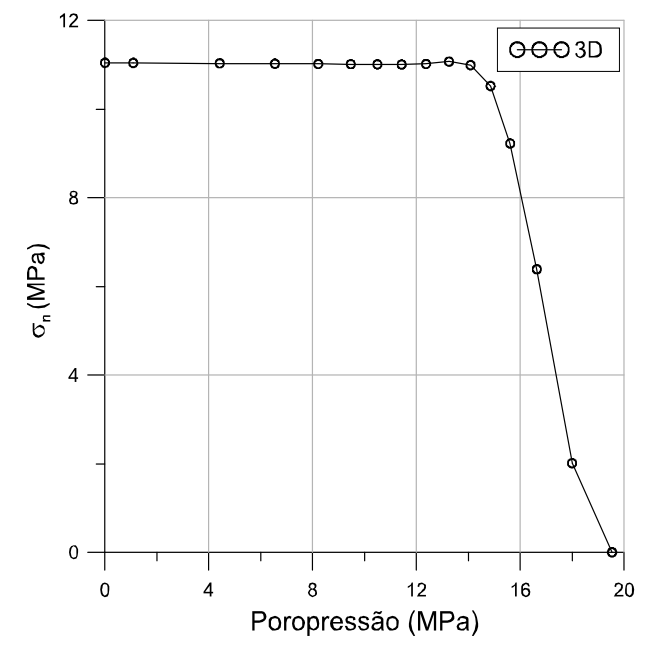

b)

Figura 4-23 a) Evolução do índice de reativação com a pressão de injeção e b) Evolução da tensão normal efetiva com a pressão de injeção, ambos na região indicada na Figura 4-22. 


\section{5 \\ Conclusões e Sugestões}

A seguir são apresentadas as conclusões finais e sugestões para trabalhos futuros com o propósito de ajudar no desenvolvimento cientifico do tema de reativação de falhas geológicas pela explotação de reservatórios de petróleo e fornecer ideias que possam servir de base para futuras pesquisas.

\section{1. \\ Conclusões}

Neste trabalho foram implementadas famílias de elementos de interface $2 \mathrm{D}$ e 3D no programa de elementos finitos para análises de problemas hidromecânicos.

Foram avaliadas diferentes metodologias por elementos finitos para a predição do comportamento de falhas. São elas: representação da falha por meio do elemento de interface, do elemento de continuo equivalente e o elemento solido com fraturas embutidas e acoplamento hidromecânico.

Através das análises de reativação de falhas usando modelos 2D constatou-se que a representação da falha por meio do elemento solido com fraturas embutidas, do elemento de interface e do elemento continuo equivalente, apresentam resultados similares para os primeiros pontos de reativação. No entanto ao final da análise, quando já reativaram mais pontos, os resultados obtidos com o modelo de continuo equivalente fornecem previsões um pouco diferentes daquelas com os demais modelos.

Das análises 2D nota-se também a importância de incluir todas as componentes que atuam no solido para cálculo das tensões sobre o plano de falha, já que não incluir a componente cisalhante na rotação das tensões pode gerar resultados bastante diferentes. Dessas analises conclui-se também que o esquema de migração empregado no elemento de interface para a poropressão, fornece resultados similares aos obtidos pelo elemento solido com fraturas embutidas no qual o problema é resolvido por um acoplamento total. 
Investigou-se ainda se adoção de modelos 2D seria indicada para avaliar a reativação e a migração de fluidos através da falha. Neste estudo foram empregados elementos de interface 2D e 3D. Adicionalmente foram comparados os resultados de modelos 3D com elementos hexaédricos e tetraédricos.

Das análises 3D realizadas neste trabalho pode-se concluir que o modelo com elementos tetraédricos apresenta resultados similares aos obtidos pelo modelo com elementos hexaédricos. Observou-se também que malhas com elementos tetraédricos representam melhor as geometrias mais complexas do que as malhas com elementos hexaédricos. Além disso observou-se também que o tempo de análise necessário para o processamento do modelo com elementos tetraédricos é bastante menor que aquele para o processamento do modelo com elementos hexaédricos.

Para as análises 2D vs 3D foi apresentada uma metodologia para análise de reativação de falhas geológicas e para a definição de pressões de injeção máximas em reservatórios. Embora esta metodologia seja baseada em uma abordagem que simplifica o nível de acoplamento entre os processos hidráulicos e geomecânicos, é possível identificar as principais características dos fenômenos de reativação e abertura de falhas geológicas. Um modelo de um campo hipotético considerando camadas com rejeitos e três falhas geológicas foi simulado empregando modelos 2D e 3D. Da comparação dos resultados, verificaram-se situações em que as análises 2D forneceram previsões bastante similares àquelas obtidas nas análises 3D. No entanto, o fenômeno de migração de fluido através dos planos de falha que não têm contato com a zona de injeção não pode ser reproduzido pelas análises 2D. Isto confirma a importância do uso de modelos 3D em certos cenários apesar da elevada complexidade na construção dos modelos e do maior custo computacional. Por fim, os resultados obtidos nas análises demonstram a aplicabilidade da metodologia apresentada, que emprega elementos sólidos hexaédricos e tetraédricos em conjunto com elementos de interface planos, a problemas de campos reais.

As análises 2D podem ser utilizadas com resultados satisfatórios em estudos preliminares, para calibração de propriedades físicas e mecânicas, para depois realizar um modelo 3D mais realístico. 


\section{2.}

Sugestões

Como sugestões que podem servir de origem para trabalhos futuros desta dissertação apresentam-se:

- Avaliar a influência do ângulo de dilatância na função do potencial plástico para incluir no modelo a plasticidade não associada.

- Implementar o acoplamento hidromecânico para análises de problemas de fluxo transiente no elemento de interface.

- Incorporar novos modelos constitutivos, como modelos de dano que permitam aplicações para faturamento hidráulico, e representações de fissuras em concreto.

- Incorporar modelos que permitam simular a variação da permeabilidade com respeito as deformações volumétricas.

- Investigar propriedades de deformabilidade e resistência do material da falha. 


\section{Referências bibliográficas}

ABBO, A. J. \& SLOAN, S. W., A smooth hyperbolic approximation to the Mohr-Coulomb yield criterion. Computers \&Structures, vol 54, no 3, pp427-441, 1995.

ABBO, A. J., SLOAN, S. W., An automatic load stepping algorithm with error control. International Journal of Numerical Methods in Engineering, vol 39, pp. 1737-1759, 1996.

ALTMANN, J. B., ET AL. Pore pressure stress coupling in 3D and consequences for reservoir stress states and fault reactivation. Geothermics, 2014, vol. 52, p. 195-205.

BOLTON, MR D.; LAU, C. K. Vertical bearing capacity factors for circular and strip footings on Mohr-Coulomb soil. Canadian Geotechnical Journal, vol. 30, no 6, p. 1024-1033, 1993.

BRETAN, P. AND YIELDING, G. Using buoyance pressure profiles to asses uncertainty in fault seal calibration. In: Evaluating Fault and Cap Rock Seals, Boult P. and Kaldi J.(edits.), AAPG Hedberg Series 2, p 151-162. 2005.

BOSSIE-CODREANU. The CO2-EOR sequestration equation: recovery, dynamic monitoring, and co-optimization, First Break, 26 (January), 2008

BOSTRØM, B., \& SKOMEDAL, E. Reservoir aeromechanics with ABAQUS . ABAQUS Users' Conference, p 117-131, 2004

CAINE, JONATHAN SAUL, JAMES P. EVANS, AND CRAIG B. FORSTER, Fault zone architecture and permeability structure. Geology 24.11 (1996): 1025-1028 
CAPPA, F. AND RUTQVIST, J. Modeling of coupled deformation and permeability evolution during fault reactivation induced by deep underground injection of $\mathbf{C O}_{2}$. International Journal of Greenhouse Gas Control, 5(2), p 336-346 2010.

CHAMBON, G., SCHMITTBUHL, J., CORFDIR, A., ORELLANA, N., DIRAISON, M., GÉRAUD, Y., Effective fault core thickness: from laboratory experiments to field scale observations, 2006

CHAN, A. W., ZOBACK, M. D. The role of hydrocarbon production on land subsidence and fault reactivation in the Lousiana Coastal Zone. Journal of Coastal Research 23 p 771-786, 2007

CHAPMAN RE. Petroleum geology. Amsterdam, New York: Elsevier, 1983

CIMNE-INTERNATIONAL CENTER FOR NUMERICAL METHODS IN ENGINEERING.GID The personal pre and postprocessor. Version 10.0. User Manual, 2010

COSTA, A. M, An application of computational methods and principles of rock mechanics in the design and analysis of underground excavation for the underground mining. PhD Thesis, Graduate School of Engineering (COPPE), Federal University of Rio de Janeiro (UFRJ) 1984

DAY, R. A., POTTS, D. M. Zero thickness interface elements: numerical stability and application. International journal for numerical and analytical methods in geomechanics, vol. 18, n. 4, p. 689-708, 1994

DRUCKER, DANIEL CHARLES. A definition of stable inelastic material. BROWN UNIV PROVIDENCE RI, 1957. 
Evans, James P., Craig B. Forster, and James V. Goddard. Permeability of fault-related rocks, and implications for hydraulic structure of fault zones. Journal of Structural Geology 19.11 (1997): 1393-1404.

FANG, Z., YOUNESSI, A., HON, V. Y., REFLI, I., PIAH, M., \& FAIZZUDIN, M. 3D Numerical Dynamic Geomechanical Analyses of Compaction, Subsidence and Fault Reactivation Throughout Multiple Producing and Injecting Reservoirs of a Sarawak Offshore Oil and Gas Field, Malaysia. International Petroleum Technology Conference, 2014

FAULKNER, D. R., et al. A review of recent developments concerning the structure, mechanics and fluid flow properties of fault zones. Journal of Structural Geology, 2010, vol. 32, no 11, p. 1557-1575.

FAULKNER, D.R. AND RUTTER, E.H. Comparisons of water and argon permeability in natural clay-bearing fault gouge under high pressure at $\mathbf{2 0}$ degrees C. J Geophys. Research-Solid Earth 105 (B7), p 16415-16426, 2000.

FINKBEINER, T., BARTON, C. A., \& ZOBACK, M. D. Relationships among in-situ stress, fractures and faults, and fluid flow: Monterey Formation, Santa Maria Basin, California. AAPG bulletin, 81(12), 1975-1999, 1997.

FINKBEINER, THOMAS, ET AL. Stress, pore pressure, and dynamically constrained hydrocarbon columns in the South Eugene Island 330 field, northern Gulf of Mexico. AAPG bulletin, vol. 85, no 6, p. 1007-1031, 2001.

FOULADVAND, A., BARONI, A., CANGENI, L \& DEFLANDE, J Geomechanical modeling integrating subseismic faults. SPE Asia Pacific Oil and Gas conference and exhibition, Society of Petroleum Engineering, 2009.

GHABOUSSI, J., WILSON, E. L., ISENBERG, J. Finite element for rock joints and interfaces. Journal of the soil mechanics and foundations division, vol 99, n. 10, p. 833-848, 1973. 
GARTRELL, ANTHONY, ET AL. Enhanced hydrocarbon leakage at fault intersections: an example from the Timor Sea, Northwest Shelf, Australia. Journal of Geochemical Exploration, 2003, vol. 78, p. 361-365.

GUIMARÃES, L. J. N., GOMES, I. F., FERNANDES, J. P. V. Influence of mechanical constitutive model on the coupled hydro-geomechanical analysis of fault reactivation. Reservoir Simulation Symposium. Society of Petroleum Engineers, SPE 119168. 2009

GOODMAN, E. L.; TAYLOR, R. L.; \& BREKKE, A. M. A model for the mechanics of jointed rock. Journal of Soil and Mechanics and Foundation Engineering, vol. 94, 637-659, 1968.

HEGGLAND, R. Gas seepage as an indicator of deeper prospective reservoirs. A study on exploration 3D seismic data. Marine and Petroleum Geol. 15, p1-9, 1998.

HEALY, J. H., et al. The denver earthquakes. Science, 1968, vol. 161, no 3848, p. 1301-1310.

HEPPARD, P. D.; CANDER, H. S.; EGGERTSON, E. B. Memoir 70, Chapter 13: Abnormal Pressure and the Occurrence of Hydrocarbons in Offshore Eastern Trinidad, West Indies. 1998.

Hobbs B.E., Means W.D., Williams P.E. An Outline of Structural Geology Wiley \& Sons 1976

KIM, J., TCHELEPI, H. A. AND JUANES, R. Stability and Convergence of Sequential Methods for Coupled Flow and Geomechanics: Fixed-Stress andFixed-Strain Splits. Comput. Method. Appl. M. 200 (13-16), p1591-1606, 2011.

KOESTLER, A.G., MAKURAT, A., BARTON, N AND MONSEN, K. Numerical simulation of jointed and faulted rock behavior for petroleum 
reservoirs. In. Larsen et al. (eds.): Structural and tectonic modelling and its application to petroleum geology, Elsevier, p. 277-288.

LANGHI, L., ZHANG, Y., GARTRELL, A., UNDERSCHULTZ, J., AND DEWHURST, D. Evaluating hydrocarbon trap integrity during fault reactivation using geomechanical three-dimensional modeling: An example from the Timor Sea, Australia. AAPG Bulletin, 94:567-591, 2009

LEE J., MIN K.B., RUTQVIST J. Probabilistic analysis of fracture reactivation associated with deep underground $\mathrm{CO} 2$ injection, Rock Mechanics and Rock Engineering, 2012.

MALVERN, LAWRENCE E. Introduction to the Mechanics of a Continuous Medium. 1969.

MATHIAS, S. Fault Study, Annex 3 in CO2 Storage Liabilities in the North Sea- An Assessment of Risks and Financial Consequences, Summary report for DECC, UK, 2012

MEJIA, E.C, PEZO, E, OLIVEIRA, M.F.F, AND ROEHL, D. Application of a 2D equivalent continuum approach to the assessment of geological fault reactivation in reservoirs. In: XXXIVII Iberian Latin American Congress on Computational Methods in Engineering (CILAMCE 2015), p. 1-10.

MENDES, R. A., COSTA, A., SOUZA, L., PEREIRA, .L \& OLIVEIRA, M. F. Risks and mitigation problems in a $\mathrm{CO} 2$ injection project for a petroleum onshore field in Brazil. ARMA, American Rock Mechanics Association, 2010.

MICHAL, S. GEO FEM-Theoretical manual 2009. A computer program for nonlinear finite element analysis of geotechnical problems. 2009.

MILDREN, S.D., HILLIS, R.R. AND KALDI, J. Calibrating predictions of fault seal reactivation in the Timor Sea. APPEA Journal p 187-202, 2002 
MOECK, I., KWIATEK, G., ZIMMERMANN, G. Slip tendency analysis, fault reactivation potential and induced seismicity in a deep geothermal reservoir. Journal of Structural Geology. 31 p. 1174-1182, 2009

MORTON, R.A., BERNIER, J.C. AND BARRAS, J. A. Evidence of regional subsidence and associated interior wetland loss induced by hydrocarbon production, Gulf Coast region, USA, Environmental Geology, 50, 261-274, 2006

NEVES, M. C.; PAIVA, L. T.; LUIS, J. Software for slip-tendency analysis in 3D: A plug-in for Coulomb. Computers \& Geosciences, 2009, vol. 35, no 12, p. $2345-2352$.

NG, K. L. A.; \& SMALL, J. C. Behavior of Joints and Interfaces Subjected to Water Pressure. Computers and Geotechnics, vol. 20, pp. 71-93, 1997.

OLIVELla PASTALLÉ, SEBASTIÀ; ALONSO PÉREZ DE AGREDA, EDUARDO. Gas flow through clay barriers. $G_{i}$ otechnique, vol. 58, no 3, p. 157$176,2008$.

PANDE, G.N., SHARMA, K.G. On joint/interface elements and associated problems of ill-conditioning, Short communications. International Journal for Numerical and Analytical Methods in Geomechanics 3 (1979) 293-300.

PEREIRA, FERNANDA LG, ET AL. Fault reactivation case study for probabilistic assessment of carbon dioxide sequestration. International Journal of Rock Mechanics and Mining Sciences, vol. 71, p. 310-319, 2014.

PEZO, E., NOREÑA, N., ROEHL, D. M., \& ROMANEL. Modelo do continuo equivalente para junta em maciço de rocha fracturado. In: XXXIV Iberian Latin American Congress on Computational Methods in Engineering (CILAMCE 2013), p. 1-14. 
POLLARD, DD., SEGALL, P, Theoretical displacements and stresses near fractures in rock: with applications to faults, joints, veins, dikes, and solution surfaces. Fracture mechanics of rock, 1987.

PRIEST, S.D. Discontinuity Analysis for Rock Engineering. Springer, 1993.

POTTS, M. D., ZDRAVKOVIC, L. Finite element analysis in geotechnical engineering. Imperial College of Science, Technology and Medicine, 1999.

QUEVEDO, R. Analise tridimensional de problemas hidromecânicos em solos parcialmente saturados. Tese de Doutorado Ponficia Universidade Catolica do Rio de Janeiro, 2012.

RALEIGH, C. B.; HEALY, J. H.; BREDEHOEFT, J. D. An experiment in earthquake control at Rangely, Colorado. work (Fig. Ib), 1976, vol. 108, no 52, p. 30.

RUEDA, J. A., NORENA, N., OLIVEIRA, M. F. F., \& ROEHL, D. M. Numerical models for detection of fault reactivation in oil and gas fields. In: $48^{\text {th }}$ US Rock Mechanics Conference (ARMA 2014), p. 1-8, 2014.

RUEDA, J. A., OLIVEIRA, M. F. F, \& ROEHL, D. M. Geological fault reactivation with discrete and distributed numerical models. In: XXXIV Iberian Latin American Congress on Computational Methods in Engineering (CILAMCE 2013), p. 1-14, 2013.

RUEDA, J. A. Reativação de falhas geológicas com modelos numéricos discretos e distribuído. MSc. Thesis, Pontifical Catholic University of Rio de Janeiro, 2013.

RUTQVIST, J., RINALDI A.P., CAPPA, F. \& MORIDIS, G. J. Modeling of fault reactivation and induced seismicity during hydraulic fracturing of shale- 
gas reservoirs. Journal of Petroleum Science and Engineering 107, p 1798-1807, 2013.

RUTQVIST, J. The Geomechanics of CO2 Storage in Deep Sedimentary Formations. Geotech. Geol. Eng. 30, p 525-551, 2012.

RUTQVIST, J., BIRKHOLZER, J., CAPPA, F. \& TSANG, C. F. Estimating maximum sustainable injection pressure during geological sequestration of $\mathrm{CO} 2$ using coupled fluid flow and geomechanical fault-slip analysis. Energy Convers. Manag. 48, p 1798-1807, 2007.

RUTQVIST, J. AND TSANG, C. F. A study of cap rock hydromechanical changes associated with $\mathrm{CO}_{2}$ injection into a brine aquifer. Environ. Geol. 42, p 296-305, 2002

RUTQViST, J., WU, Y. S., TSANG, C. F. \& BODVARSSON, G. A modeling approach for analysis of coupled multiphase fluid flow, heat transfer, and deformation in fractured porous rock. International Journal of Rock Mechanics \& Mining Sciences 39, 2002.

SAFARI, M.R. AND GHASSEMI, A. 3D modeling of natural fracture simulation using a poroelastic displacement discontinuity method with slip weakening, ARMA 2012, Chicago, USA, 2012

SARMA, S. KV. Seismic stability of earth dams and embankments. Geotechnique, vol. 25, no 4, p. 743-761, 1975.

SEGALL, PAUL; FITZGERALD, SHAUN D. A note on induced stress changes in hydrocarbon and geothermal reservoirs. Tectonophysics, 1998, vol. 289, no 1, p. 117-128.

SEGALL, P. S., GRASSO, J.R., MOSSOP, A. Poroelastic stressing and induced seismicity near the Lacq gas field, southwestern France. J. Geophys. Res. 99 (B8), p 15423-15438, 1994 
SERAJIAN, V., DIESSL, J., BRUNO, M. S., HERMANSSON, L. C., HATLAND, J., RISANGER, M., \& TORSVIK, R. M. 3D Geomechanical Modeling and Fault Reactivation Risk Analysis for a Well at Brage Oilfield, Norway. In SPE Europec featured at 78th EAGE Conference and Exhibition. Society of Petroleum Engineers, 2016

SETTARI, A., \& WALTERS, D. A. Advances in coupled geomechanical and reservoir modeling with applications to reservoir compaction. Spe Journal,6(03), p 334-342, 2001.

SHEN, JIAYI; PRIEST, S. D.; KARAKUS, M. Determination of MohrCoulomb shear strength parameters from generalized Hoek-Brown criterion for slope stability analysis. Rock mechanics and rock engineering, vol. 45, no 1, p. 123-129, 2012.

SIBSON, R.H. Faulting and fluid flow. In: Short Course on Fluids in Tectonically Active Regions of the Continental Crust, (Ed. Nerbitt, B.E.). Mineralogical Association of Canada Handbook, 1990.

SOLTANZADEH, H., \& HAWKES, C. D. 2008. Semi-analytical models for stress change and fault reactivation induced by reservoir production and injection. Journal of Petroleum Science and Engineering, 60(2), p 71-85, 2008

SPENCER, J. M. Continuum Mechanics Longmans. 1980.

STREIT, J.E., HILLIS, R. R. Estimating fluid pressures that can induce reservoir failure during hydrocarbon depletion. SPE/ISRM Rock Mechanics Conference, Society of Petroleum Engineers, 2002

TADOKORO, K., ANDO, M. AND NISHIGAMI, K. Induced earthquake accompanying the water injection experiment at the Nojima fault zone, Japan: seismicity and its migration. J. Geophys. Research-Solid earth 105 (B3), p 60896104, 2000. 
TALWANI, P., COBB, J.S, AND SCHAEFFER, M.F. In-situ measurements of hydraulic properties of a shear zone in northwestern South Carolina. J. Geophys. Research-Sold Earth 104(B7), p 14993-15003, 1999.

TRESCA, H. Memoir on the flow of solid bodies under strong pressure. Comptes-rendus de l'académie des sciences, vol. 59, p. 754-758, 1864.

VIDAL-GILBERT, S. ET AL. 3D geomechanical modeling for $\mathrm{CO}_{2}$ geologic storage in the Dogger carbonates of the Paris Basin. International Journal of Greenhouse Gas Control, p 288-299, . 2009

WANG, X., A. GHASSEMI. A 3D thermalporoelastic model for geothermal reservoir stimulation. 36th Workshop on Geothermal Reservoir Engineering, Stanford University. CA, USA,. 2012,

WATTS, N.L. Theoretical aspects of cap-rock and fault seals for single and two-phase hydrocarbon columns. Marine and Petroleum Geology 4, p 274307,1987

ZHANG, X., SANDERSON, D. J. Numerical modelling of the effects of fault slip on fluid flow around extensional faults. Geomechanics Research Group, Departement of Geology, University of Southampton. Journal of Structural Geology. P 109-119, 1996.

ZHANG, Y., GARTRELL, A., UNDERSCHULTZ, J.R, \& DEWHURST, D. N. Numerical modelling of strain localisation and fluid flow during extensional fault reactivation: Implications for hydrocarbon preservation. Journal of Structural Geology volume 31, p 315-327, 2009.

ZHU, W., \& ZHAO, J. Stability Analysis and Modelling of Underground Excavations in Fractured Rocks. In Hudson, J. A. ed, Elsevier Geo-Engineering Book Series, vol. 1, Elsevier., 2004. 
ZOBACK, M.D. Reservoir geomechanics. Cambridge University Press, 2007

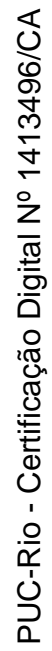




\section{Apêndice A}

Para os elementos de interface INT2D4 e INT2D6 2D suas respectivas funções de interpolação $\left(N_{i}\right)$, em ralação ao sistema de coordenadas locais $(\xi, \eta, \zeta)$ são apresentadas nas expressões abaixo:

\section{Elemento NT2D4}

$$
\begin{aligned}
& N_{1}(\xi)=\frac{1}{2}(1-\xi) \\
& N_{2}(\xi)=\frac{1}{2}(1+\xi) \\
& N_{3}(\xi)=\frac{1}{2}(1+\xi) \\
& N_{4}(\xi)=\frac{1}{2}(1-\xi)
\end{aligned}
$$

\section{Elemento INT2D6}

$$
\begin{gathered}
N_{1}(\xi)=\frac{1}{2} \xi(\xi-1) \\
N_{2}(\xi)=\frac{1}{2} \xi(\xi+1) \\
N_{3}(\xi)=\frac{1}{2} \xi(\xi+1) \\
N_{4}(\xi)=\frac{1}{2} \xi(\xi-1) \\
N_{5}(\xi)=1-\xi^{2} \\
N_{6}(\xi)=1-\xi^{2}
\end{gathered}
$$

O elemento de interface INT3D6 e suas respectivas funções de interpolação $\left(N_{1}\right)$, em ralação ao sistema de coordenadas locais $(\xi, \eta, \zeta)$ são apresentadas nas expressões abaixo: 


$$
\begin{gathered}
N_{1}(\xi, \eta, \zeta)=1-\xi-\eta \\
N_{2}(\xi, \eta, \zeta)=\xi \\
N_{3}(\xi, \eta, \zeta)=\eta \\
N_{4}(\xi, \eta, \zeta)=1-\xi-\eta \\
N_{5}(\xi, \eta, \zeta)=\xi \\
N_{6}(\xi, \eta, \zeta)=\eta
\end{gathered}
$$

O elemento de interface INT3D12 e suas respectivas funções de interpolação (Ni), em ralação ao sistema de coordenadas locais $(\xi, \eta, \zeta)$ são apresentadas nas expressões abaixo:

$$
\begin{gathered}
N_{1}(\xi, \eta, \zeta)=(1-\xi-\eta)(2 *(1-\xi-\eta)-1) \\
N_{2}(\xi, \eta, \zeta)=\xi(2 \xi-1) \\
N_{3}(\xi, \eta, \zeta)=\eta(2 \eta-1) \\
N_{4}(\xi, \eta, \zeta)=(1-\xi-\eta)(2 *(1-\xi-\eta)-1) \\
N_{5}(\xi, \eta, \zeta)=\xi(2 \xi-1) \\
N_{6}(\xi, \eta, \zeta)=\eta(2 \eta-1) \\
N_{7}(\xi, \eta, \zeta)=4 \xi(1-\xi-\eta) \\
N_{8}(\xi, \eta, \zeta)=4 \xi \eta \\
N_{9}(\xi, \eta, \zeta)=4 \eta(1-\xi-\eta) \\
N_{10}(\xi, \eta, \zeta)=4 \xi(1-\xi-\eta) \\
N_{11}(\xi, \eta, \zeta)=4 \xi \eta \\
N_{12}(\xi, \eta, \zeta)=4 \eta(1-\xi-\eta)
\end{gathered}
$$

O elemento de interface INT3D8 e suas respectivas funções de interpolação (Ni), em ralação ao sistema de coordenadas locais $(\xi, \eta, \zeta)$ são apresentadas nas expressões abaixo: 


$$
\begin{aligned}
& N_{1}(\xi, \eta, \zeta)=\frac{1}{4}(1-\xi)(1-\eta) \\
& N_{2}(\xi, \eta, \zeta)=\frac{1}{4}(1+\xi)(1-\eta) \\
& N_{3}(\xi, \eta, \zeta)=\frac{1}{4}(1+\xi)(1+\eta) \\
& N_{4}(\xi, \eta, \zeta)=\frac{1}{4}(1-\xi)(1+\eta) \\
& N_{5}(\xi, \eta, \zeta)=\frac{1}{4}(1-\xi)(1-\eta) \\
& N_{6}(\xi, \eta, \zeta)=\frac{1}{4}(1+\xi)(1-\eta) \\
& N_{7}(\xi, \eta, \zeta)=\frac{1}{4}(1+\xi)(1+\eta) \\
& N_{8}(\xi, \eta, \zeta)=\frac{1}{4}(1-\xi)(1+\eta)
\end{aligned}
$$

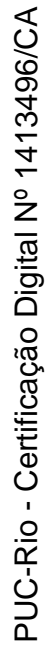

$$
\begin{aligned}
& N_{1}(\xi, \eta, \zeta)=\frac{1}{4}(1-\xi)(1-\eta)(-1-\xi-\eta) \\
& N_{2}(\xi, \eta, \zeta)=\frac{1}{4}(1+\xi)(1-\eta)(-1+\xi-\eta) \\
& N_{3}(\xi, \eta, \zeta)=\frac{1}{4}(1+\xi)(1+\eta)(-1+\xi+\eta) \\
& N_{4}(\xi, \eta, \zeta)=\frac{1}{4}(1-\xi)(1+\eta)(-1-\xi+\eta) \\
& N_{5}(\xi, \eta, \zeta)=\frac{1}{4}(1-\xi)(1-\eta)(-1-\xi-\eta) \\
& N_{6}(\xi, \eta, \zeta)=\frac{1}{4}(1+\xi)(1-\eta)(-1+\xi-\eta) \\
& N_{7}(\xi, \eta, \zeta)=\frac{1}{4}(1+\xi)(1+\eta)(-1+\xi+\eta)
\end{aligned}
$$




$$
\begin{aligned}
N_{8}(\xi, \eta, \zeta)=\frac{1}{4}(1-\xi)(1+\eta)(-1-\xi+\eta) \\
N_{9}(\xi, \eta, \zeta)=\frac{1}{2}(1-\eta)\left(1-\xi^{2}\right) \\
N_{10}(\xi, \eta, \zeta)=\frac{1}{2}(1+\xi)\left(1-\eta^{2}\right) \\
N_{11}(\xi, \eta, \zeta)=\frac{1}{2}(1+\eta)\left(1-\xi^{2}\right) \\
N_{12}(\xi, \eta, \zeta)=\frac{1}{2}(1-\xi)\left(1-\eta^{2}\right) \\
N_{13}(\xi, \eta, \zeta)=\frac{1}{2}(1-\eta)\left(1-\xi^{2}\right) \\
N_{14}(\xi, \eta, \zeta)=\frac{1}{2}(1+\xi)\left(1-\eta^{2}\right) \\
N_{15}(\xi, \eta, \zeta)=\frac{1}{2}(1+\eta)\left(1-\xi^{2}\right) \\
N_{16}(\xi, \eta, \zeta)=\frac{1}{2}(1-\xi)\left(1-\eta^{2}\right) \\
\end{aligned}
$$

